VICTOR CORACINI TONACIO

\title{
AVALIAÇÃO DE PROPULSORES NAVAIS EM RELAÇÃO A EFICIÊNCIA E EXCITAÇÃO DE VIBRAÇÃO
}

São Paulo

2014 
VICTOR CORACINI TONACIO

\section{AVALIAÇÃO DE PROPULSORES NAVAIS EM RELAÇÃO A EFICIÊNCIA E EXCITAÇÃO DE VIBRAÇÃO}

Dissertação apresentada à Escola Politécnica da Universidade de São Paulo para obtenção de título de Mestre em Engenharia.

Área de Concentração:

Engenharia Naval

Orientador: Prof. Dr. Bernardo Luis Rodrigues de Andrade

São Paulo 
VICTOR CORACINI TONACIO

\section{AVALIAÇÃO DE PROPULSORES NAVAIS EM RELAÇÃO A EFICIÊNCIA E EXCITAÇÃO DE VIBRAÇÃO}

Dissertação apresentada à Escola Politécnica da Universidade de São Paulo para obtenção de título de Mestre em Engenharia.

Orientador: Prof. Dr. Bernardo Luis Rodrigues de Andrade

São Paulo 
Este exemplar foi revisado e corrigido em relação à versão original, sob responsabilidade única do autor e com a anuência de seu orientador.

São Paulo, de fevereiro de 2014.

Assinatura do autor

Assinatura do orientador

FICHA CATALOGRÁFICA

Tonacio, Victor Coracini

Avaliação de propulsores navais em relação à eficiência e excitação de vibração / V.C. Tonacio. -- versão corr. -- São Paulo, 2014

p.96

Dissertação (Mestrado) - Escola Politécnica da Universidade de São Paulo. Departamento de Engenharia Naval e Oceânica.

1.Propulsores navais I.Universidade de São Paulo. Escola Politécnica. Departamento de Engenharia Naval e Oceânica II.t. 


\section{RESUMO}

A escolha do propulsor é uma etapa-chave no projeto de um navio. Muito do que se espera qualitativamente do desempenho de uma embarcação implica em economia de energia, em condições de operação e habitabilidade adequadas à tripulação, e em baixo custo de manutenção dos elementos estruturais e dos equipamentos. Essas questões estão diretamente relacionadas ao aproveitamento de combustível pelo sistema propulsivo e à propagação de vibração, cabendo ao propulsor um papel significativo para a performance do navio em ambos os aspectos. Por esta razão, a dissertação propõe a avaliação de propulsores navais com respeito à excitação de vibração e à eficiência, quando atuando em esteira não uniforme.

A dissertação inicia-se com uma abordagem resumida especificamente sobre os estudos já realizados sobre indução de vibração pelo propulsor focados nas chamadas forças de mancal. Em seguida, revisam-se os assuntos pertinentes ao projeto de propulsor, isto é, definição de sua geometria, de seus coeficientes de operação, e dos métodos teóricos e computacionais utilizados para estudar seu comportamento hidrodinâmico.

A metodologia do trabalho fundamenta-se no estudo paramétrico da geometria do hélice, objetivando identificar a influência de cada um dos parâmetros de projeto do propulsor nos dois aspectos destacados no início. As diversas configurações geométricas são submetidas a campos de velocidades advindos de diferentes navios, que representam três grupos de embarcações (navios série 60 , porta-containers e navios-tanque), com o intuito de verificar as diferentes tendências de comportamento possíveis.

Para a execução computacional, elabora-se uma rotina encarregada de sistematizar o processo de alterações geométricas, encaminhar os numerosos casos à análise hidrodinâmica, realizar o processo de integração casco-hélice e o pós-processamento dos resultados. A análise hidrodinâmica citada é feita através do uso de um software comercial, que, baseado na teoria do escoamento potencial, aplica o método dos painéis para a resolução do escoamento ao redor do propulsor.

Os esforços excitados pelo hélice são traduzidos em critérios objetivos, baseados na transmissão de vibração através do eixo, que, associados ao critério de eficiência propulsora e à restrição relativa à ocorrência de cavitação, avaliam os casos e identificam-se o comportamento dos parâmetros de projeto. Obtém-se, como conclusão, uma metodologia de avaliação aplicável em outros casos de propulsores e navios.

Palavras-Chave: Propulsores navais. Vibração induzida. Estudo Paramétrico 


\begin{abstract}
The propeller choice is a key-step of the ship design. The high quality of the vessel performance requires energy economy, appropriated operating and environmental conditions for the crew, and low maintenance costs of structural elements and equipment. These questions consider directly fuel consumption by the propulsion system and the transmitted vibration, regarding the propeller an important role in the ship's performance about both attributes. For this reason, the evaluation of marine propellers, regarding the induced vibration and the propulsive efficiency under a non-uniform inflow, is proposed.
\end{abstract}

The study begins with a briefly state of the art about the propeller induced vibration focused in bearing forces. Then, a propeller design overview is made about subjects such as geometry definition, operation coefficients, and theoretical and computed methods for studying its hydrodynamic behavior

The methodology is based on a parametric study of the propeller geometry, in order to identify the influence of each of the propeller design parameters in both aspects highlighted in beginning. The several geometric configurations are submitted to the wake fields from different ships, that represent three groups of vessels (60 series, containers and tankers), then different tendencies of behavior can be expected.

For computational execution, a routine is in charge of systematizing the process of geometrical parameterization, send the cases to the hydrodynamic analysis, make the hull-propeller integration and post process the data. The hydrodynamic analysis is compelled by a HSVA ${ }^{\circledR}$ software, which applies the panel method in the propeller flow, based on potential flow theory.

The propeller induced bearing forces are converted in objective criteria, based on vibration transmission through the shaft, which, combined with the propulsive efficiency criteria and the cavitation restriction, evaluate the propeller geometric configurations. As a conclusion, a propeller evaluation methodology applicable to another kind of propeller series and wake fields is obtained.

Keywords: Marine propellers. Induced vibration. Parametric study. 


\section{ÍNDICE DE TABELAS}

Tabela 1 - Flutuações dos esforços gerados pelo propulsor ............................. 13

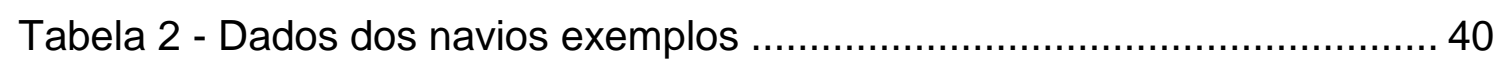

Tabela 3 - Dados do propulsor do caso inicial (proposto pela 14a ITTC) ......... 46

Tabela 4 - Comparação entre os resultados experimentais (14a ITTC) e os obtidos através do PPB para esforços axias ................................................ 47

Tabela 5 - Valores para variação dos parâmetros geométricos de projeto de

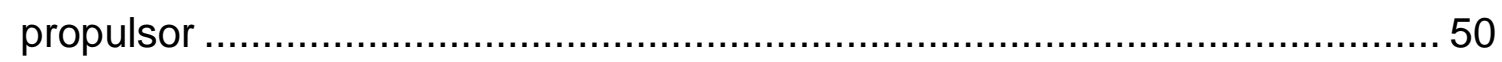

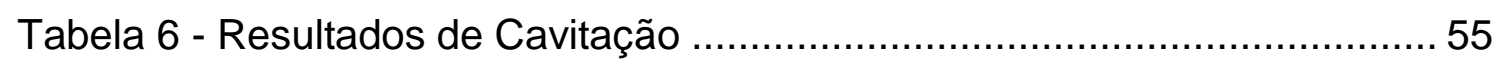




\section{ÍNDICE DE FIGURAS}

Figura 1 - Vibração horizontal (longitudinal) e torcional .................................. 8

Figura 2 - Vibração Transversal (Whirling Vibration) ………………............... 9

Figura 3 - Gráfico que relaciona a velocidade de vibração ao grupo

adimensional de fatores (Fonte: WARD, 1975) ........................................... 10

Figura 4 - Determinação do fator $\mathrm{k}$ relacionado à forma da popa (Fonte: WARD,

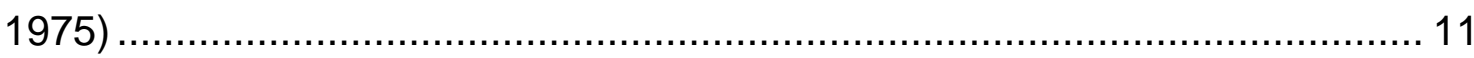

Figura 5- Bosso, plano do propulsor e linhas principais (adaptado de

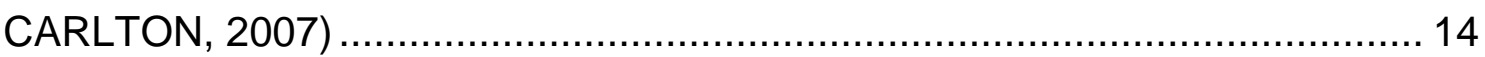

Figura 6 - perfil e parâmetros do fólio (Adaptado de CARLTON, 2007) ............ 15

Figura 7 - Definição do ângulo de pitch para uma seção da pá (adaptado de CARLTON, 2007)

Figura 8 - Definições de pitch (Fonte: CARLTON, 2007) ................................ 17

Figura 9 - Seção da pá do propulsor (definição de rake e skew) ..................... 18

Figura 10 - Parâmetros geométricos da pá: skew e rake............................... 19

Figura 11 - Definição do contorno expandido da pá (Fonte: CARLTON, 2007) 20

Figura 12 - Exemplo de curva característica de propulsor B5-75 (Fonte:

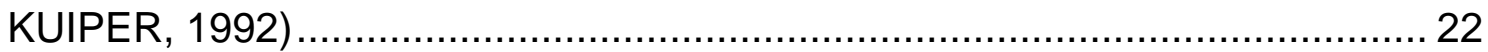

Figura 13 - Determinação do ângulo na análise multi-quadrante .................... 23

Figura 14 - Análise multiquadrante :Ct/Cq x $\varphi$ (Fonte: KUIPER, 1992)........... 24

Figura 15 - Salto de pressão e velocidade no escoamento (Fonte: BERTRAN, $2000)$

Figura 16 - Elemento de pá e componentes de drag e lift (Fonte: CARLTON,

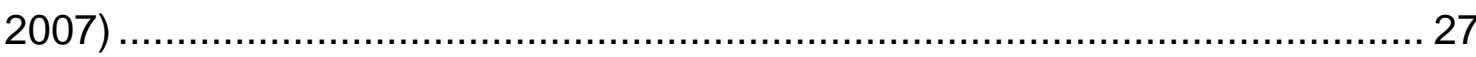

Figura 17 - Representação do propulsor em aplicação da TLS (Fonte:

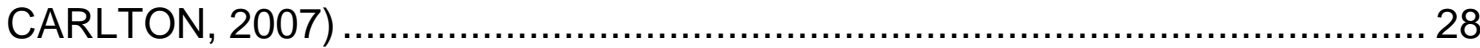

Figura 18 - Trajetória de uma linha de vórtice na TLS (Fonte: LERBS, 1952) .. 28

Figura 19 - representação de um fólio segundo a teoria de fólios finos (Fonte:

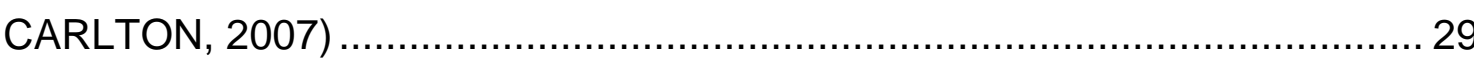

Figura 20 - Representação do propulsor segundo a TSS (Fonte: CARLTON, 2007)

Figura 21 - Aplicação do método dos painéis em propulsores (Fonte:

HOSHINO, 1989) 
Figura 22- Condição de Kutta aplicada em fólio (fonte: CARLTON, 2007) ...... 35

Figura 23 - Caracterização do propulsor (malha) ....................................... 37

Figura 24 - Fluxograma das etapas do estudo ........................................ 40

Figura 25 - Velocidade axial adimensional versus posição angular no plano do

propulsor

Figura 26 - Velocidade tangencial adimensional versus posição angular no

plano do propulsor.

Figura 27 - Velocidade tangencial adimensional versus posição angular no plano do propulsor

Figura 28-Os três tipos de campo de velocidade escolhidos para o estudo.... 43

Figura 29 - Curvas características do propulsor nas esteiras e em água aberta

Figura 30 - Velocidade adimensional tangencial e axial da esteira fornecida

pela 14르 ITTC

Figura 31 - Processo de integração casco-hélice utilizando curva KT em esteira aproximada. 51

Figura 32 - Componentes do momento fletor do eixo 53

Figura 33 - Eficiência em função de № de pás, para diferentes Ae/Ao (skew de $20 \%$ e $50 \%$ - esteiras 260 e 355 ) 56

Figura 34 - Eficiência em função de № de pás, para diferentes Ae/Ao (rake 0ํe $15^{\circ}$ - esteiras 260 e 355) 57

Figura 35 - Eficiência em função de № de pás, para diferentes valores de rake e skew (esteiras 170, 260 e 355) 57

Figura 36 - Eficiência em função de skew, para diferentes valores de rake (P/D

0.7 a 1.3 - esteiras 260 e $355-Z=6$ ) 58

Figura 37 - Eficiência em função de skew, para diferentes valores de rake (P/D

0.7 a 1.3 - esteiras 260 e $355-Z=4$ ) 58

Figura 38 - Eficiência em função de P/D, para diferentes valor de Z (Ae/Ao 0.90

e 1.05 - esteiras 260 e 355). 59

Figura 39 - Eficiência em função de skew, para diferentes valores de rake (Ae/Ao 0.60; 0.75; 1.05 - esteiras 260 e 355 - Z=3) 59

Figura 40 - Eficiência em função de skew, para diferentes valores de rake (Ae/Ao 0.75; 0.90; 1.05 - esteiras 260 e 355 - Z=6) 60 
Figura 41 - Eficiência em função de skew, para diferentes valores de rake (esteiras 170, 260 e 355) 60

Figura 42 - Eficiência em função de skew, para diferentes valores de rake (esteiras 260 e 355) 61

Figura 43 - Amplitudes de $1^{\mathrm{a}}$ ordem de força (Fx1) vs momento (Mx1) (axial) 62 Figura 44 - Amplitudes de $2^{a}$ ordem de força (Fx2) vs momento (Mx2) (axial) 63 Figura 45 - Amplitude de 1a ordem de força axial (Fx1) em função do número de pás para diferentes valores de rake e skew (esteiras 170, 260 e 355) ..... 63 Figura 46 - Amplitude de 2a ordem de força axial (Fx2) em função do número de pás para diferentes valores de rake e skew (esteiras 170, 260 e 355) 63 Figura 47 - Amplitude de $1^{\underline{a}}$ ordem de força axial (Fx1) em função do skew, para diferentes valores de rake (esteiras 170, 260 e 355) 64

Figura 48 - Amplitude de $2^{\mathrm{a}}$ ordem de força axial (Fx2) em função do skew, para diferentes valores de rake (esteiras 170, 260 e 355) 64 Figura 49 - Amplitude de $1^{\underline{a}}$ ordem de força axial (Fx1) em função do skew, para diferentes valores de rake (Ae/Ao 0.750 .901 .05 esteiras 260 e 355 $Z=6)$.

Figura 50 - Amplitude de $1^{\underline{a}}$ ordem de força axial (Fx1) em função do skew, para diferentes valores de rake (Ae/Ao 0.60; 0.75; 1.05 esteiras 260 e 355 $\mathrm{Z}=3$ ) 65

Figura 51 - Amplitude de $1^{a}$ ordem de força axial (Fx1) em função do skew, para diferentes valores de rake (variação de P/D 0.7 a 1.3 - esteiras 260 e 355 $-Z=4)$. 66

Figura 52 - Amplitude de $2^{\mathrm{a}}$ ordem de força axial (Fx2) em função do skew, para diferentes valores de rake (Ae/Ao 0.60; 0.75; 1.05 esteiras 260 e 355 $Z=3)$ 66

Figura 53 - Amplitude de $2^{\mathrm{a}}$ ordem de força axial (Fx2) em função do skew, para diferentes valores de rake $(Z=3 ; 4$ - esteiras 260 e 355 - Ae/Ao=0.75) ... 67 Figura 54 - Amplitude de $2^{\mathrm{a}}$ ordem de força axial (Fx2) em função do skew, para diferentes valores de rake (P/D 0.7; 1.0; 1.3 - esteiras 260 e 355 $\mathrm{Ae} / \mathrm{Ao}=1.05$ ) 67

Figura 55 - Amplitude de $1^{\underline{a}}$ ordem de força axial (Fx1) em função de P/D, para diferentes valores de $Z$ (esteiras 260 e 355 ). 68 
Figura 56 - Amplitude de $2^{\mathrm{a}}$ ordem de força axial (Fx2) em função de $P / D$, para diferentes valores de $Z$ (esteiras 260 e 355) 68

Figura 57 - Amplitude de 1aㅗ ordem de força axial (Fx1) em função de Z, para diferentes valores de Ae/Ao (esteiras 260 e 355)

Figura 58 - Amplitude de $2^{\mathrm{a}}$ ordem de força axial (Fx2) em função de $Z$, para diferentes valores de Ae/Ao (P/D 0.7 e 1.0 - esteiras 260 e 355).

Figura 59 - Amplitude de $2^{\mathrm{a}}$ ordem de força axial (Fx2) em função de Z, para

diferentes valores de Ae/Ao (skew $20 \%$ e $50 \%$ - esteiras 260 e 355) 70

Figura 60 - Excentricidade do Empuxo em função de Z, para diferentes valores de rake e skew (esteiras 170, 260 e 355) 71

Figura 61 - Excentricidade do Empuxo em função de skew, para diferentes valores de rake (esteiras 170, 260 e 355).

Figura 62 - Excentricidade do Empuxo em função de skew, para diferentes

valores de rake (esteiras 260 e 355 ) 73

Figura 63 - Excentricidade do empuxo em função de Z, para diferentes valores de Ae/Ao (P/D 0.7 e 1.0 - esteiras 260 e 355).

Figura 64 - Excentricidade do empuxo em função de Z, para diferentes valores de Ae/Ao (skew $20 \%$ e $50 \%$ - esteiras 260 e 355 )

Figura 65 - Excentricidade do empuxo em função de P/D, para diferentes

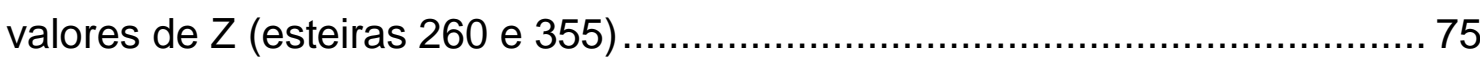

Figura 66 - Diagrama de Burril (adaptado de Harvald, 1980) .......................... 96 


\section{SUMÁRIO}

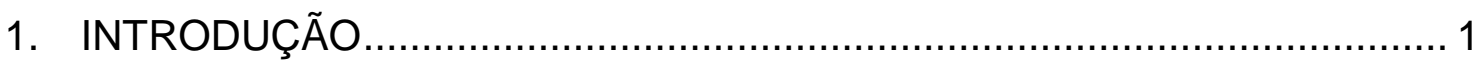

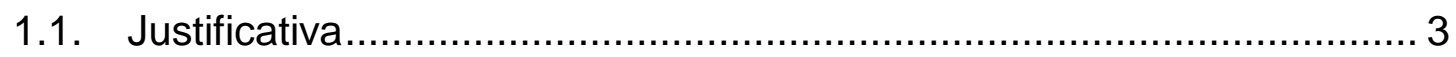

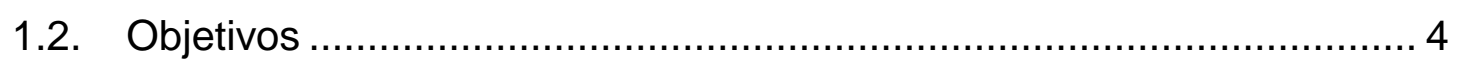

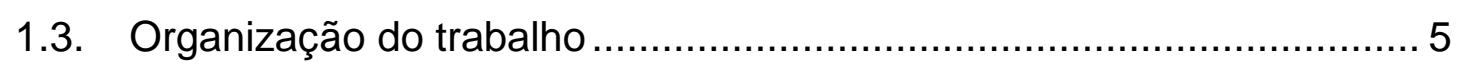

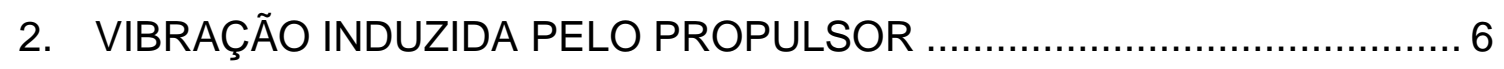

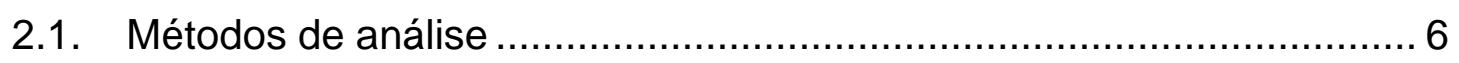

2.2. Transmissão de vibração através do eixo ……...................................... 8

2.3. Informações experimentais ......................................................... 9

3. ASPECTOS GERAIS SOBRE PROPULSORES …............................... 14

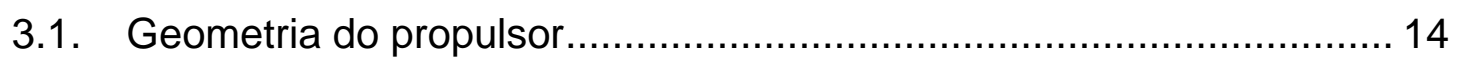

3.2. Operação do propulsor .................................................................... 21

3.3. Histórico dos métodos de análise de propulsor.................................. 25

3.3.1. Teoria da Quantidade de Movimento ............................................ 25

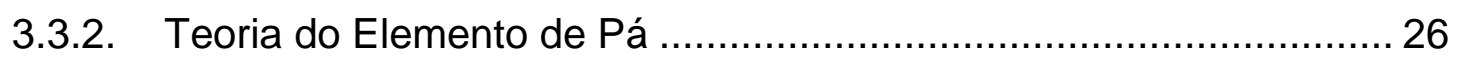

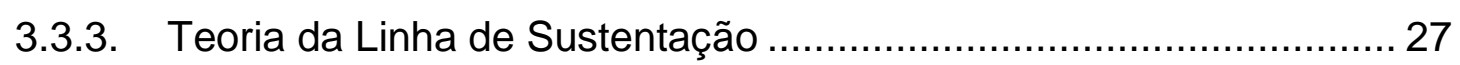

3.3.4. Teoria da Superfície de Sustentação ............................................. 29

3.3.5. Método de Elemento de Contorno …............................................ 30

3.3.6. Métodos CFD (Computational Fluid Dynamics) ................................ 31

3.3.7. Conclusão: método a ser utilizado para análise hidrodinâmica ........ 32

3.4. Aplicação do Método dos Painéis em propulsores .............................. 32

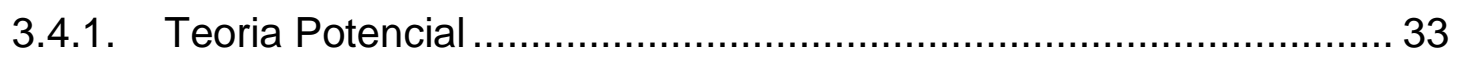

3.4.2. Escoamento Potencial ao redor de um corpo …............................. 34

3.4.3. Aplicação numérica do Escoamento Potencial em propulsores........ 36

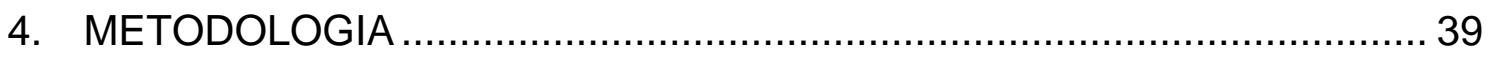

4.1. Análise da esteira das embarcações............................................... 40

4.2. Validação do software para o propósito do estudo ............................. 44 


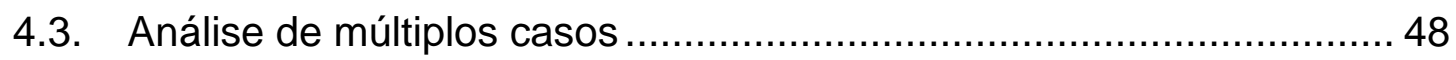

4.3.1. Sistematização e execução da análise numérica ............................. 48

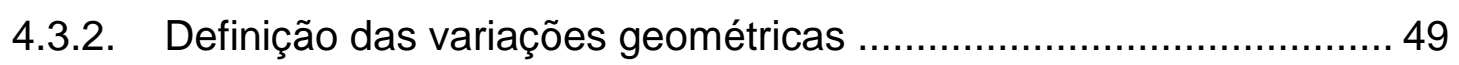

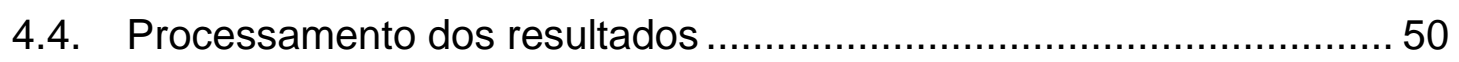

4.4.1. Processo de integração casco-hélice ............................................ 51

4.4.2. Definição dos critérios de avaliação............................................... 52

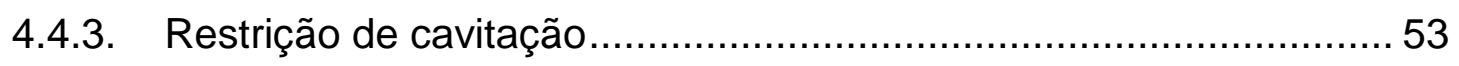

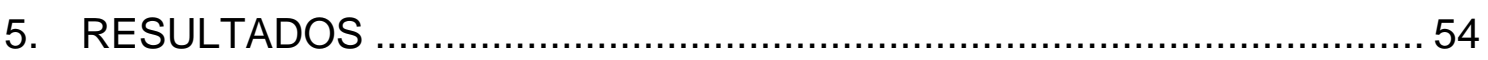

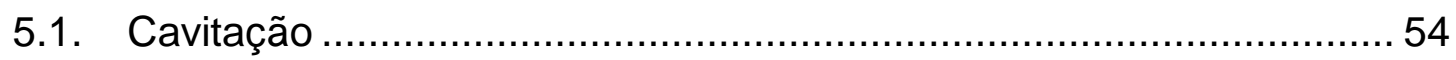

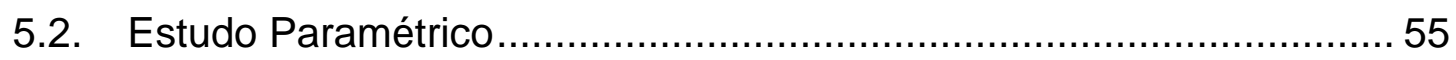

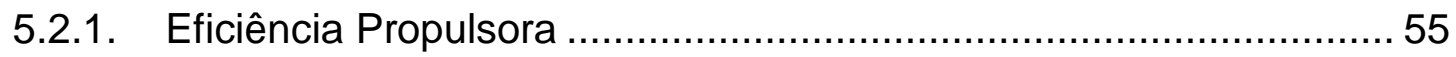

5.2.2. Forças e Momentos Axiais de $1^{\mathrm{a}}$ ordem e $2^{\mathrm{a}}$ ordem .......................... 62

5.2.3. Excentricidade do Empuxo …………………............................ 71

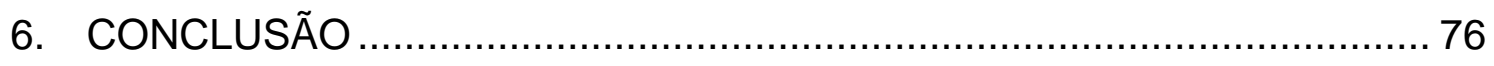

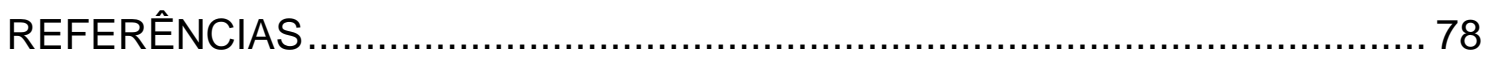

ANEXO A - ESTEIRA DO EXERCÍCIO PADRÃO PROPOSTO PELA 14a ITTC 80

ANEXO B - ROTINA DE EXECUÇÃO PRÉ-INTEGRAÇÃO (MATLAB) ........... 82

ANEXO C - FORMULAÇÂO DE BURRIL ......................................................96 


\section{INTRODUÇÃO}

Um navio, dentro do âmbito da Engenharia, eleva a multidisciplinaridade ao topo, pela quantidade e variedade de recursos materiais e intelectuais envolvidos em seu projeto, construção e operação. Em uma grande rede, cada sistema que o compõe é capaz de influenciar todos os outros sob diversas formas.

O sistema propulsivo não foge a esta característica. Em seu dimensionamento estão envolvidos, entre outros, aspectos logísticos, econômicos e estruturais, que podem ser exemplificados respectivamente pela exigência de velocidade de operação, consumo de combustível, suportes e alocação de seu elevado peso. O propulsor, uma peça-chave do sistema propulsivo, se reporta ao navio através do recebimento de energia rotativa e fornecimento da força necessária ao avanço da embarcação.

$\mathrm{Na}$ transformação desta energia rotativa em força propulsora, há a dissipação de energia pelo contato viscoso com a água e arraste induzido pela própria força de sustentação gerada pela lâmina, fração traduzida em suma na eficiência propulsora, e pela geração de esforços mecânicos alheios à necessidade de avanço do navio, que podem gerar distúrbios internos à embarcação, conhecidos por compor o fenômeno da vibração.

A vibração é um movimento oscilatório, caracterizado por sua amplitude, fase e frequência. Esse movimento pode consistir de uma simples componente ou de uma composição dessas com amplitudes variadas regidas por diferentes frequências, em fases distintas, em decorrência de uma ou mais fontes de excitação. Um dado importante do sistema neste âmbito é a sua frequência natural, propriedade que depende de sua massa e rigidez, pois, quando esta se iguala à frequência de excitação, ocorre o fenômeno da ressonância, em que as amplitudes de movimento são radicalmente aumentadas. Em um sistema mecânico, a vibração indica dissipação de energia, consequente perda de eficiência e até risco ao seu funcionamento. Além disso, um ambiente de elevados níveis de vibração e ruído é extremamente danoso às outras 
máquinas e às pessoas ali presentes, prejudicando sua produtividade e, principalmente, sua saúde.

Em navios, as vibrações podem apresentar diversas origens, dentre elas: a incidência de ondas; o funcionamento de todos os tipos de máquinas mecânicas, principalmente tratando-se de motores Diesel; no caso de embarcações rápidas, a ocorrência de Slamming, em que o fundo bate na superfície do mar periodicamente; e, geralmente a principal causadora, a operação do propulsor, principalmente atuando em uma esteira não favorável, ou seja, muito heterogênea.

As consequências desse fenômeno podem abranger tanto danos à tripulação, conforme já citado, como aos equipamentos, além de fadiga de elementos estruturais da embarcação. No caso de submarinos militares, pode-se ainda destacar a propagação de ruído, indesejado por facilitar a detecção de sua presença. São listados alguns problemas relatados pelo Ship Vibration Symposium, SNAME (1980):

- Inoperância e danificação de equipamentos de navegação, comunicação e controle.

- Alarmes ativados em falso

- Rachaduras em soldas

- Esmagamento de mancais

- Afrouxamento de fundações de bombas

- Danos na máquina do leme

- Engrenagens danificadas

- Descalibragem de aparelhos/ instrumentos de medida

- Vazamento em buchas de retenção de vapor

- Rachadura na pintura do casco

- Rachadura no duto do propulsor

- Problemas de habitabilidade: inutilização da sala de descanso; impedimento de realização de manuscritos; dificuldades durante refeição; perda de audição, entre outros.

Além dos problemas citados anteriormente, que podem ser considerados diretos, existem os indiretos, ligados à prevenção e à remediação dos mesmos, como a inclusão de amortecedores na montagem dos equipamentos, gerando maiores custos, e o tempo do pessoal gasto na manutenção excessiva e necessária dos elementos danificados pelo fenômeno da vibração. 


\subsection{Justificativa}

A elevada ocorrência de vibração em uma embarcação mostra-se nociva ao seu bom funcionamento, sendo cabíveis todos os esforços para a investigação e atenuação desses. Conhecidas e já citadas as possíveis causas, foi observado, em um estudo elaborado por Johannessen e Skarr(1980), que 80\% destes problemas são causados pelo propulsor. Sob o ponto de vista do projeto de um propulsor, a excitação de vibração, seja pela ocorrência de cavitação, seja pela má integração com a esteira incidente, é um dos fatores que prejudica a eficiência do mesmo.

Em paralelo, através da influência sobre o aproveitamento da energia do motor, logo sobre consumo de combustível, a eficiência propulsora tem impacto direto sobre o custo operacional da embarcação, refletindo, portanto, nos custos de transporte e, consequentemente, no preço final dos produtos pago pelos consumidores.

Segundo Grim (1980), o aspecto da vibração representa em uma escolha de propulsor quase o mesmo papel decisivo da eficiência. Portanto, a otimização do propulsor sob ambos os aspectos se traduz em grande benefício, inclusive econômico.

Frente à importância do assunto em questão, é oportuna a possibilidade de desfrutar de mais recursos numéricos, intensificado atualmente com a maior capacidade de processamento computacional, pois permite novas análises do fenômeno e uma contribuição aos estudos já realizados, que serão lembrados no decorrer dos próximos itens.

Enfim, como tema de dissertação de mestrado, o estudo paramétrico a respeito da avaliação de propulsores frente à eficiência e à excitação de vibração se dá como uma nova maneira de aprendizado para especialização e capacitação do aluno no projeto de hélices marítimos. 


\subsection{Objetivos}

Inicialmente, revisam-se os assuntos envolvidos no projeto de propulsor naval. Dessa forma, serão introduzidos brevemente os aspectos gerais de sua geometria e coeficientes de operação, os métodos numéricos utilizados para descrever o escoamento ao seu redor, e um relato sobre os estudos já realizados diretamente relacionados à vibração induzida pelo seu funcionamento, elucidando as conclusões que se tem no momento sobre 0 problema em questão.

Em seguida objetiva-se a análise dos esforços gerados pelo propulsor através da utilização do software PPB (Propeller Potential Based), que se baseia na teoria potencial e aplicação método dos painéis para a resolução do problema de escoamento ao redor do propulsor. Primeiro será estudado o caso padrão apresentado na 14 ITTC (1975), para que se possam realizar comparações com os resultados presentes na mesma e, assim, validar o uso do software para este fim.

Em seguida, um estudo paramétrico analisa diferentes configurações de propulsores da série B-Troost, variando-se os seus parâmetros geométricos (número de pás, relação de área expandida, relação de passo, skew e rake), sob a incidência de esteiras não uniformes, a fim de se detectar a influência de tais parâmetros na excitação de vibração e na eficiência propulsora. Para tanto, pretende-se realizar um processo intermediário de integração com esteiras típicas de navio-tanque, porta-container e série 60, com a intenção de se especificar as diferenças no comportamento do propulsor.

Pretende-se que a metodologia a ser desenvolvida seja aplicável a mais casos de séries de propulsor e a mais tipos de navios, como uma forma eficaz de se avaliar propulsores no que diz respeito à sua eficiência e à indução de vibração. 


\subsection{Organização do trabalho}

A dissertação está dividida em seis capítulos: um introdutório, dois de revisão bibliográfica, um de metodologia, um de análise dos resultados e um de conclusões gerais.

Após a introdução, em que se justifica a importância do tema e se descreve o objetivo do trabalho, seguem os dois capítulos de revisão bibliográfica. $O$ segundo capítulo, sobre vibração induzida pelo propulsor, apresenta um resumo sobre os principais métodos numéricos já criados para o cálculo dos esforços produzidos pelo hélice, outro subitem que caracteriza a transmissão desses através do eixo, e, por último, uma coleta de dados empíricos retirados de embarcações reais a respeito da geração e propagação de vibração. A terceira seção apresenta aspectos gerais sobre propulsores, subdividindo-se nos itens de geometria, coeficientes propulsivos e métodos numéricos de análise hidrodinâmica, incluindo um subitem que se especifica na descrição mais detalhada da aplicação do método dos painéis a propulsores, contendo uma revisão dos fundamentos da teoria do escoamento potencial, da sua aplicação para o escoamento ao redor de um corpo, e, em seguida, a especificação ao propulsor.

O quarto capítulo apresenta a metodologia do trabalho, que se inicia com o subitem de análise de esteira de diferentes tipos de navios e segue com o de validação da utilização do software para o propósito do estudo. Também se apresenta o subitem da sistematização dos casos, contendo o funcionamento da rotina e a escolha dos valores dos parâmetros nos quais se dá a variação geométrica dos numerosos casos. No próximo subitem dessa seção, se explicam o processo de integração casco-hélice, os critérios adotados para avaliar os propulsores e a restrição imposta relativa à cavitação.

A dissertação se define com o capítulo de análise de resultados, cujos subitens indicam as influências de cada parâmetro geométrico nos atributos estudados. No sexto e último capítulo, são apresentadas as conclusões sobre os objetivos alcançados com o trabalho em um contexto mais amplo. 


\section{VIBRAÇÃO INDUZIDA PELO PROPULSOR}

Segundo Hirata (1983), a excitação que causa vibração ao propulsor e ao casco é originada de duas formas: pela proximidade com o casco e pela não uniformidade da esteira.

Na maioria dos navios, a popa se alonga acima do propulsor, portanto a região ao redor do hélice, em sua porção superior, tem seu campo de pressão alterado. A diferença de pressão causada pela proximidade seguida do afastamento das pás em relação ao casco provoca forças oscilatórias (de frequência igual ao número de pás vezes a rotação do propulsor) chamadas forças de superfície. Tais forças geram vibração no casco (hull pressure vibration) que podem ser agravadas pela ocorrência de cavitação no propulsor. Para combater tal fenômeno, foram estipuladas pelas sociedades classificadoras distâncias mínimas entre o casco e o propulsor (clearance).

A outra forma de vibração induzida pelo propulsor ocorre sob a condição de avanço, que impõe um escoamento ao redor da embarcação que proporciona um campo de velocidades (esteira) heterogêneo no plano do propulsor, que é mínimo na região superior, pela interação viscosa com o casco, e aproximadamente igual à velocidade da embarcação na região inferior. Ao incidir em um escoamento que varia, não só radialmente, mas também angularmente, o ângulo de ataque se altera durante a rotação, produzindo um empuxo variável, que excita forças vibratórias conhecidas como forças de mancal, que serão abordadas pelo presente estudo.

\subsection{Métodos de análise}

O primeiro método utilizado para estimar as forças de mancais foi chamado método quase permanente (Lewis, 1935). Este trata o escoamento incidente considerando a heterogeneidade espacial com uma variação senoidal, que provoca a variação do ângulo de ataque do elemento de pá, para o cálculo da sustentação. 
Uma década mais tarde, no meio aeronáutico, iniciou-se a utilização do método bidimensional não permanente. Pelo fato da razão de aspecto da pá nesta área ser muito alta, despreza-se alguns efeitos tridimensionais como: geometria helicoidal do escoamento a ré e interação entre as pás. A pá é discretizada em elementos ao longo do raio. É imposto um escoamento incidente senoidal nos mesmos, produzindo as forças de sustentação calculadas a partir da fórmula de Sears (1941), que em seguida são integradas. Ainda assim podem ser usadas algumas correções para razão de aspecto junto com a função de Sears.

$\mathrm{Na}$ década de 60 , foi apresentado um modelo analítico tridimensional não permanente desenvolvido por Hanaoka (1962). Este permite uma abordagem geométrica mais fiel ao propulsor, para o cálculo do campo de pressões no mesmo, dado o campo de velocidade incidente. Na época, necessitou de algumas simplificações para que fosse implementado computacionalmente. Mais tarde, Kerwin (1978) propôs uma nova abordagem tridimensional, já com o foco numérico e de mais fácil implementação. Essa classe de métodos produziram resultados mais coerentes em relação aos resultados experimentais.

A 14a ITTC (1975) padronizou dados, provenientes de ensaio, para a comparação de modelos de diversas naturezas para a estimativa dos esforços sobre o propulsor devido à não uniformidade da esteira. Foram fornecidos um propulsor específico (Série B-Troost, D, P/D, Z, $A_{E} / A_{\circ}$ ), a uma dada rotação e uma esteira típica (axial e tangencial). Os esforços oscilatórios, de empuxo e torque, foram decompostos em harmônicos e compararam-se as respectivas amplitudes e fases, tanto para a incidência de esteira somente axial quanto para combinada (axial + tangencial).

Os resultados dessa comparação mostraram a boa aderência dos métodos tridimensionais em geral e de alguns bidimensionais não permanentes (o método bidimensional proposto por Hirata (1983), juntou-se a este seleto grupo, mais tarde). Outro fato relevante foi a proximidade entre os resultados provenientes das simulações com esteira axial e combinada. Esses 
apresentaram uma variação em média de $3 \%$, sendo que a máxima foi de $10 \%$, tanto para mais quanto para menos.

Há uma preocupação maior com os esforços axiais pela possibilidade maior de ressonância com o casco. No entanto, diferentemente do estudo apresentado na 14a ITTC, os esforços transversais, a princípio, são considerados relevantes à transmissão de vibração ao navio e, portanto, devem ser abordados no presente estudo.

\subsection{Transmissão de vibração através do eixo}

O estudo de vibração no eixo propulsor envolve, em suma, tanto os esforços vindos do hélice, quanto do motor, além de depender da configuração estrutural, isto é, do seu comprimento, do seu diâmetro, da quantidade de apoios e da disposição dos mesmos. A vibração no eixo é analisada sob três componentes: horizontal, torcional e transversal.

A vibração horizontal, também conhecida como longitudinal, refere-se ao movimento de translação na direção axial, em decorrência da oscilação do empuxo produzido pelo propulsor, normalmente ocasionada pela não uniformidade da esteira. A torcional tem a mesma origem, uma vez que o torque exigido torna-se variável com o próprio empuxo, provocando a torção do eixo. Em virtude da inércia do propulsor e da massa de água carregada em seu movimento, a última componente citada acaba ocorrendo com maior gravidade que a primeira.

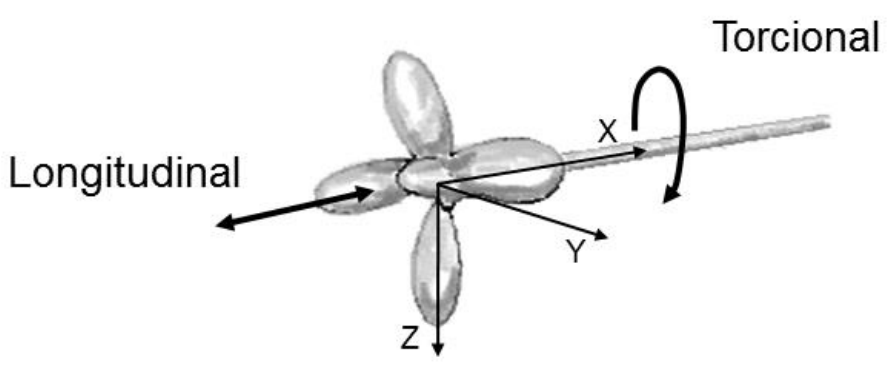

Figura 1 - Vibração horizontal (longitudinal) e torcional 
As componentes citadas anteriormente são excitadas pelas flutuações de $\mathrm{K}_{T}$ (empuxo) e $\mathrm{K}_{\mathrm{Q}}$ (torque) na direção $\mathrm{X}$. Os outros quatro graus de liberdade $\left(\mathrm{K}_{\mathrm{T}} \mathrm{e}\right.$ $\mathrm{K}_{\mathrm{Q}}$ em $\mathrm{Y}$ e Z), isto é, as forças e momentos transversais compõem a terceira parte da análise de vibração, também conhecida como lateral. Em inglês, o nome whirling vibration faz alusão justamente ao movimento de rodopio do eixo propulsor, que descreve uma trajetória circular ou elíptica no plano transversal, causada pela combinação da própria rotação aos momentos fletores em Y e Z (Figura 2).

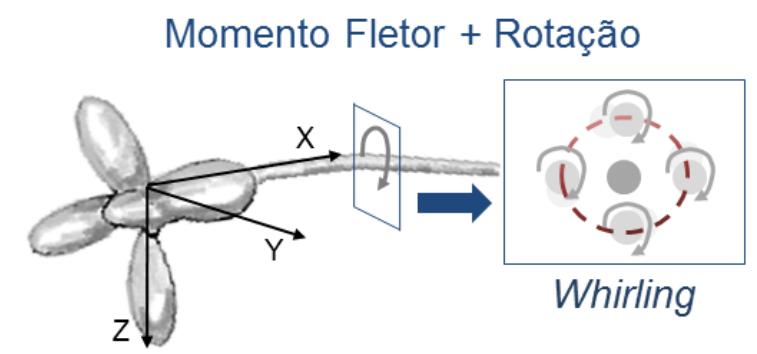

Figura 2 - Vibração Transversal (Whirling Vibration)

Conforme consultado em Veritec (1980), em fase de projeto, se analisa a frequência natural do sistema relativa a todas essas componentes, para que justamente o propulsor que venha a ser escolhido não opere nesta faixa e provoque ressonância. Além dessa etapa, o autor faz questão de ressaltar que, embora o propulsor opere a uma frequência distinta da natural, é muito importante a análise dos esforços produzidos, pois, mesmo não estando em ressonância, colaboram para a ocorrência de vibração propagada à embarcação e para a fadiga do eixo.

\subsection{Informações experimentais}

O trabalho de Ward e Willshare (1975) levantou a necessidade de resultados empíricos em escala real para serem comparados e acoplados aos métodos teóricos para melhor entendimento do fenômeno e desenvolvimento de projetos relacionados. A BSRA (British Ship Research Association) realizou um trabalho 
que consistia na medição em escala real da vibração em uma grande variedade de navios (tamanhos e formatos), em condição padrão de operação.

Apresentaram-se resultados para uma condição diferente, a manobra em S, em que houve uma considerável redução de vibração, pelo uso do leme, possivelmente porque altera as características de cavitação do propulsor. Durante as curvas, os níveis de vibração medidos na bucha do eixo propulsor se reduziam e retornavam aos níveis normais quando o leme reassumia a posição central. Tal fato tornava-se mais evidente nos navios que apresentavam maior cavitação no propulsor.

Nove entre os navios foram submetidos a um teste de excitação mecânica, para se determinar os níveis de resposta mediante a força excitante, considerando uma faixa abrangente para uma e duas vezes a frequência de pá. O objetivo final desse estudo era prever os níveis de vibração de resposta em vários locais da estrutura mediante uma dada excitação e determinar quais áreas permitem uma boa previsão teórica comparada aos dados experimentais.

As medições foram realizadas em alguns pontos da estrutura da embarcação e na bucha do eixo principal. Foi observada uma proporcionalidade entre este último ponto e os demais, possibilitando extrapolações para diversos pontos desejados a partir da medição realizada no eixo do propulsor.

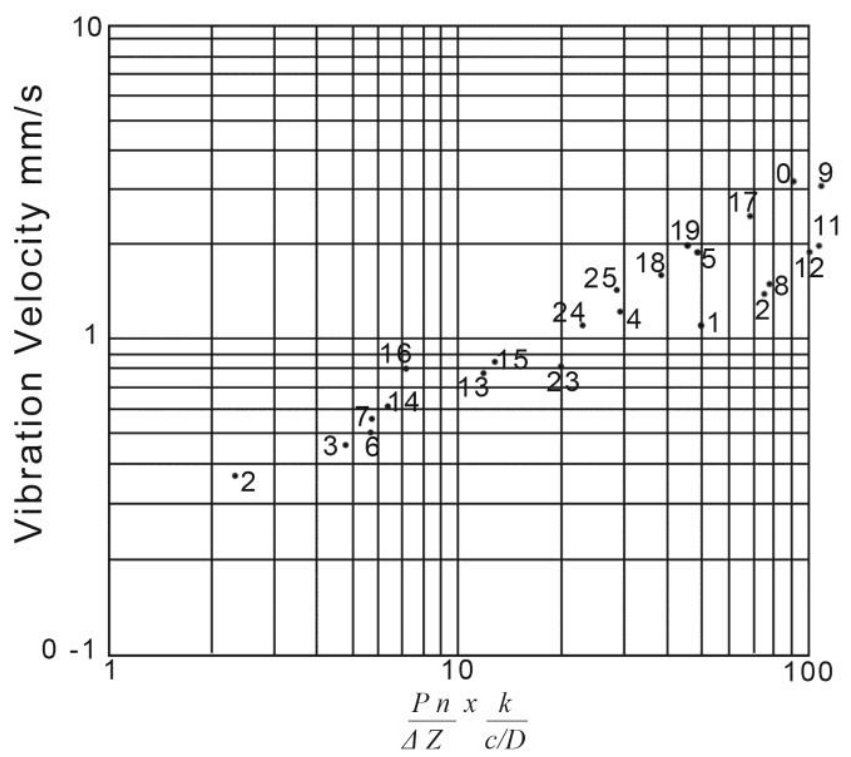

Figura 3 - Gráfico que relaciona a velocidade de vibração ao grupo adimensional de fatores (Fonte: WARD, 1975) 
Como se observa o gráfico da Figura 3 o resultado estatístico das medições, sob condições operacionais, em 25 navios diferentes, de diversos tamanhos, geometrias e com características variadas de propulsor, sugere uma correlação entre a velocidade de vibração vertical na bucha do eixo propulsor e a combinação das seguintes características do navio: potência $(P)$, rotação $(n)$, diâmetro $(D)$ e número de pás $(Z)$ do hélice, deslocamento da embarcação $(\Delta)$, distância entre a ponta superior do propulsor e a popa (c) e, por fim, um fator (k) relativo ao formato da seção transversal da popa (este pode ser melhor explicado através da Figura 4).

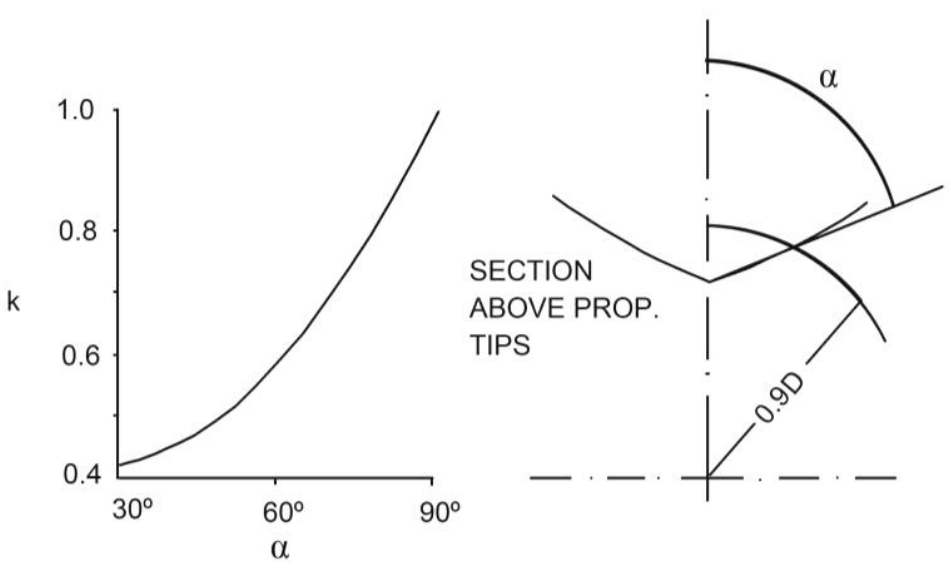

Figura 4 - Determinação do fator k relacionado à forma da popa (Fonte: WARD, 1975)

As curvas de oscilação da pressão no casco causada pela rotação do propulsor e de velocidade de vibração vertical no mancal apresentadas no estudo mostraram o mesmo comportamento frente ao valor da rotação. Ambas apresentaram um aumento abrupto no ponto em que se inicia o fenômeno da cavitação na pá do hélice. Tal fato reforça a relevância da cavitação no fenômeno de vibração, que, apesar de não ser possível de evitá-la completamente, pode-se combatê-la, reconsiderando o formato da popa e através da inclusão de apêndices para a alteração/correção da esteira, reduzindo-a a nível aceitável.

O autor (Ward, 1975) classifica o espectro de vibrações da estrutura induzidas pelo propulsor em duas grandes categorias. A primeira refere-se às componentes relacionadas à frequência da pá, em que, quando predominam, os níveis de vibração podem ser considerados satisfatórios, com exceção dos 
casos de ressonância, em que a rotação coincide com a frequência natural do sistema. A outra categoria são as componentes que correspondem aos harmônicos de duas vezes a frequência de pá. Segundo o autor, quando essas últimas são iguais ou superiores às primeiras, condição associada à alta ocorrência de cavitação no propulsor, danos estruturais podem ocorrer e as condições de habitabilidade podem ser comprometidas, além dos efeitos de fadiga tornarem-se intensos, manifestando-se em até apenas uma viagem.

Os resultados mostraram também que as vibrações na direção vertical são predominantes em relação às horizontais.

No caso da análise de vibração nas anteparas dos tanques de lastro, foi observado que o fato de estarem cheios não elimina a vibração. Quando cheios, a frequência natural dos tanques é diminuída em relação a quando vazios, fazendo com que a velocidade de vibração nos tanques aumente pela influência dos harmônicos de menor ordem da frequência de pá. Por essa razão, é necessário o reforço das estruturas dos tanques para eliminar ou reduzir este problema.

Uma análise sonora verificou que os efeitos de pressão no casco acima do propulsor são bem localizados e caracterizam-se como impactos periódicos (marteladas).

Para a análise estrutural, o método de elementos finitos é amplamente utilizado e pode ser empregado para a predição da resposta do sistema no que diz respeito aos níveis de vibração. Para tanto, exige-se uma representação da estrutura em questão suficientemente detalhada a ponto de permitir a determinação dos modos naturais e as respectivas frequências de excitação. Além disso, outro fator da modelagem do problema seria a caracterização das forças de excitação do sistema. No estudo em questão (Ward, 1975), essas foram determinadas a partir dos dados medidos em escala real e aplicadas à modelagem segundo método dos elementos finitos. Foram comparados os resultados calculados aos obtidos pela medição, verificando-se a eficácia do método ao menos para a predição da resposta do sistema durante a fase de projeto. 
Foi constatado pelo autor, ao final de seus experimentos, que o reforçamento da estrutura pode reduzir os efeitos da vibração, no entanto, em geral não pode ser considerado como a melhor solução do problema. O melhor jeito de lidar com a vibração é, na fase de projeto, realizar uma análise detalhada da esteira, levando em conta o formato da popa e a inclusão de apêndices, para torná-la mais homogênea possível, em conjunto com o desenvolvimento do propulsor mais adequado.

Outra base empírica muito importante para este estudo encontra-se em Veritec (1980). Os dados reais medidos em 20 navios diferentes, apresentados na Tabela 1, mostram os esforços excitados pelo propulsor nos seis graus de liberdade, de primeira e segunda ordem.

Tabela 1 - Flutuações dos esforços gerados pelo propulsor

\begin{tabular}{|c|c|c|c|c|c|c|}
\hline № de pás & \multicolumn{2}{|c|}{4} & \multicolumn{2}{c|}{5} & \multicolumn{2}{c|}{6} \\
$\begin{array}{c}\text { Ordem } \\
\text { harmônica }\end{array}$ & $1^{\mathrm{a}}$ & $2^{\mathrm{a}}$ & $1^{\mathrm{a}}$ & $2^{\mathrm{a}}$ & $1^{\mathrm{a}}$ & $2^{\mathrm{a}}$ \\
\hline $\mathrm{F}_{X}(\% \mathrm{~T})$ & $8.4 \pm 3.1$ & $2.2 \pm 0.4$ & $2.0 \pm 0.6$ & $1.7 \pm 0.3$ & $3.6 \pm 0.2$ & $1.5 \pm 0.2$ \\
\hline $\mathrm{F}_{Y}(\% \mathrm{~T})$ & $1.2 \pm 1.1$ & $0.1 \pm 0.1$ & $2.1 \pm 1.6$ & $0.6 \pm 0.3$ & $0.9 \pm 0.4$ & $0.3 \pm 0.1$ \\
\hline $\mathrm{F}_{Z}(\% \mathrm{~T})$ & $0.8 \pm 0.4$ & $0.8 \pm 0.4$ & $1.1 \pm 0.9$ & $0.2 \pm 0.2$ & $0.3 \pm 0.2$ & $0.1 \pm 0.1$ \\
\hline $\mathrm{M}_{X}(\% \mathrm{Q})$ & $6.2 \pm 2.5$ & $1.6 \pm 1.0$ & $0.1 \pm 0.1$ & $0.1 \pm 0.8$ & $3.0 \pm 2.0$ & $1.0 \pm 0.2$ \\
\hline $\mathrm{M}_{Y}(\% \mathrm{Q})$ & $13.8 \pm 9.0$ & $4.0 \pm 3.6$ & $12.5 \pm 8.5$ & $8.0 \pm 4.0$ & $7.3 \pm 6.2$ & $1.5 \pm 0.2$ \\
\hline $\mathrm{M}_{Z}(\% \mathrm{Q})$ & $7.5 \pm 5.1$ & $1.9 \pm 1.3$ & $3.9 \pm 2.6$ & $1.2 \pm 1.1$ & $4.0 \pm 1.5$ & $0.7 \pm 0.2$ \\
\hline
\end{tabular}

Os dados são um bom comparativo para se verificar a ordem de grandeza dos resultados numéricos a serem obtidos durante o estudo, mas não servem para comparar os propulsores de 4, 5 e 6 pás, uma vez que foram empregados sob condições distintas. Pode-se destacar a ocorrência de momentos fletores de até $20 \%$ do torque e flutuação do empuxo superando $10 \%$. Por outro lado, as forças transversais $F_{Y}$ e $F_{Z}$ indicam uma baixa relevância.

Além disso, nota-se a superioridade de $M_{Y}$ em relação a $M_{Z}$, verificando a diferença significante entre a geração de empuxo na região superior e na região inferior do propulsor, no entanto, os dois mostram-se muito relevantes, revelando que a excentricidade do empuxo se dá na direção horizontal também, em decorrência da componente tangencial do campo de velocidade no plano do propulsor. 


\section{ASPECTOS GERAIS SOBRE PROPULSORES}

Neste capítulo, serão abordados aspectos introdutórios sobre o projeto de um propulsor marítimo, sua geometria e os conceitos que envolvem a sua operação, e, em seguida, será apresentado um breve histórico sobre os métodos numéricos utilizados para representá-lo e analisar o seu funcionamento.

\subsection{Geometria do propulsor}

O propulsor é composto por um bosso no centro (hub ou boss) e um número de pás $Z$ ao redor. A localização das pás ao longo da circunferência do Bosso é definida pelas respectivas linhas diretrizes (propeller reference line - Directrix), essas sempre igualmente espaçadas, partindo do eixo axial $(X)$ e perpendicular ao mesmo. O plano do propulsor pode ser então definido pelo plano que contém as diretrizes, perpendicular ao eixo.
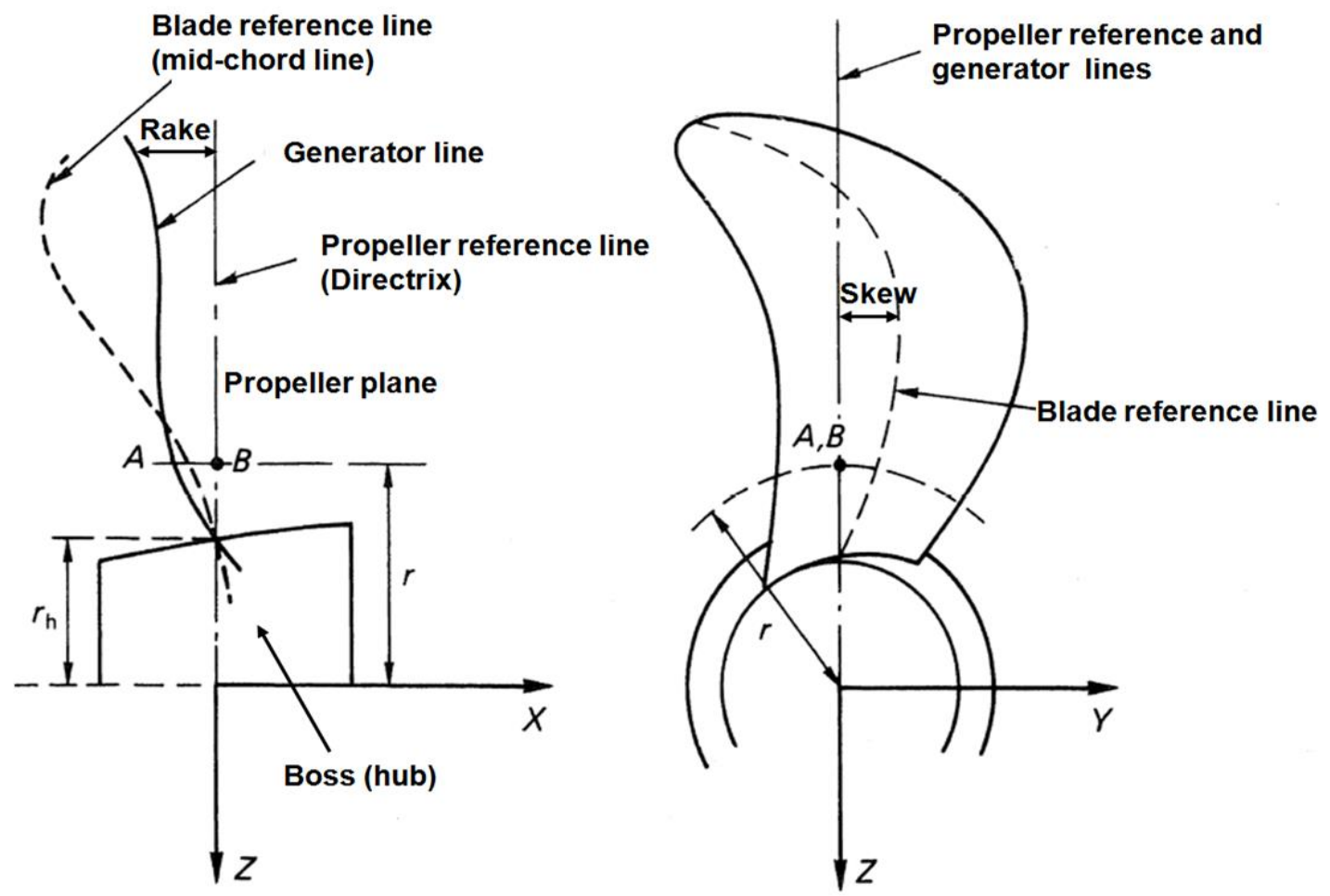

Figura 5- Bosso, plano do propulsor e linhas principais (adaptado de CARLTON, 2007) 
A pá do propulsor se forma a partir da linha geradora (Generator line). Esta linha está contida no plano formado pela respectiva diretriz e pelo eixo axial, e a distância que a separa da própria diretriz é conhecida como a propriedade geométrica rake, que pode variar radialmente. Outra linha importante para a descrição geométrica do propulsor é a linha de referência da pá (Blade Reference line ou mid-chord line), formada pelos pontos centrais (na metade da corda) de cada seção radial.

As pás possuem dois lados: o dorso (suction side), onde a força de sustentação é gerada, e a face (pressure side), e dois bordos: o de ataque (leading edge) e o de fuga (trailing edge). São dotadas de seções transversais em forma de fólio, que apresentam características de comprimento de corda e espessura diferentes conforme a posição radial em que se encontram. $\mathrm{Na}$ Figura 6, pode-se observar um perfil exemplo de seção de pá.

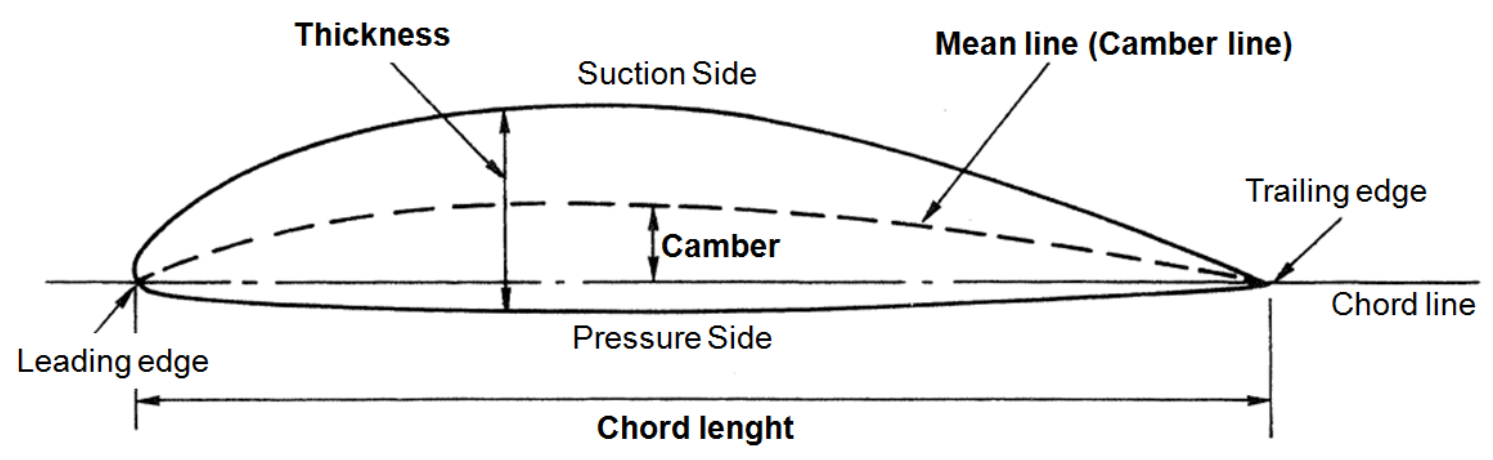

Figura 6 - perfil e parâmetros do fólio (Adaptado de CARLTON, 2007)

A geometria de um fólio é definida pelo comprimento de corda (chord lenght), distância entre o trailing edge e o leading edge, pela distribuição de espessura (thickness) ao longo da corda, dada a dimensão e a posição de espessura máxima da seção, e a linha média (mean line ou camber line). O parâmetro camber define a excentricidade da linha média em relação à corda.

O passo (pitch) de um propulsor é a distância percorrida ao longo de uma revolução. Pode-se estender o conceito para cada uma das seções de uma pá, conforme a Figura 7. Nessa, um cilindro concêntrico ao propulsor com o raio $r$, 
correspondente ao da seção, registra o trajeto, que pode assim ser planificado. O parâmetro $\theta$ é então definido como ângulo de pitch, para cada seção, na equação 1 :

$$
\theta=\operatorname{atan}\left(\frac{p}{2 \pi r}\right)
$$

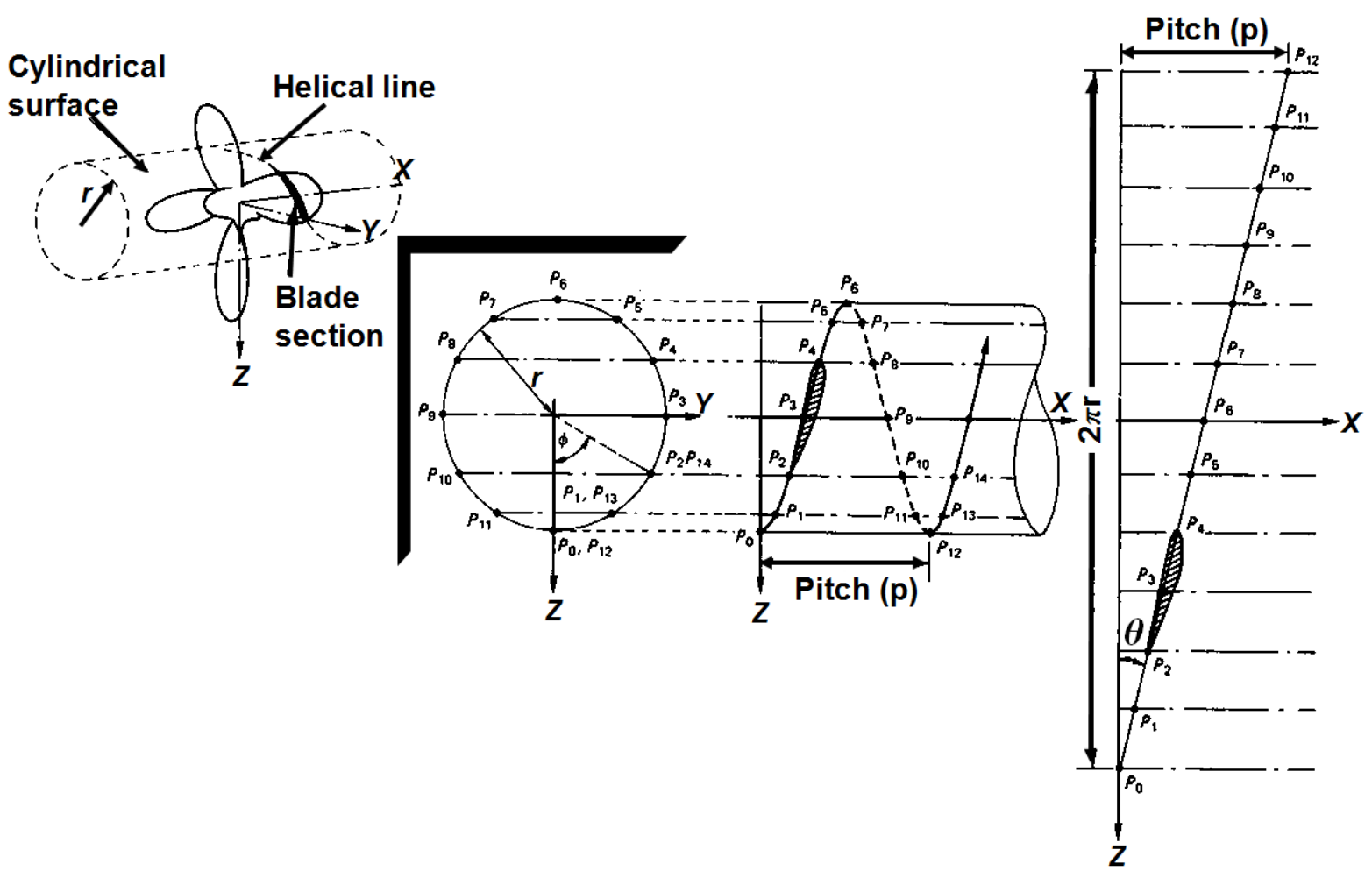

Figura 7 - Definição do ângulo de pitch para uma seção da pá (adaptado de CARLTON, 2007)

No entanto, como pode ser visualizado na Figura 8, existem diferentes definições para o ângulo de passo de uma seção, que foram criadas em diferentes contextos para finalidades de representação geométrica ou mesmo conceitos hidrodinâmicos. 


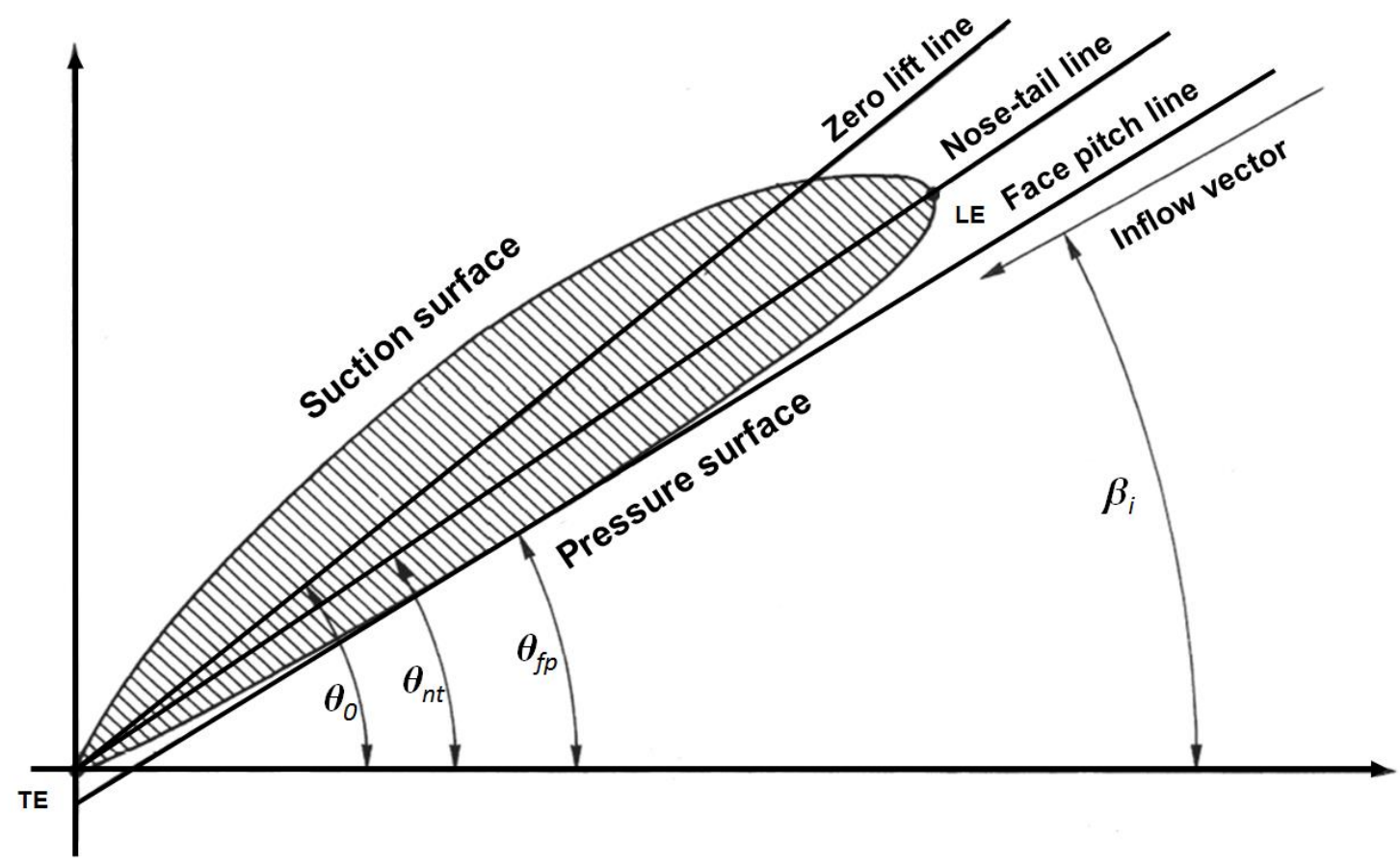

Figura 8 - Definições de pitch (Fonte: CARLTON, 2007)

O ângulo de passo geométrico $\left(\theta_{n t}\right)$ utiliza a reta descrita pelos pontos do leading edge e o trailing edge do fólio (LE e TE), também conhecida como nose-tail line. O ângulo de passo hidrodinâmico $\left(\beta_{i}\right)$, por sua vez, é limitado pelo vetor do escoamento incidente, que leva em conta tanto a velocidade axial como as tangenciais e as induzidas pelo hélice. Existem outros conceitos menos utilizados atualmente: o passo de sustentação nula, cujo ângulo $\left(\theta_{0}\right)$ é determinado pela linha de sustentação nula (zero lift line), sobre a qual um escoamento incidente não geraria nenhuma força de sustentação; e o ângulo de face pitch, que se forma a partir da face pitch line, uma reta tangente ao pressure side, o que dá um caráter ambíguo a este parâmetro, pois existem infinitas retas tangentes a esta face.

Em termos práticos, o passo de um propulsor é definido pela relação $P / D$, que o adimensionaliza pelo diâmetro. Geralmente, estabelece-se como um P/D nominal a relação $P / D$ da seção a $0.7 R$ e, então, segue-se uma distribuição radial referenciada pela nominal. A relação P/D resulta diretamente no ângulo de passo, conforme equação 1, e determina a pitch line de cada seção radial. 
Estabelecidas as definições das principais linhas que descrevem a geometria do propulsor, é possível compreender alguns conceitos importantes de maneira precisa através da representação de uma seção radial qualquer, presente na Figura 9.

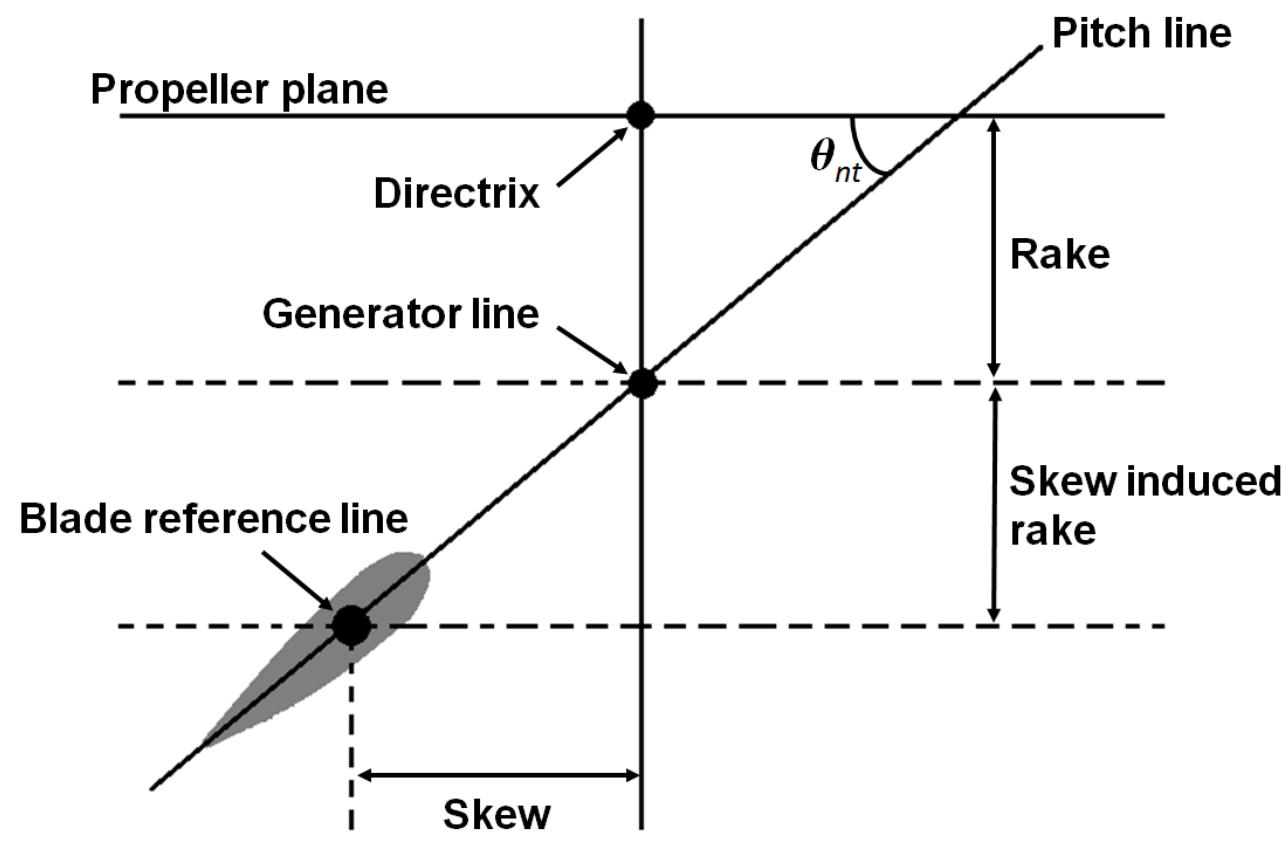

Figura 9 - Seção da pá do propulsor (definição de rake e skew)

Como se pode observar, existe uma excentricidade entre o ponto de meia corda (intersecção da Blade Reference line com esta seção radial planificada) e o ponto da linha geradora. Este segmento descrito sobre a pitch line não recebe nenhum nome particular, porém suas projeções ortogonais são especificadas de forma exata. A propriedade geométrica skew desta seção se estabelece, então, como a projeção do segmento sobre o plano do propulsor, enquanto um rake adicional, mais conhecido como skew induced rake, se forma pela projeção sobre o plano perpendicular, porém esta última se configura como uma propriedade redundante, uma vez que, de forma prática, a seção radial de um propulsor pode ser precisamente posicionada em posse dos valores de rake, skew e ângulo de passo da seção. 
O skew como propriedade geral do propulsor pode ser compreendido como o máximo ângulo possível, centrado no eixo, entre dois pontos da blade reference line, do ponto de vista do plano do propulsor, conforme ilustrado na Figura 10. Da mesma forma, pode se estabelecer o ângulo de rake, cuja tangente resulta da fração entre o rake da última seção (tip) e o raio. Há uma discordância entre os autores quanto à origem deste ângulo ser no eixo ou na superfície do hub, como se observa na Figura 10. Enquanto que, para a ITTC, a origem do ângulo se dá na raiz, na série B-Troost, no eixo.

Vale ressaltar que, embora ocorra na série B-Troost, a distância rake não varia ao longo do raio necessariamente de forma linear, fato que não altera o conceito descrito acima sobre o ângulo de rake.
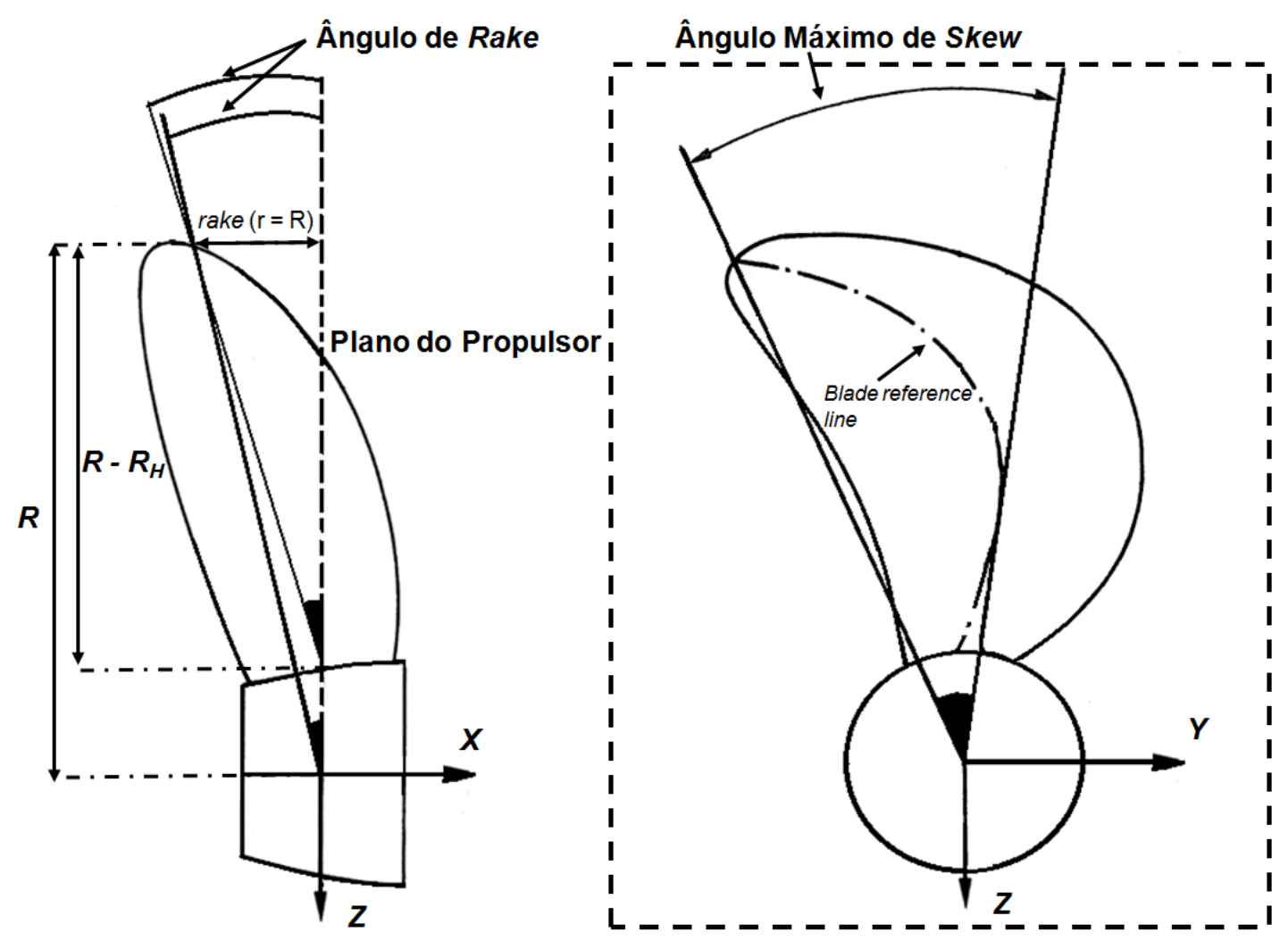

Figura 10 - Parâmetros geométricos da pá: skew e rake

Uma observação muito oportuna pode ser feita neste momento, pois se relaciona intimamente com os conceitos dessas duas últimas propriedades e 
das linhas principais definidas anteriormente. Na literatura pesquisada, não foi possível concluir que exista uma obrigatoriedade em que a seção da pá que marca sua intersecção com o hub, conhecida também como root section, coincida seu centro com a linha diretriz do propulsor. Em outras palavras, a linha geradora, a blade reference line e a diretriz não necessariamente se interceptam, seja no hub do propulsor ou em outro lugar. Esta intersecção é algumas vezes sugerida em algumas ilustrações, mas não está determinada, de fato, pelas definições. Este fato, exemplificado inclusive pela série B-Troost, não impede a descrição geométrica do propulsor, mas acaba deixando à linha diretriz um caráter vago e de determinação arbitrária, problema que resulta em más interpretações oriundas de uma não uniformidade de linguagem.

Em relação à área do propulsor, o parâmetro mais utilizado em projeto é a razão entre a área expandida $\left(A_{E}\right)$ e a área do círculo $\left(A_{O}\right)$, estabelecida pelo seu raio. A área expandida, conforme ilustrado na Figura 11, é definida pelo somatório, ao longo do raio (a partir do Bosso $R_{H}$ até a ponta $R$ ), dos comprimentos de corda $(c)$ das seções radiais das pás do propulsor (ver equação 2).

$$
\frac{A_{E}}{A_{O}}=\frac{Z \int_{R_{H}}^{R} c d r}{\pi R^{2}}
$$

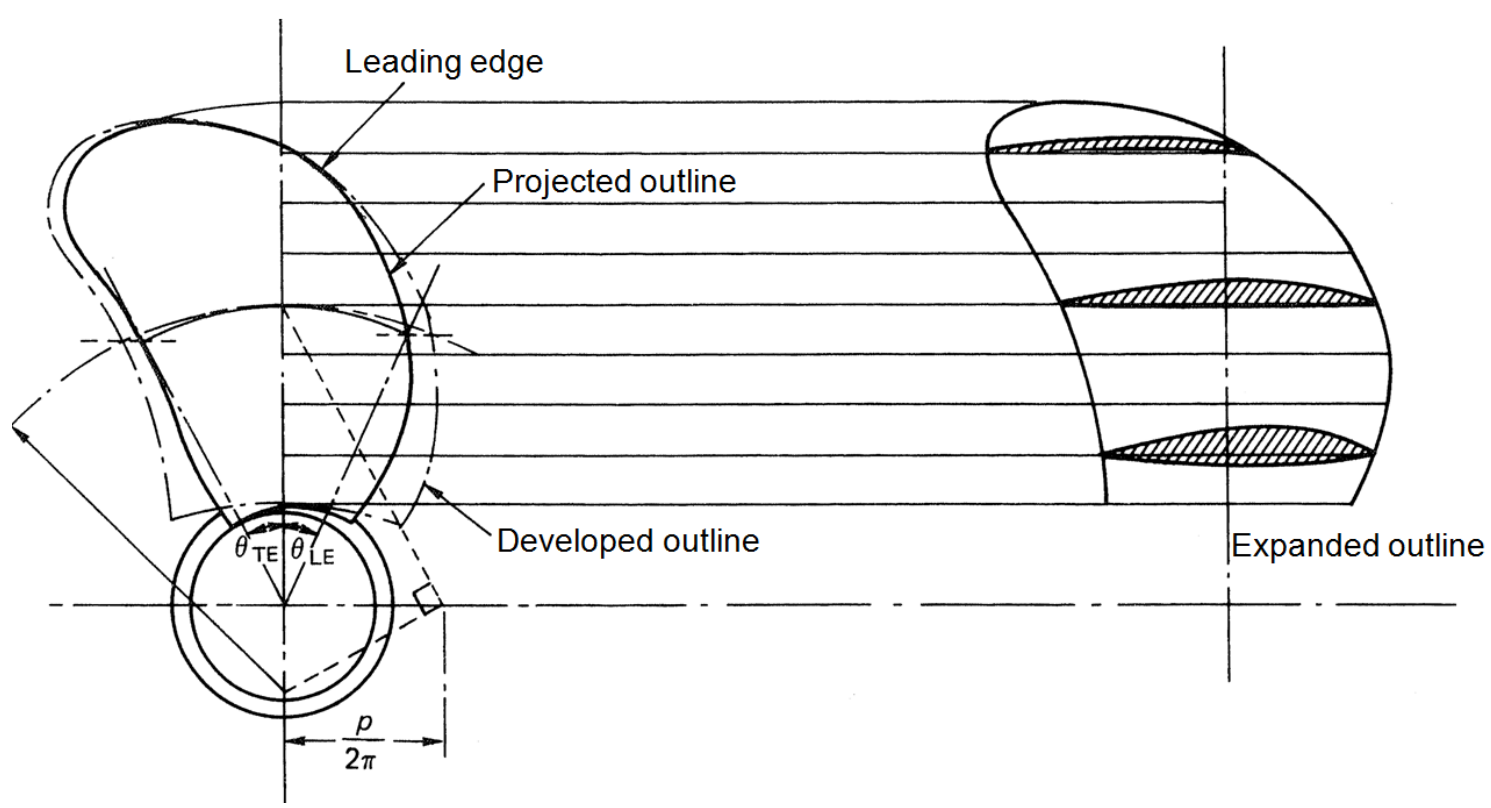

Figura 11 - Definição do contorno expandido da pá (Fonte: CARLTON, 2007) 


\subsection{Operação do propulsor}

Para caracterizar a operação dos propulsores, realizam-se ensaios em água aberta. Os resultados empíricos são apresentados na curva característica do propulsor. Nessa, o torque $(Q)$ exigido e 0 empuxo $(T)$ gerado são adimensionalizados pela densidade da água $(\rho)$, a rotação $(n)$ e o diâmetro $(D)$, e fornecidos respectivamente sob forma dos coeficientes $K_{Q}$ e $K_{T}$ em função do coeficiente de avanço $(\mathcal{J})$.

$$
\begin{gathered}
J=\frac{V_{A}}{n D} \\
K_{T}=\frac{T}{\rho n^{2} D^{4}} \\
K_{Q}=\frac{Q}{\rho n^{2} D^{5}}
\end{gathered}
$$

A velocidade $V_{A}$ é conhecida como velocidade média de avanço no plano do propulsor, aproximada para $V(1-w)$, onde $w$ é o coeficiente de esteira nominal média da embarcação medido neste plano.

A eficiência em água aberta $\left(\eta_{0}\right)$ é definida pela razão entre a potência fornecida pelo propulsor $\left(T x V_{A}\right)$ e a potência entregue pelo eixo ao propulsor $(2 \pi \times Q \times n)$, conforme a equação 6 :

$$
\eta_{O}=\frac{T V_{A}}{2 \pi Q n}=\frac{K_{T} J}{2 \pi K_{Q}}
$$

Diversas séries de propulsores já foram ensaiadas desde o século passado e, em muitas delas, os resultados empíricos foram já inseridos em regressões polinomiais do tipo 7 e 8 , para que, dadas as características de um propulsor 
(Z, $\left.A_{E} / A_{O}, P / D\right)$, seja possível a obtenção da respectiva curva característica, a exemplo da Figura 12.

$$
\begin{aligned}
K_{T} & =\sum_{n=1}^{p} X_{n}(J)^{a_{n}}(P / D)^{b_{n}}\left(A_{E} / A_{O}\right)^{c_{n}}(Z)^{d_{n}} \\
K_{Q} & =\sum_{n=1}^{q} Y_{n}(J)^{e_{n}}(P / D)^{f_{n}}\left(A_{E} / A_{O}\right)^{g_{n}}(Z)^{h_{n}}
\end{aligned}
$$

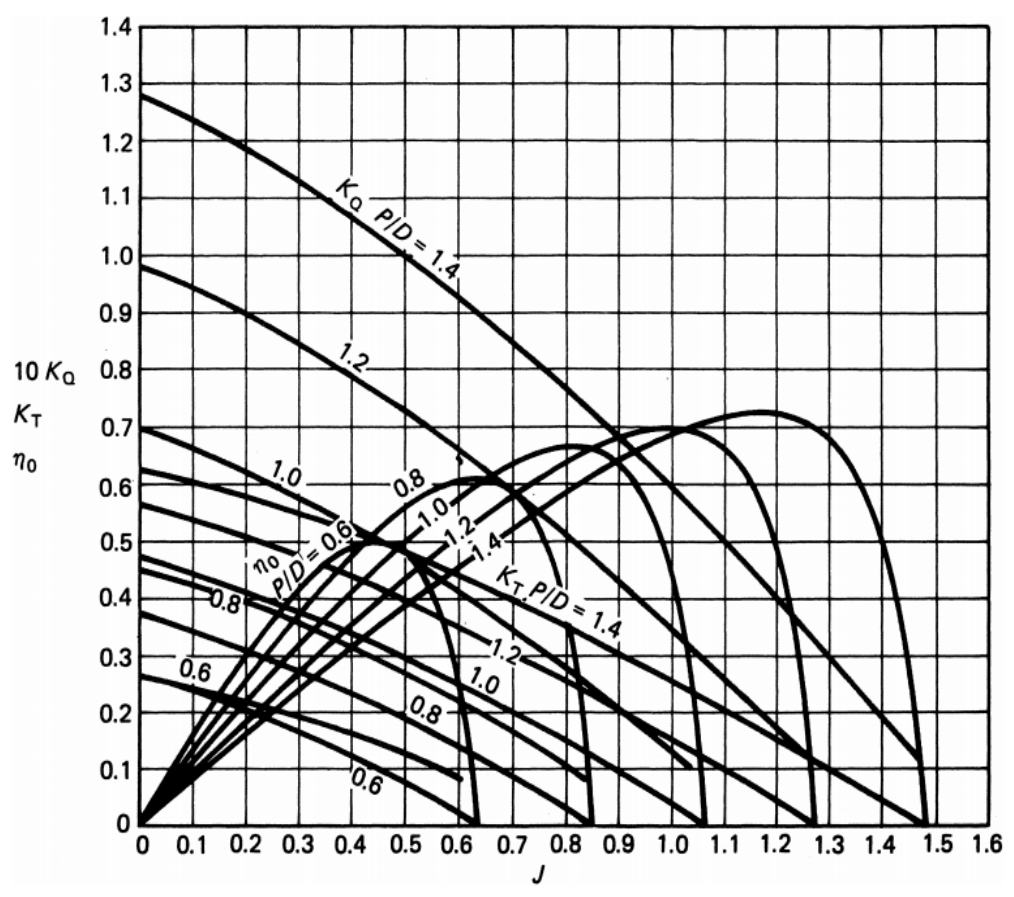

Figura 12 - Exemplo de curva característica de propulsor B5-75 (Fonte: KUIPER, 1992)

Para a simulação de manobras em que o propulsor opera fora da condição de avanço, isto é, acelerando tanto a favor quanto contrário ao movimento da embarcação, é realizada a representação multi-quadrante. Essa se baseia na caracterização da performance do propulsor segundo o ângulo $\varphi$ (definido na Figura 13 e expressão 9) entre a velocidade tangencial do movimento da pá, a $70 \%$ do raio, e a velocidade axial de translação instantânea (velocidade de avanço). 


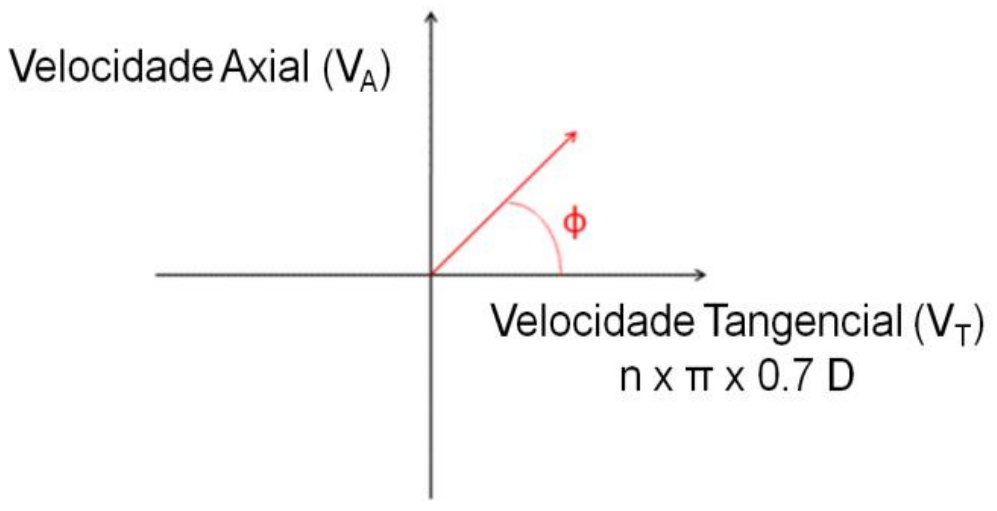

Figura 13 - Determinação do ângulo na análise multi-quadrante

$$
\varphi=\operatorname{atan}\left(\frac{V_{A}}{\pi n 0,7 D}\right)
$$

Os quatro quadrantes que podem ser percorridos pelo ângulo $\varphi$ representam as seguintes condições de operação:

- quadrante 1: velocidade no sentido de avanço; rotação no sentido de geração positiva de força propulsora;

- quadrante 2: velocidade no sentido de avanço; rotação no sentido de geração negativa de força propulsora;

- quadrante 3: velocidade no sentido de marcha a ré; rotação no sentido de geração negativa de força propulsora;

- quadrante 4: velocidade no sentido de marcha a ré; rotação no sentido de geração positiva de força propulsora.

São obtidos experimentalmente os coeficientes de torque e de empuxo $C_{Q}$ e $C_{T}$, análogos a $K_{Q}$ e $K_{T}$, definidos por [10] e [11]:

$$
\begin{aligned}
& C_{Q}=\frac{Q}{\frac{\pi}{8} \rho\left(V_{A}^{2}+(\pi n 0,7 D)^{2}\right) D^{3}} \\
& C_{T}=\frac{T}{\frac{\pi}{8} \rho\left(V_{A}^{2}+(\pi n 0,7 D)^{2}\right) D^{2}}
\end{aligned}
$$


Esses podem ser decompostos e obtidos numericamente por série de Fourier [12], em função do ângulo $\varphi$, resultando no gráfico presente na Figura 14.

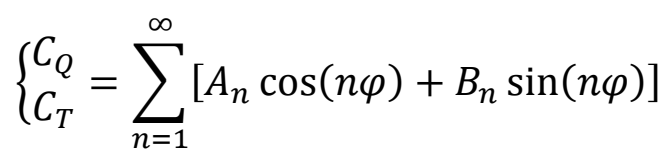

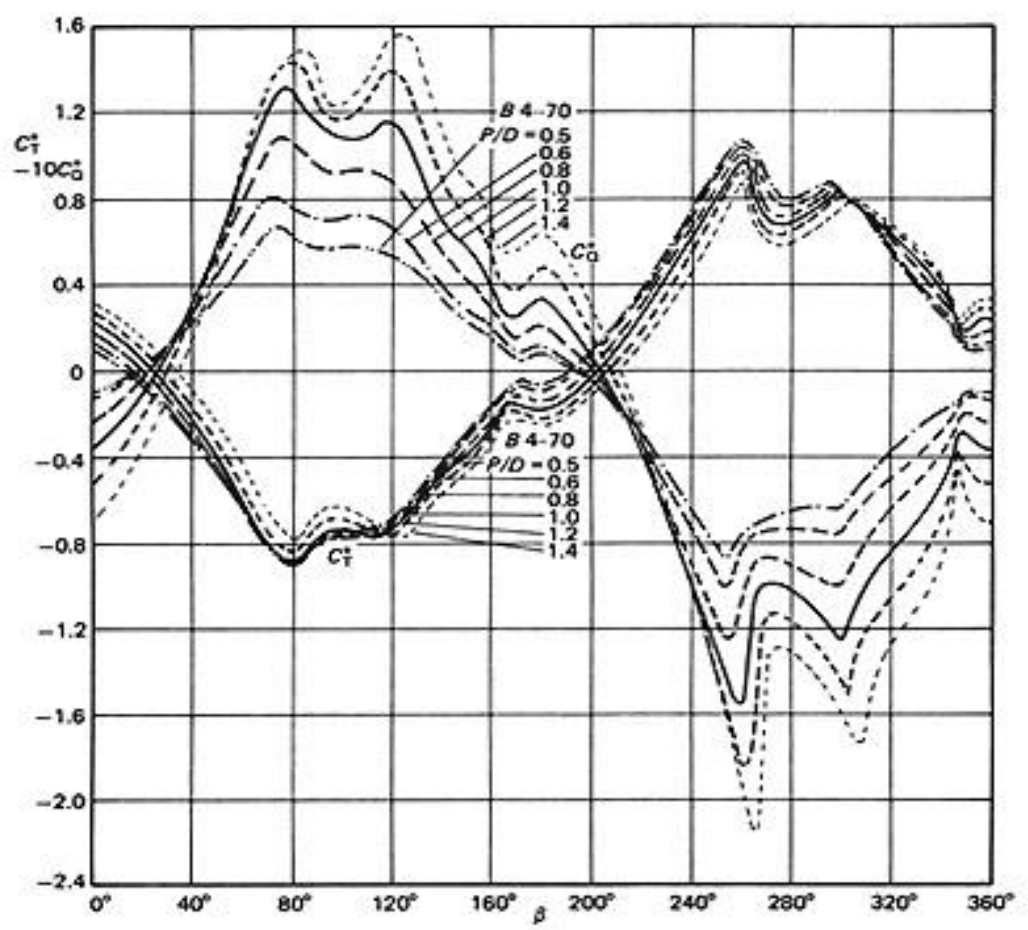

Figura 14 - Análise multiquadrante :Ct/Cq x $\varphi$ (Fonte: KUIPER, 1992)

Efeitos de escala e de cavitação não estão devidamente mensurados nessas curvas, e não podem ser desprezados. A cavitação é um fenômeno físico que ocorre quando se atinge em algum ponto do escoamento a pressão de vapor do fluido, devido aos efeitos dinâmicos. As bolhas formadas prejudicam o funcionamento do propulsor, podendo causar corrosão das pás e sendo uma das principais responsáveis pela geração de vibração, além da não uniformidade da esteira incidente.

A série B-Troost, exemplificada, e que será utilizada para o estudo, apresenta inclusive correções para efeito de escala, uma vez que as curvas foram feitas 
para um número de Reynolds de $10^{6}$ e objetivam a aplicação a casos reais $\left(\operatorname{Re} \sim 10^{8}\right)$. Além disso, existem métodos para prever a ocorrência e a intensidade de cavitação, desde os mais simples como o diagrama de Burril, aos mais complexos, que analisam cada um dos fólios dos perfis seccionais isoladamente.

Geralmente, o processo de integração casco-hélice, em fase inicial de projeto, consiste em determinar o coeficiente de avanço $(J)$ de integração a partir da intersecção da curva de resistência adimensionalizada do casco com a curva $K_{T}$ de água aberta de um propulsor e, a partir disso, dimensionar a rotação e a potência requerida pelo propulsor. No entanto, a utilização da curva de água aberta sob a hipótese de uma esteira homogênea é um procedimento muito impreciso frente à complexidade do escoamento na região do propulsor. Dessa forma, para etapas mais avançadas de projeto, são necessários outros métodos de análise do funcionamento do propulsor, antes ainda de se recorrer a ensaios com modelos. Os métodos apresentados no próximo item abrangem desde modelos analíticos simplificados a modelos numéricos refinados e de elevado custo computacional.

\subsection{Histórico dos métodos de análise de propulsor}

\subsubsection{Teoria da Quantidade de Movimento}

Proposta por Rankine em 1865 e incrementada por R. E. Froude em 1887, a teoria da quantidade de movimento foi a primeira formulação para simular a operação de um propulsor. O princípio de funcionamento do hélice é descrito como um escoamento através de um disco atuador. A aplicação desta teoria fornece uma primeira estimativa da eficiência ideal do hélice e dos esforços atuantes, porém não é capaz de caracterizar a sua geometria, uma vez que o trata como um disco de infinitas pás.

Assume-se que o propulsor opera em um fluido ideal e que, portanto, não há perdas por fricção. $O$ disco atuador, de mesmo diâmetro do hélice e alocado no 
plano do propulsor, impõe no escoamento uma descontinuidade no campo de pressão que altera a velocidade do fluxo, conforme ilustrado na Figura 15.

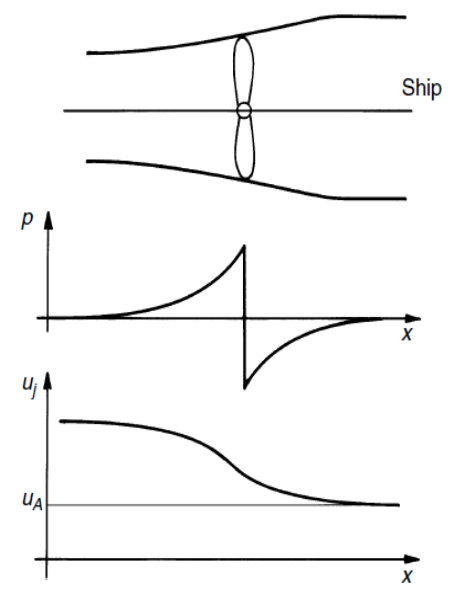

Figura 15 - Salto de pressão e velocidade no escoamento (Fonte: BERTRAN, 2000)

Inicialmente, no modelo proposto por Rankine, considerava-se que o disco não causava rotação no escoamento, mas Froude incluiu a parcela de velocidade angular no fluxo após a passagem pelo disco atuador. A diferença entre as velocidades de entrada e de saída multiplicada pela vazão em massa do fluxo de água resulta em uma variação de quantidade de movimento e, portanto, geração de empuxo.

\subsubsection{Teoria do Elemento de Pá}

Paralelamente ao modelo de quantidade de movimento, W. Froude desenvolveu um modelo que levasse em conta a geometria da pá do propulsor. Esse consistia na divisão da pá em varias seções radiais, conforme a Figura 16 , e para cada uma delas calcular, mediante o ângulo de avanço $(\beta)$, as parcelas de lift e drag atuantes no fólio seccional. Com essas parcelas de força integradas em toda pá, era possível a determinação do empuxo e torque total.

O modelo ainda permitia a alteração do ângulo de avanço, devido às velocidades induzidas pelo propulsor, para o ângulo de passo hidrodinâmico, a fim de aumentar a acurácia dos resultados. No entanto a vulnerabilidade do modelo residia na obtenção dos coeficientes de drag e de lift, devido à dificuldade de se obter a efetiva razão de aspecto da seção. 

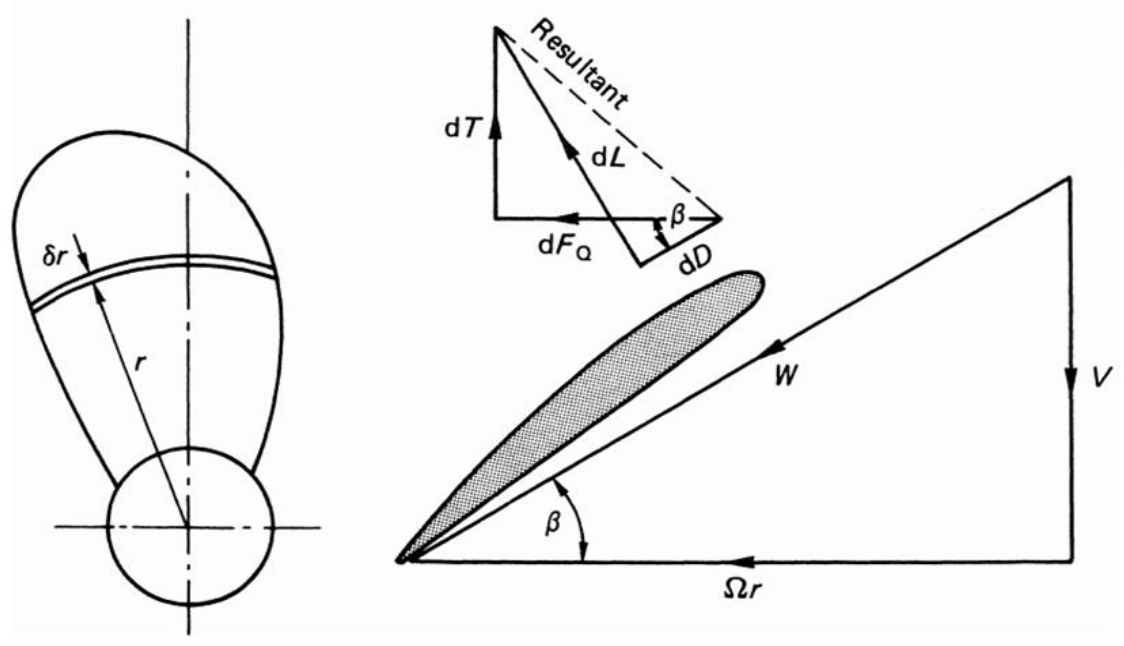

Figura 16 - Elemento de pá e componentes de drag e lift (Fonte: CARLTON, 2007)

Apesar da simplicidade e imprecisão desse método, ele pode ser considerado um grande avanço, e foi amplamente utilizado durante o final do século XIX e início do século XX.

\subsubsection{Teoria da Linha de Sustentação}

Lerbs, em 1952, propôs um método de análise para um propulsor sujeito a um carregamento moderado em um fluido invíscido. Neste modelo, cada seção transversal da pá (fólio) é substituída por um vórtice, que obedece às condições de Helmholtz ${ }^{1}$. A intensidade desses vórtices varia radialmente de seção para seção, permitindo a obtenção da distribuição do carregamento em uma pá, o que representa um avanço no que diz respeito ao projeto de propulsor.

Assume-se que a linha contínua radial, onde as linhas de vórtices são alocadas, permeia os supostos centros aerodinâmicos das seções, ou simplesmente é tomada como a linha diretriz do propulsor, como nas primeiras aplicações do modelo. A modelagem do propulsor pela TLS é ilustrada na Figura 17.

\footnotetext{
${ }^{1} \mathrm{O}$ teorema de Helmholtz estabelece que:

1- A intensidade do vórtice correspondente a cada seção é constante ao longo do escoamento.

2- A linha do vórtice não termina no fluido. Portanto ela deve se estender até as fronteiras do fluido, o que poderia ocorrer no limite de $\pm \infty$, ou formar uma curva fechada.
} 


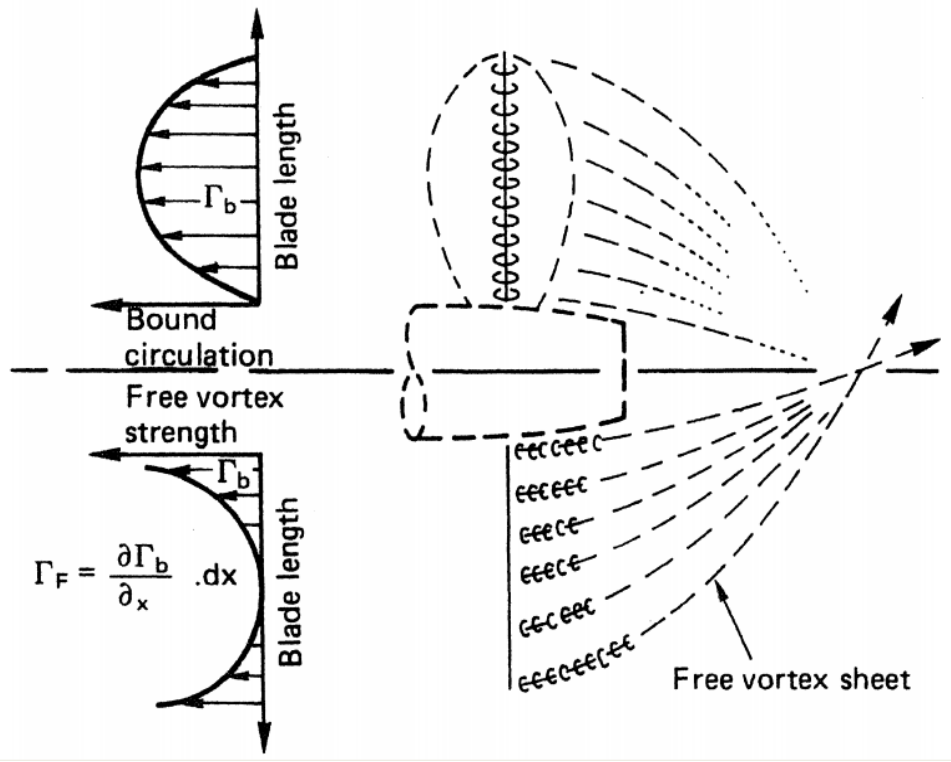

Figura 17 - Representação do propulsor em aplicação da TLS (Fonte: CARLTON, 2007)

A vorticidade alocada sobre a pá (bound vortex), que varia radialmente segundo uma distribuição $\Gamma(r)$, origina uma folha de vórtices livres (free vortex) $\Gamma_{\mathrm{F}}$, que segue uma trajetória helicoidal. Além disso, uma terceira vorticidade referente ao bosso (hub vortex) é incluída nos cálculos, porém imposta como zero, como conveniência computacional. Além das velocidades no plano do propulsor, axial e tangencial, são calculadas as parcelas de velocidade induzida pela folha de vórtices, através da lei de Biot-Savart, cuja complexidade matemática é maior.

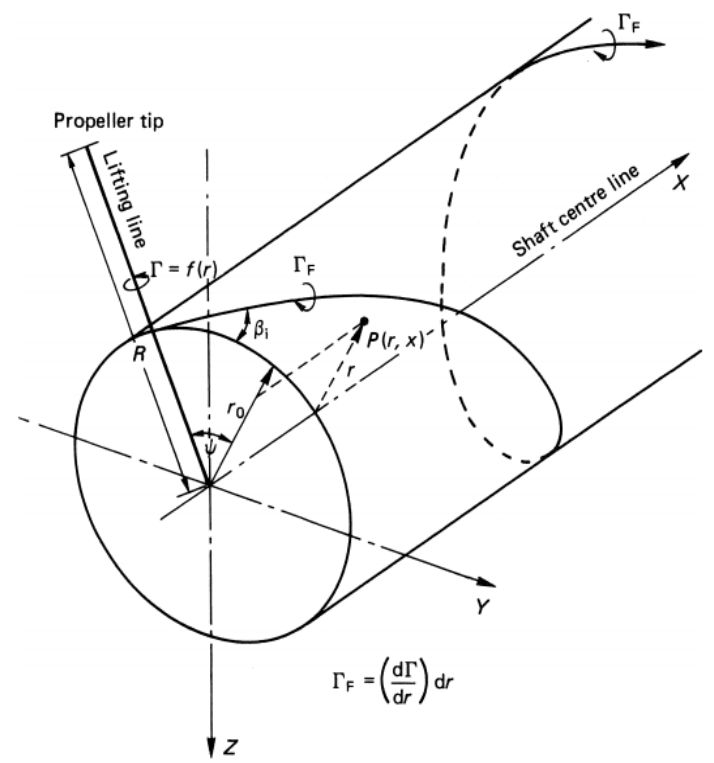

Figura 18 - Trajetória de uma linha de vórtice na TLS (Fonte: LERBS,1952) 
O cálculo das integrais ao longo da folha de vórtices livres é complexo, exigindo uma solução numérica para a obtenção da distribuição das velocidades induzidas, da circulação e do ângulo de passo hidrodinâmico e, consequentemente, a sustentação. Finalmente, os efeitos viscosos são aproximadamente considerados através de dados experimentais, para 0 cálculo do empuxo.

\subsubsection{Teoria da Superfície de Sustentação}

A representação do propulsor pela teoria da superfície de sustentação (TSS) é um aprimoramento em relação à metodologia utilizada na TLS, uma vez que, ao invés de substituir cada uma das seções da pá por uma única linha de vótice, o fólio seccional é tratado analogamente à modelagem utilizada para fólios finos, na qual uma linha dotada de uma certa distribuição de vorticidade representa o fólio, gerando portanto uma folha de vórtices para cada seção da pá e não mais uma linha de vórtices para toda a pá. Na Figura 19, pode-se visualizar a representação do perfil de uma das seções da pá segundo a teoria de fólios finos, base da representação da superfície de sustentação.

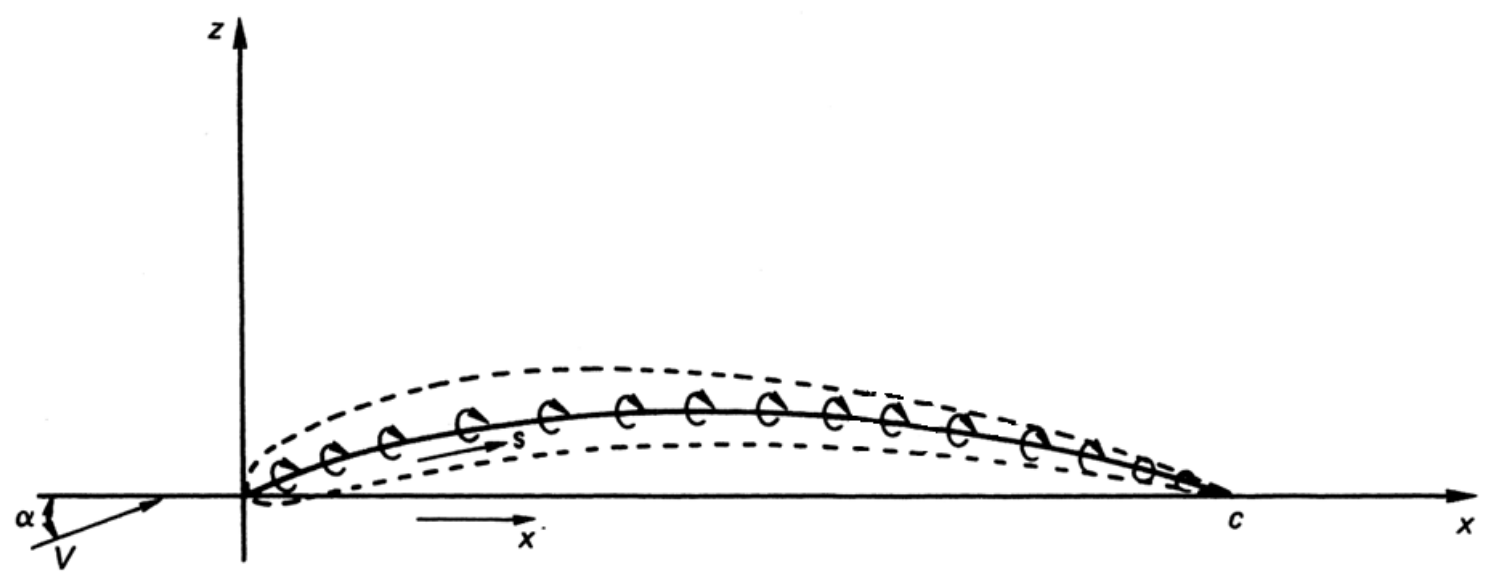

Figura 19 - representação de um fólio segundo a teoria de fólios finos (Fonte: CARLTON, 2007)

A pá como um todo pode ser representada de acordo com a Figura 20. 


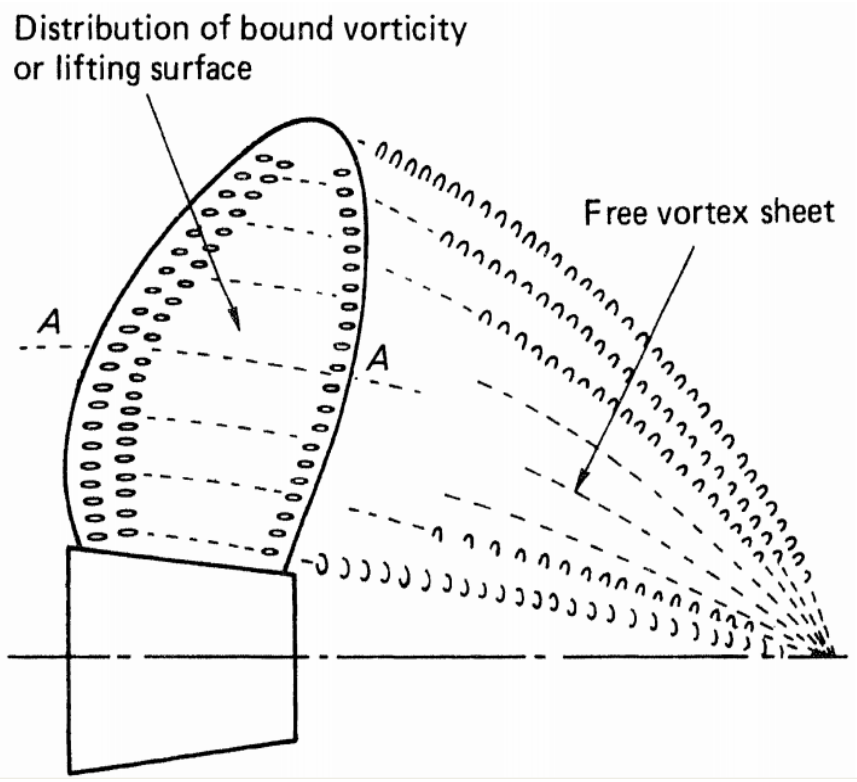

Figura 20 - Representação do propulsor segundo a TSS (Fonte: CARLTON, 2007)

A TSS segue a mesma modelagem matemática da TLS, com a adição de uma dimensão, que permite a inclusão da representação dos efeitos espaciais da pá, levando em consideração a variação da geometria ao longo da corda do fólio seccional, da distribuição de curvatura e da inclusão dos efeitos geométricos de torção (skew).

\subsubsection{Método de Elemento de Contorno}

Os métodos de elemento de contorno (BEM - Boundary Element Method) se desenvolveram na análise de propulsores com o objetivo de superar duas dificuldades dos métodos de superfície de sustentação: a ocorrência de erros localizados próximos ao leading edge e nas proximidades das pás com 0 bosso. Essencialmente, podem ser resumidos no mais difundido método dos painéis. As primeiras aplicações de métodos de painéis em propulsores datam da década de 1980, como exemplo o trabalho de Hoshino (1989) de análise hidrodinâmica de um propulsor operando em escoamento uniforme. 


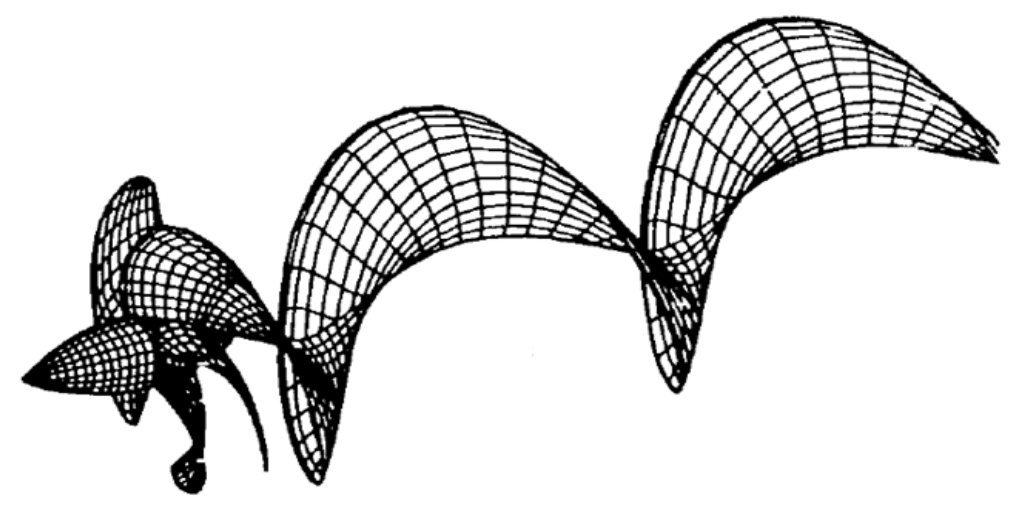

Figura 21 - Aplicação do método dos painéis em propulsores (Fonte: HOSHINO, 1989)

Como pode ser observado na Figura 21, o método dos painéis consiste na discretização da superfície do propulsor, tanto das pás quanto do bosso, e da folha de vórtices (trailing vortex) em painéis quadriláteros. Cada um dos painéis é dotado de um ponto de colocação (null points), sobre o qual são impostas as condições de contorno do escoamento. Uma abordagem mais detalhada deste método será feita no subitem 3.4.

Obteve-se boa concordância do método em questão com os resultados experimentais no que diz respeito às características de água aberta. $O$ desenvolvimento mais recente de métodos de elementos de contorno permitiu a análise de casos mais complexos, tais como escoamentos não permanentes e cavitantes, já considerando, ainda que superficialmente, efeitos viscosos.

\subsubsection{Métodos CFD (Computational Fluid Dynamics)}

Nos procedimentos descritos anteriormente, a hipótese fundamental adota escoamento ideal em que os efeitos da viscosidade são incluídos aproximadamente através da larga base de dados existente para seções/fólios bidimensionais. Esse, por sua vez, se revela como um dos principais avanços dos métodos RANSE (Reynolds Averaged Navier-Stokes Equation), que, apesar do alto custo e tempo computacional, permite incorporar os efeitos viscosos com maior precisão e capturar as particularidades do escoamento em 
função da complexa geometria do propulsor, inclusive os efeitos do bosso e da extremidade da pá.

Somente com a evolução da capacidade computacional, estes métodos puderam ser desenvolvidos, uma vez que utilizam extensas e densas malhas volumétricas por todo o domínio fluido, cujas células são regidas pela equação de Navier-Stokes, com o auxílio de modelos de turbulência sobre os quais as opiniões dos especialistas ainda divergem.

\subsubsection{Conclusão: método a ser utilizado para análise hidrodinâmica}

Apesar de já ser aplicável em propulsores, o CFD não será utilizado no presente estudo, dada a quantidade restrita e a pouca clareza de informações das publicações a respeito de análise de hélices por este tipo de método. A complexidade do escoamento ao redor de um propulsor torna-se muito mais elevada em relação aos problemas de resistência ao avanço sobre o casco de uma embarcação, por exemplo, e neste ponto, as incertezas que tangemos modelos de turbulência podem complicar ainda mais a aplicação deste método.

Por outro lado, a existência de uma vasta bibliografia a respeito de aplicação da teoria potencial a propulsores, como Vaz (2005) e Kerwin (1975), a boa aderência de resultados de análise em escoamento uniforme, obtidos até através da utilização de softwares como o PPB, comparados aos ensaios em água aberta, e a menor sofisticação e tempo computacional exigidos pelo método dos painéis corroboram para sua aplicação neste estudo.

\subsection{Aplicação do Método dos Painéis em propulsores}

A ação do propulsor deve ser modelada de acordo com a teoria potencial e implementada numericamente através da utilização do método dos painéis. $O$ problema hidrodinâmico em questão, um escoamento incompressível ao redor de um corpo, pode ser aplicado na superfície da pá e na esteira através da identidade de Green, para a obtenção da solução, isto é, o potencial de velocidades em cada ponto da mesma. 
Para a definição desses potenciais, são distribuídas vorticidades ao longo da superfície da pá e uma folha de vórtices livres é emanada a partir da mesma, caracterizando a indução de velocidades na esteira. O método de painéis é aplicado justamente para discretizar tais superfícies e alocar a distribuição de vorticidades em cada painel pertencente a esta malha.

\subsubsection{Teoria Potencial}

A equação de movimento que rege o escoamento de um fluido, derivada da segunda lei de Newton, pode ser expressa como:

$$
\rho(\vec{x}, t) \vec{a}(\vec{x}, t)=\operatorname{div} T(\vec{x}, t)+\vec{b}(\vec{x}, t)
$$

Onde:

$\vec{x}$ é o vetor posição

$\rho(\vec{x}, t)$ é a densidade do fluído

$\vec{a}(\vec{x}, t)$ é a aceleração em um ponto do fluido

$T(\vec{x}, t)$ é o tensor das tensões

$\vec{b}(\vec{x}, t)$ representa forças de corpo atuantes sobre o fluido

Considerando-se a aceleração como derivada material da velocidade $(\vec{a}(\vec{x}, t)=$ $\left.\frac{\partial \vec{v}}{\partial t}(\vec{x}, t)+\operatorname{grad} \vec{v}(\vec{v})\right)$, a homogeneidade $\left(\rho(\vec{x}, t)=\rho_{\text {cte }}\right)$ e incompressibilidade $(\operatorname{div} \vec{v}=0)$ do fluido, chega-se a equação de Navier-Stokes, para um fluido newtoniano de viscosidade $\mu$ :

$$
\rho\left(\frac{\partial \vec{v}}{\partial t}+\operatorname{grad} \vec{v}(\vec{v})\right)=-\operatorname{grad} p+\mu \Delta \vec{v}+\vec{b}(\vec{x}, t)
$$


Onde $p$ é o campo de pressões do escoamento

Introduzidas as hipóteses de fluido ideal e irrotacional, pode-se considerar o escoamento potencial, uma vez que o campo de velocidades pode ser descrito como o gradiente de uma função potencial $(\vec{v}(\vec{x}, t)=\operatorname{grad} \varphi(\vec{x}, t))$.

Admitindo que as forças de corpo atuantes sobre o fluido são de origem conservativa $(\vec{b}(\vec{x}, t)=-$ grad $\gamma)$, a equação de movimento se reduz à equação de Bernoulli, em função do potencial $\varphi$ :

$$
\frac{\nabla \varphi \cdot \nabla \varphi}{2}+\frac{p}{\rho}+\gamma=c t e
$$

\subsubsection{Escoamento Potencial ao redor de um corpo}

Considera-se um domínio tridimensional $\vee$ de fronteira $S$, cujo vetor normal é $\vec{n}$. A superfície $S$ pode ser dividida em três partes: $S_{B}$ ao redor do corpo; $S_{W}$ representando a esteira; e a superfície externa $S_{\infty}$, suficientemente distante do corpo, onde o escoamento não é perturbado e possui velocidade $\overrightarrow{U_{\infty}}$. Determina-se um potencial $\varphi$, que representa a perturbação do corpo no escoamento e deve respeitar a conservação da massa, além das condições de contorno, equacionadas a seguir.

Conservação de massa (Equação de Laplace):

$$
\Delta \varphi=0
$$

Impenetrabilidade do corpo em $S_{B}$ ou condição cinemática:

$$
\frac{\partial \varphi}{\partial n}=\vec{n} \cdot \nabla \varphi=-\vec{n} \cdot \overrightarrow{V_{\infty}}
$$


Condição de Evanescência, que garante que a perturbação do corpo no escoamento é nula em $S_{\infty}$ :

$$
\nabla \varphi \underset{\infty}{\rightarrow} 0
$$

Espessura nula da superfície $S_{W}$, portanto nulo o salto de pressão entre os dois lados da superfície $S_{W}$.

$$
\begin{gathered}
(\Delta p)_{S_{W}}=p^{+}-p^{-}=0 \\
\left(\Delta \frac{\partial \varphi}{\partial n}\right)_{S_{W}}=\left(\frac{\partial \varphi}{\partial n}\right)^{+}-\left(\frac{\partial \varphi}{\partial n}\right)^{-}=0
\end{gathered}
$$

O salto no potencial $\varphi$ pode ser igualado à circulação $\Gamma$ :

$$
(\Delta \varphi)_{S_{W}}=\varphi^{+}-\varphi^{-}=\Gamma
$$

Condição de Kutta no traling edge do corpo: o escoamento, ao final do seu contorno sobre o corpo, possui velocidade única, isto é, igual no limite entre ambas as faces do corpo (ver Figura 22).

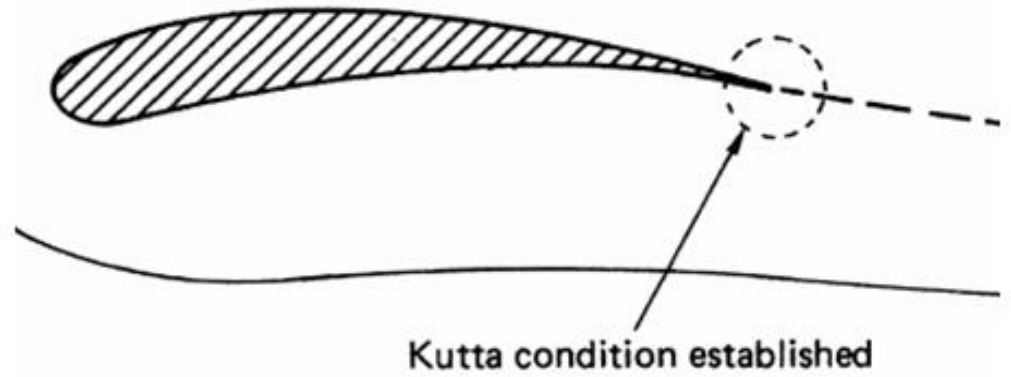

Figura 22- Condição de Kutta aplicada em fólio (fonte: CARLTON, 2007) 
O problema de contorno pode ser então definido em um sistema de equações que relacionam o potencial $\varphi$ em um ponto $P(x, y, z)$ pertencente ao volume $\mathrm{V}$, exterior ao corpo, com potencial $\varphi$ em um ponto $Q(\xi, \eta, \zeta)$ na superfície do corpo em $S_{B}$, considerando um volume fictício $\mathrm{V}$ ', interno ao corpo, de potencial $\varphi^{\prime}$.

$$
4 \pi \varphi(P)=\iint_{S_{B}}\left[\left(\varphi(Q)-\varphi^{\prime}(Q)\right) \frac{\partial}{\partial n_{Q}} \frac{1}{R_{P Q}}-\left(\frac{\partial \varphi(Q)}{\partial n_{Q}}-\frac{\partial \varphi^{\prime}(Q)}{\partial n_{Q}}\right) \frac{1}{R_{P Q}}\right] d S+\iint_{S_{W}} \Delta \varphi(Q) \frac{\partial}{\partial n_{Q}} \frac{1}{R_{P Q}} d S
$$

Onde $R_{P Q}$ é a distância entre $\mathrm{P}$ e $\mathrm{Q}$.

Esta equação representa o potencial em termos do dipolo de intensidade $(\varphi-$ $\left.\varphi^{\prime}\right)$ em $S_{B}$ e $\Delta \varphi$ em $S_{W}$. Conforme dito anteriormente, o volume $V^{\prime}$ é fictício, assim como $\varphi^{\prime}$. Portanto como o escoamento interno ao corpo não tem significado físico, pode-se adotar o valor nulo para o mesmo, convenientemente. A equação para um corpo arbitrário em escoamento potencial é, então definida.

$$
2 \pi \varphi(P)=\iint_{S_{B}}\left[\varphi(Q) \frac{\partial}{\partial n_{Q}} \frac{1}{R_{P Q}}-\frac{\partial \varphi(Q)}{\partial n_{Q}} \frac{1}{R_{P Q}}\right] d S+\iint_{S_{W}} \Delta \varphi(Q) \frac{\partial}{\partial n_{Q}} \frac{1}{R_{P Q}} d S
$$

\subsubsection{Aplicação numérica do Escoamento Potencial em propulsores}

O propulsor é constituído por $Z$ pás distribuídas axissimetricamente ao redor do Bosso, também axissimétrico. Define-se, então, um sistema fixo de coordenadas formado pelo eixo $\mathrm{X}$, axial apontando no sentido downstream, pelo eixo $Z$, apontado para cima e pelo $Y$, respeitando a regra da mão direita.

São fornecidos os parâmetros de skew, rake, pitch, camber, espessura, de acordo com a descrição do item 3.1, para a construção das pás, que são divididas em painéis, definidos em seções radiais e ao longo do fólio seccional, conforme a Figura 23. $\mathrm{O}$ bosso também é dividido em painéis quadriláteros ao 
longo de sua circunferência, respeitando a linha formada por sua intersecção da pá, evitando a descontinuidade da malha de painéis.

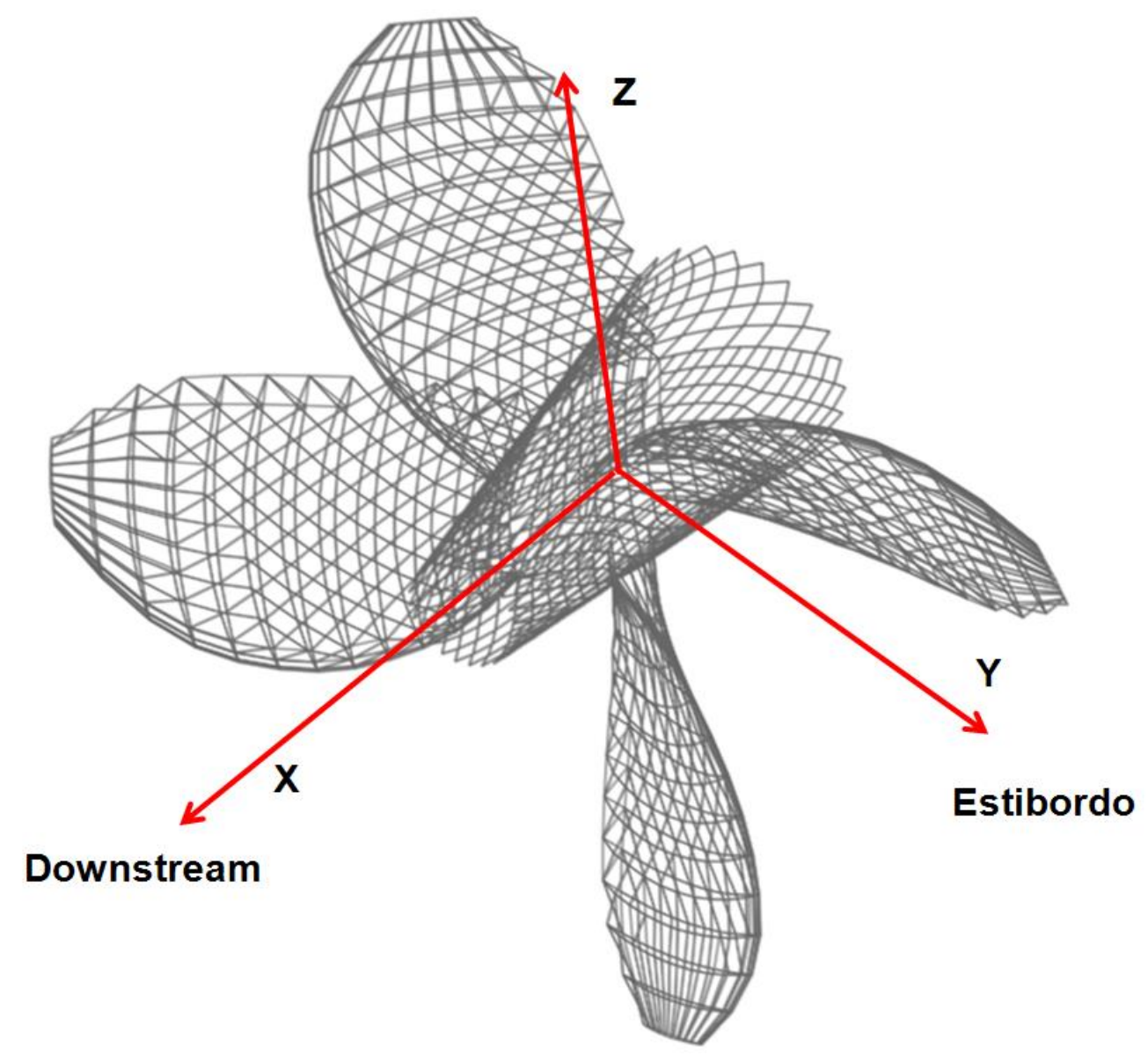

Figura 23 - Caracterização do propulsor (malha)

A caracterização da esteira é feita, conforme já citado e visualizado na Figura 21 , através de uma malha helicoidal de painéis quadriláteros que parte da pá do propulsor. Sua determinação reside em dois parâmetros: a sua geometria e intensidade. A última pode seguir a distribuição radial de circulação da própria pá, enquanto que a primeira deve estar alinhada com o escoamento, implicando na contração e deformação da mesma.

A equação integral apresentada para o escoamento potencial em torno de um corpo arbitrário pode ser discretizada e aplicada sobre um propulsor. As superfícies $S_{B}$ e $S_{W}$ podem ser substituídas por uma malha de grande 
quantidade de painéis quadriláteros, cujos centroides são chamados de pontos de colocação (controll points), onde são distribuídas continuamente as singularidades (vórtices, no caso).

São satisfeitas as condições de contorno estabelecidas no item 3.4.2, especialmente a condição de Kutta, aplicada no bordo de fuga da pá (trailing edge), que determinará a vorticidade introduzida na esteira, e aplicada equação integral [23] de forma discretizada, em todos os painéis (sobre o ponto de colocação), estabelecendo-se assim um sistema de equações, para o cálculo do potencial $\varphi$.

Determinados os valores do potencial em cada ponto, são estabelecidas as velocidades na superfície, pela a diferenciação dos respectivos potenciais. Os coeficientes de pressão são calculados através da equação de Bernoulli. E, finalmente, as forças e momentos são obtidos pela soma dos vetores de força individuais de cada painel.

Faz-se necessária uma correção viscosa, a fim de se obter resultados comparáveis aos experimentais, através da teoria de placa plana. São inclusas, portanto, em cada um dos painéis, uma componente de força viscosa na direção da velocidade do escoamento incidente. 


\section{METODOLOGIA}

Primeiramente, objetivando um caráter generalista para a aplicação do estudo, realiza-se uma avaliação sobre a esteira de diferentes tipos de embarcações, dado de entrada para as análises computacionais da operação do propulsor.

A análise computacional do escoamento ao redor de um propulsor deve ser realizada através do método dos painéis, que exige um baixo tempo computacional, ideal para alta quantidade de casos compreendidos no estudo, e já apresenta uma ampla aceitação no campo de propulsores. A fim de não se estender em desenvolvimento de métodos ou mesmo de ferramentas numéricas, utiliza-se um software comercial, que é devidamente validado para a obtenção dos esforços gerados pelo propulsor através da comparação de resultados com os dados da $14^{\mathrm{a}}$ ITTC.

A seguir, diversas configurações geométricas da série B-Troost, que combinam alterações de número de pás, relação de área expandida, relação de passo, skew e rake, são submetidas a um breve processo de integração com a esteira incidente e analisadas no software.

Os resultados das análises computacionais devem ser tratados levando-se em conta os aspectos de eficiência e de excitação de vibração. Para tanto, devem ser estipulados critérios que avaliem tais aspectos.

Dessa forma, ao se observar os resultados, busca-se identificar as interferências dos aspectos geométricos abordados na performance do propulsor frente aos atributos elegidos.

As etapas que envolvem a metodologia do processo estão ilustradas pelo fluxograma presente na Figura 24 e serão mais detalhadas nos subitens a seguir. 


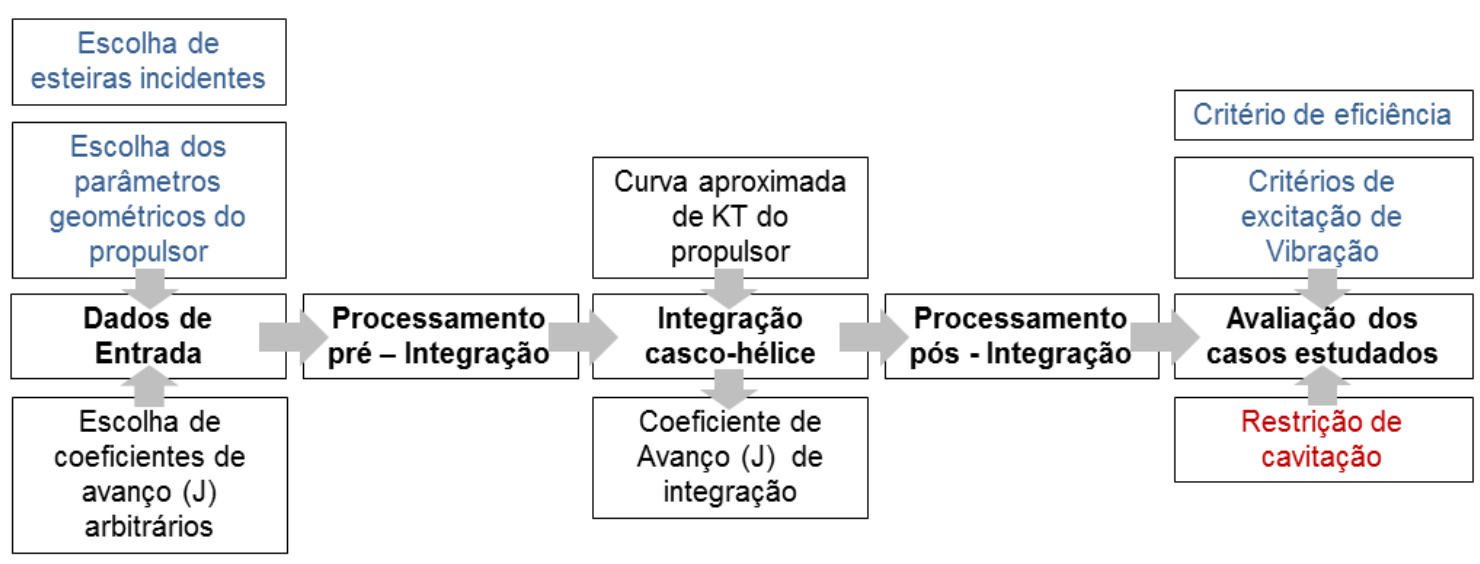

Figura 24 - Fluxograma das etapas do estudo

\subsection{Análise da esteira das embarcações}

A princípio, não se pretende realizar um estudo de caso em que se otimizaria um propulsor para um navio específico, portanto, em uma coleta de naviosexemplos dotados de resultados provindos de análises CFD já validados com os casos reais, busca-se encontrar padrões de comportamento sob aspecto do campo de velocidades na popa de alguns tipos de navios distintos.

Com um banco de dados disponível não muito extenso, sete navios-exemplos foram tratados: 1 série 60, 1 ro-ro, 2 porta-container e 3 tanqueiros, cujos dados estão apresentados na Tabela 2.

Tabela 2 - Dados dos navios exemplos

\begin{tabular}{|c|c|c|c|}
\hline Tipo de Navio & $\mathrm{C}_{\mathrm{B}}$ & $\mathrm{L}(\mathrm{m})$ & $\mathrm{V}(\mathrm{knt})$ \\
\hline \multirow{3}{*}{ Tanque } & 0.85 & 253 & 15.9 \\
\cline { 2 - 4 } & 0.84 & 270 & 15.5 \\
\cline { 2 - 4 } & 0.82 & 300 & 15.6 \\
\hline \multirow{2}{*}{ Porta-Container } & 0.65 & 170 & 19.8 \\
\cline { 2 - 4 } & 0.61 & 154 & 18.0 \\
\hline Ro-ro & 0.64 & 162 & 21.6 \\
\hline Série 60 & 0.59 & 103 & 24.6 \\
\hline
\end{tabular}

Apesar de várias tentativas utilizando análises harmônicas de $1^{\underline{a}}$ a $8^{\underline{a}}$ ordem, não foi possível encontrar padrões de distribuição desses harmônicos em função de valores do coeficiente de esteira média nominal, nem mesmo do coeficiente de bloco das embarcações. Embora pareça existir um padrão 
gradativamente alterado entre os tipos de esteiras, que pode ser identificado visualmente (Figura 25), esse não foi traduzido pelas respectivas amplitudes harmônicas, que revelaram distribuições praticamente aleatórias, impedindo qualquer possibilidade de padronização ou mesmo parametrização de tais campos de velocidade.

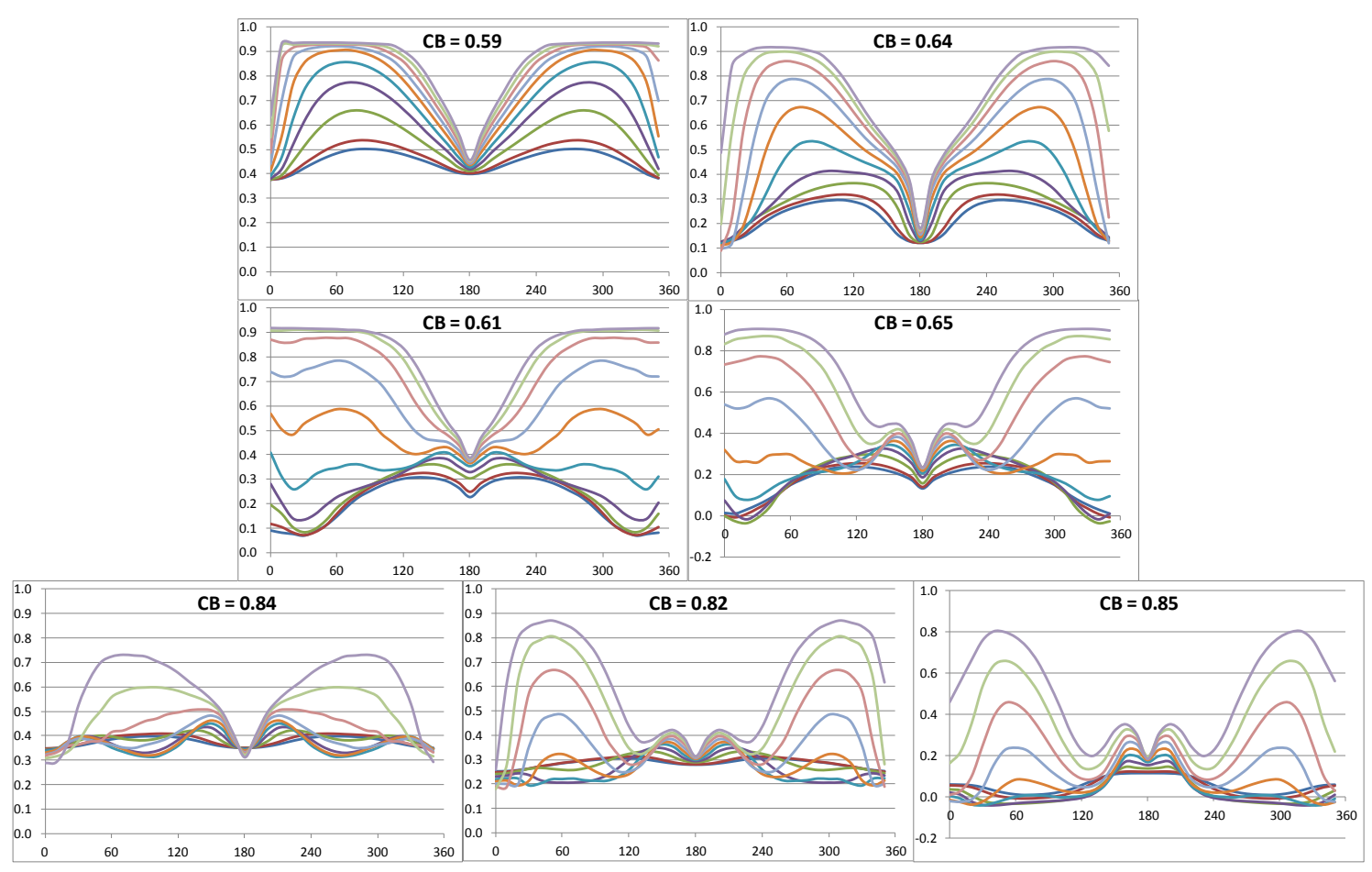

Figura 25 - Velocidade axial adimensional versus posição angular no plano do propulsor

A Figura 25, que reúne os perfis de velocidade axial incidente no plano do propulsor das embarcações, revela uma semelhança de formato entre o série 60 e o ro-ro, sendo que este último já revela um comportamento intermediário em relação aos porta-container. Esses já revelam um grau de perturbação do escoamento, que se apresenta de forma intensificada nas popas dos naviostanque, em que a velocidade em regiões mais internas do ponto de vista radial supera a de regiões intermediárias. As Figuras 26 e 27 mostram respectivamente os perfis de velocidade tangencial e radial, que, da mesma forma, apresentaram semelhanças de comportamento visuais que não foram comprovadas numericamente. 

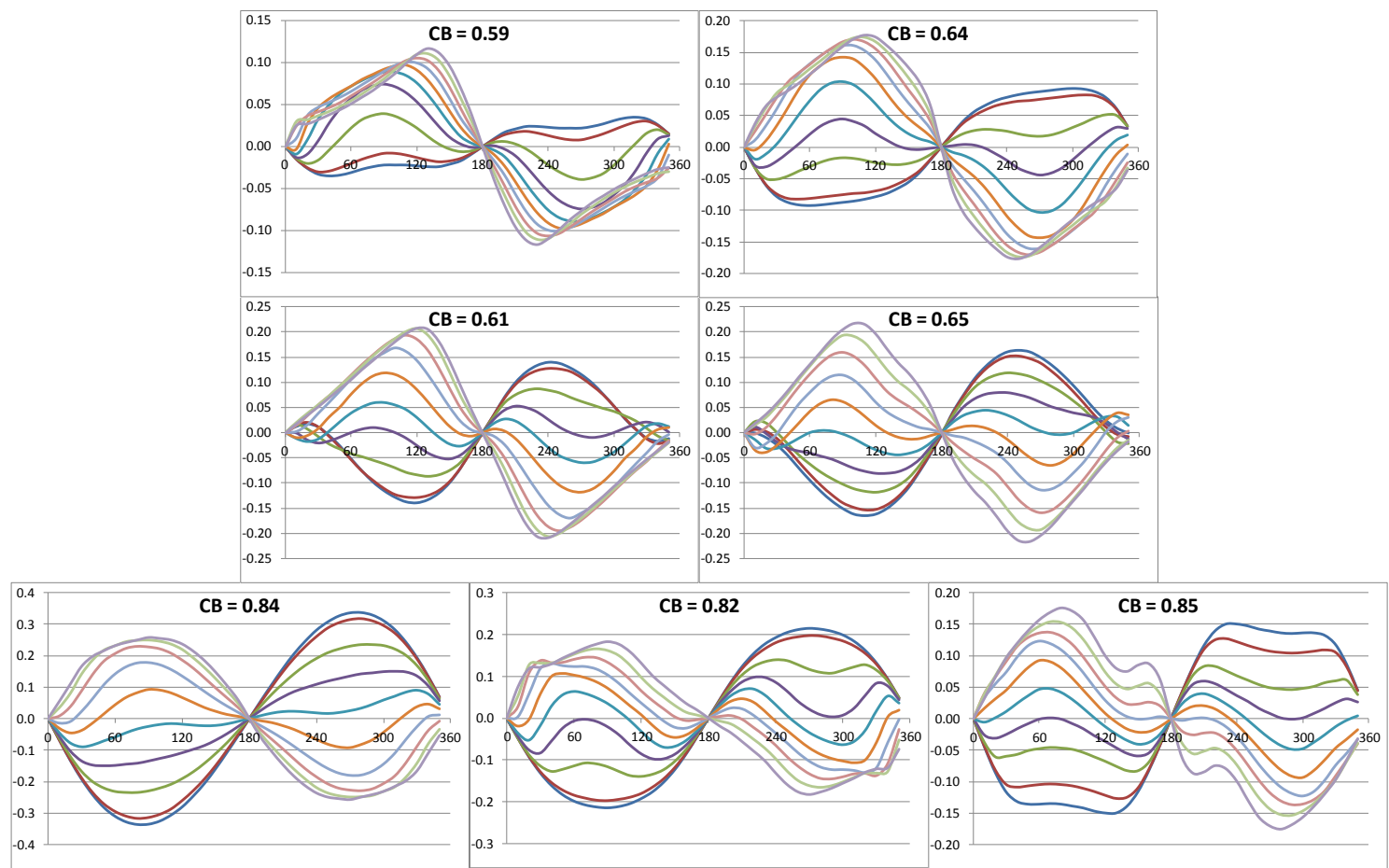

Figura 26 - Velocidade tangencial adimensional versus posição angular no plano do propulsor
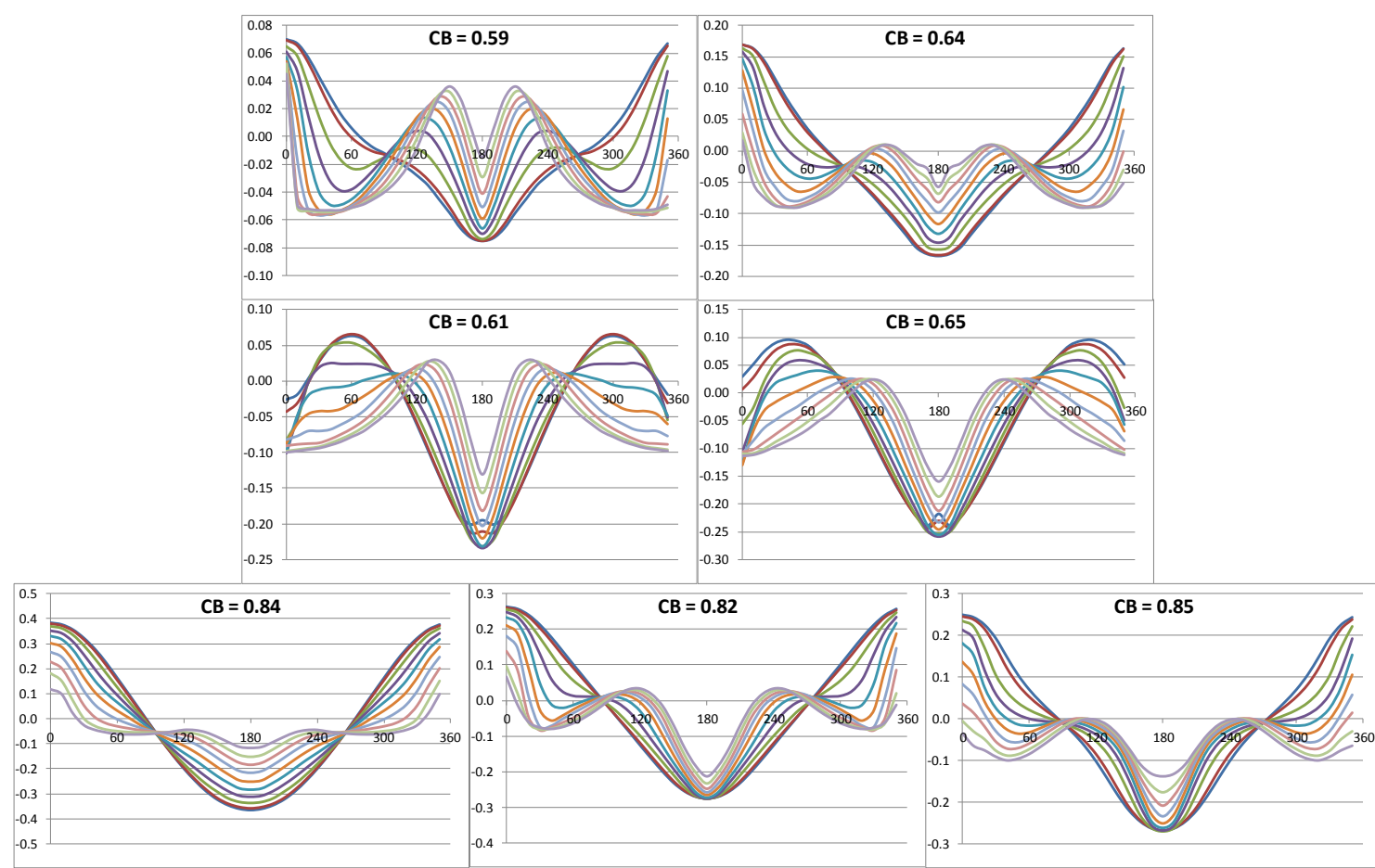

Figura 27 - Velocidade tangencial adimensional versus posição angular no plano do propulsor 
Assumindo uma perda inevitável de generalidade, as esteiras incidentes utilizadas para as análises computacionais serão representadas por três tipos: a dos navios mais afilados (tipo I); dos medianos, como porta-container (tipo II); e dos mais bojudos, como os tanqueiros (tipo III). Os três campos de velocidades representativos para o estudo estão apresentados na Figura 28. Os dados numéricos dessas podem ser encontrados na rotina presente no anexo $\mathrm{B}$.

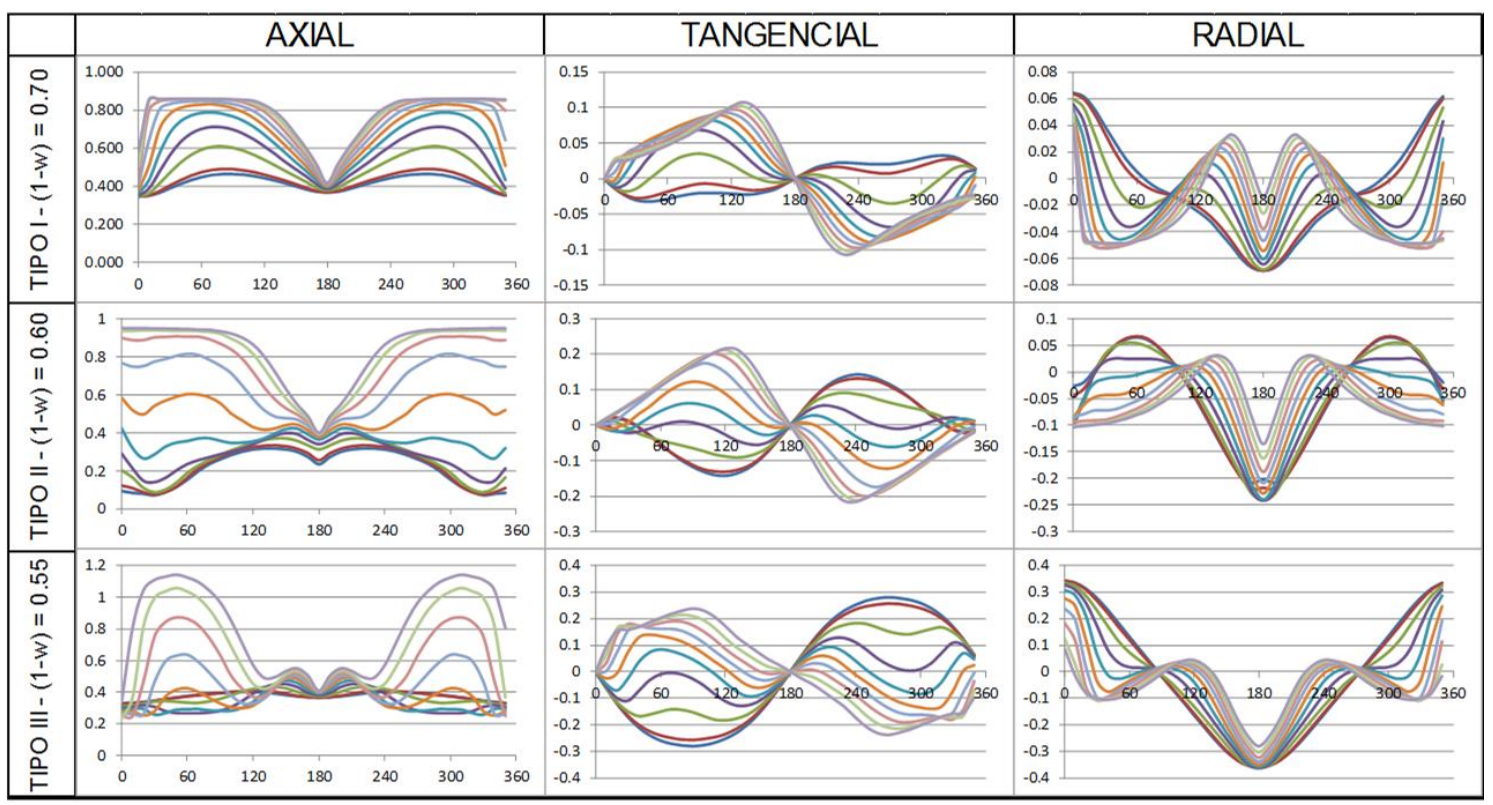

Figura 28-Os três tipos de campo de velocidade escolhidos para o estudo

Uma breve análise realizada com três propulsores B-Troost (B3-65, B4-70 e B5-75) sob a atuação desses três tipos de esteiras (tipo I - 170, tipo II - 260 e tipo III - 355) objetiva mostrar o impacto que elas exercem sobre seu desempenho. As curvas características $\mathrm{KT}$ e $\mathrm{KQ}$ por $\mathrm{J}$ de cada propulsor em cada esteira, comparadas às curvas de água aberta, estão apresentadas na Figura 29. 


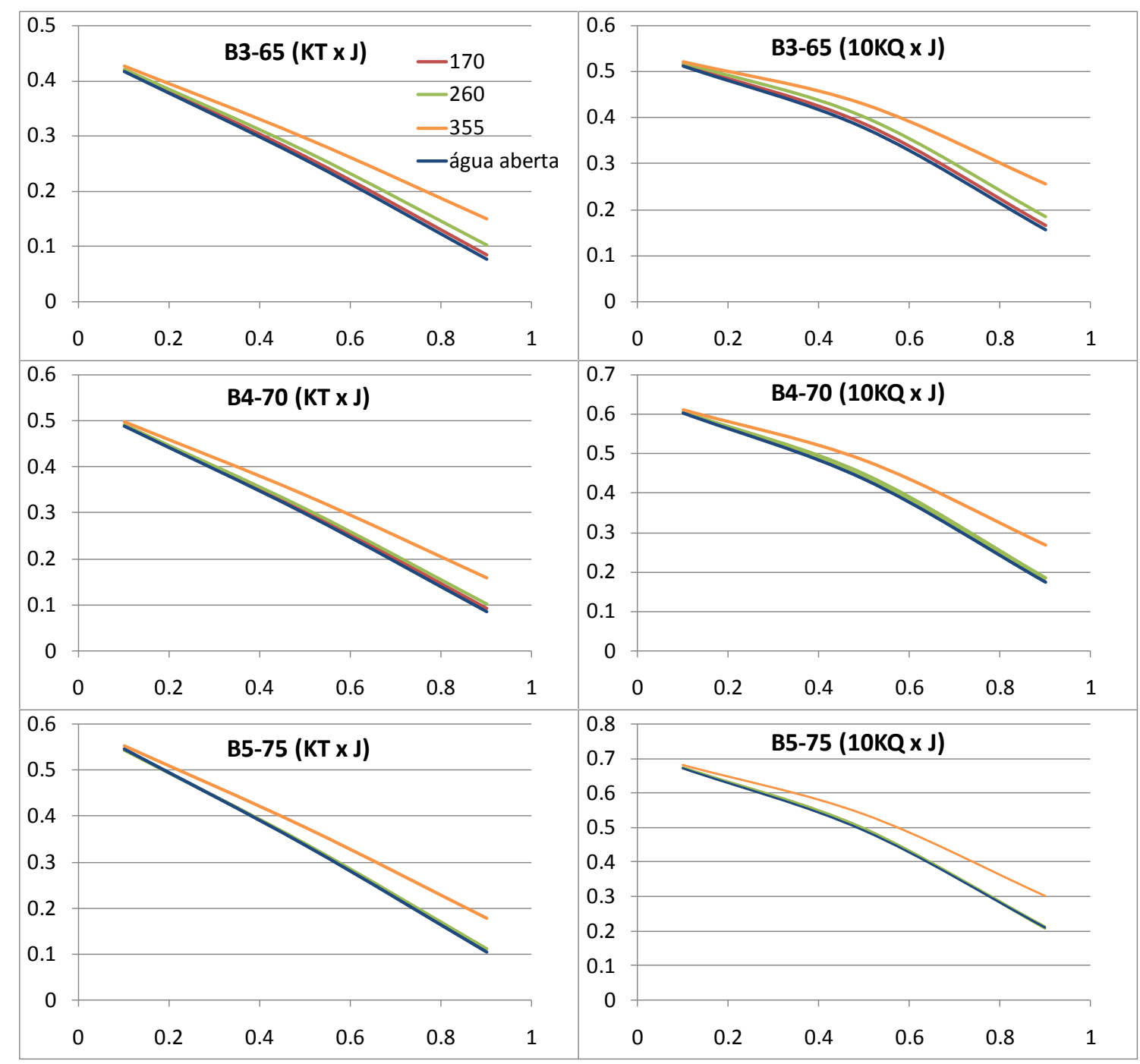

Figura 29 - Curvas características do propulsor nas esteiras e em água aberta

Pode-se observar que as esteiras 170 e 260 provocam alterações muito pequenas e apenas em alguns casos, enquanto a esteira do navio-tanque (355) apresenta maior impacto.

\subsection{Validação do software para o propósito do estudo}

O software utilizado é o PPB (Propeller Potential Based), produzido pela HSVA® em linguagem Fortran. O programa é especializado na análise de propulsores marítimos, segundo a teoria potencial, utilizando o método dos painéis e acrescentando algumas correções relacionadas ao comportamento viscoso do escoamento. 
Os resultados provenientes da execução do programa fornecem arquivos contendo as forças e momentos produzidos pelo propulsor em uma esteira não uniforme, em função do ângulo de rotação do mesmo, além do $K T$ e $K Q$ médios que acabam resultando em sua eficiência.

A fim de se estudar um problema de vibração e poder realizar comparações objetivas com os dados presentes na $14^{\underline{a}}$ ITTC, faz-se necessária a decomposição dos esforços resultantes em componentes harmônicos, conforme visto durante a revisão bibliográfica. Portanto, os resultados vindos da análise do PPB são transformados em uma série de Fourier, isto é, um somatório de senos multiplicados pela respectiva amplitude harmônica e associados à sua fase. Dessa forma, pode-se caracterizar o fenômeno pelas suas principais componentes.

Para os propulsores com números de pás $Z$, entende-se que os principais componentes harmônicos capazes de descrever o fenômeno são os de $(Z)^{\mathrm{a}} \mathrm{e}$ (2Z) harmônicos de $4^{a}$ e $8^{a}$ ordem.

$$
K=\bar{K}+A_{Z} \sin \left(Z \theta+\phi_{Z}\right)+A_{2 Z} \sin \left(2 Z \theta+\phi_{2 Z}\right)
$$

No presente estudo, a função representada pela equação 24 foi obtida numericamente. Os pontos $(K, \theta)$, onde $K$ representa os adimensionais de força e momento, relativo aos 6 graus de liberdade $\left(K T_{x}, K T_{y}, K T_{z}, K Q_{x}, K Q_{y}, K Q_{z}\right)$ e $\theta$, a posição angular do propulsor, são provenientes da análise do PPB. As incógnitas $A_{Z}, \phi_{Z}, A_{2 Z}$ e $\phi_{2 Z}$ componentes da função foram calculadas através do simples método dos mínimos quadrados, o qual proporcionou uma alta aderência para este caso, comprovando a significância das duas primeiras ordens para o fenômeno.

Como caso inicial do estudo, utilizaram-se os dados provenientes da ITTC (1975), a qual estabeleceu um exercício padrão para a avaliação do fenômeno e comparação de métodos de análise, conforme citado no item 2.1. Os dados 
do propulsor da série B-Troost utilizado são apresentados na Tabela 3. Os campos de velocidade axial e tangencial da esteira padrão, os quais apresentam uma leve assimetria em relação ao plano longitudinal, podem ser visualizados na Figura 30 e seus dados constam no anexo A.

Tabela 3 - Dados do propulsor do caso inicial (proposto pela 14ª ITTC)

\begin{tabular}{|c|c|}
\hline Diâmetro & $253 \mathrm{~mm}$ \\
\hline $\mathrm{P} / \mathrm{D}$ & 1.025 \\
\hline $\mathrm{A}_{\mathrm{E}} / \mathrm{A}_{\circ}$ & 0.475 \\
\hline $\mathrm{Z}$ & 4 \\
\hline $\mathrm{n}$ & $9.8 \mathrm{rps}$ \\
\hline $\mathrm{J}$ & 0.91 \\
\hline
\end{tabular}
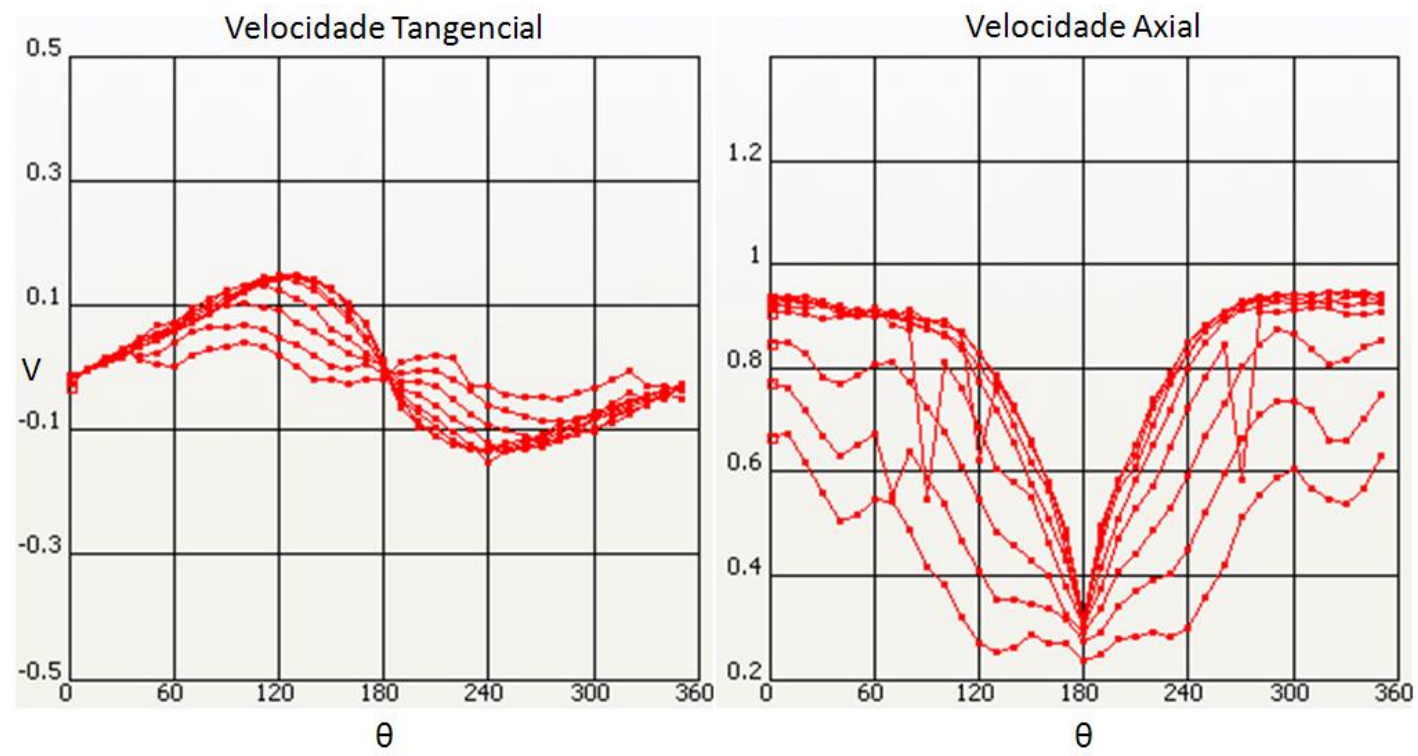

Figura 30 - Velocidade adimensional tangencial e axial da esteira fornecida pela $14^{\mathrm{a}}$ ITTC

As pás foram discretizadas em 12 seções radiais e o fólio de cada uma dessas seções em 24 elementos. O bosso foi descrito como um tronco cônico. O refino dessa não obteve maior precisão dos resultados.

Os resultados obtidos pela análise numérica foram comparados com os fornecidos pela ITTC (1975). Os dados experimentais presentes na 14른 ITTC 
se restringem à quarta componente harmônica, apenas. Enquanto as informações das componentes referentes à oitava ordem são apenas indicadas por uma zona de valores que abrange grande parte dos resultados provenientes dos diversos métodos utilizados para avaliar o fenômeno, que formaram essa base de dados publicada em 1975.

Tabela 4 - Comparação entre os resultados experimentais (14ํํㄹ ITTC) e os obtidos através do PPB para esforços axias

\begin{tabular}{|c|c|c|c|c|c||}
\hline \multirow{2}{*}{ Parâmetro } & \multirow{2}{*}{$\begin{array}{c}\text { Ordem do } \\
\text { harmônico }\end{array}$} & \multicolumn{2}{|l|}{ Experimental (14 ${ }^{\text {a }}$ ITTC) } & \multicolumn{2}{||}{ PPB } \\
\cline { 3 - 6 } & & Amplitude & fase (rad) & amplitude & fase (rad) \\
\hline \multirow{2}{*}{$\mathrm{KT}_{\mathrm{x}}$} & $4^{\underline{\mathrm{a}}}$ & 0.0046 & 1.5 & 0.0046 & 1.91 \\
\cline { 2 - 6 } & $8^{\underline{a}}$ & $0.0009-0.0016$ & $0.5-3.5$ & 0.0029 & 3.48 \\
\hline \multirow{2}{*}{$\mathrm{KQ}_{\mathrm{x}}$} & $4^{\underline{a}}$ & 0.00058 & 1.5 & 0.00048 & 2.28 \\
\cline { 2 - 6 } & $8^{\underline{a}}$ & $0.00015-0.00025$ & $0-6.28$ & 0.00039 & 3.45 \\
\hline
\end{tabular}

Como pode ser notado na Tabela 4 , a amplitude de força axial de $4^{\mathrm{a}}$ ordem obtida pela análise no PPB se igualou ao resultado experimental, com um erro muito pequeno, isto é, além da quarta casa decimal, enquanto a relativa ao momento torçor se equiparou a resultados de outros métodos teóricos (presentes na 14 ITTC), mas não se mostrou tão próxima ao experimental, porém ainda aceitável, tratando-se da relação entre resultados numéricos e experimentais.

A comparação entre fases foi também prejudicada por tal ausência, pois um dado importante, que seria a defasagem entre os harmônicos, fica impossível de se determinar sem o dado exato da fase da componente de $8^{\mathrm{a}}$ ordem. Mesmo assim, fornecem-se as fases, para que o leitor tenha a possibilidade de reescrever tais curvas facilmente, caso necessário. 
Dada a proximidade entre os resultados referentes à amplitude de $4^{\mathrm{a}}$ ordem, e considerando a escassez de resultados experimentais para este caso e o caráter sobretudo qualitativo do objetivo central desse estudo, o método dos painéis baseado na teoria potencial, por meio do software PPB, pode ser considerado aplicável para análise do escoamento sobre o hélice advindo de uma esteira não uniforme.

\subsection{Análise de múltiplos casos}

Visando ao uso extenso e sistematizado do software, elaborou-se uma rotina computacional que recebe os dados de entrada e automatiza a execução do programa PPB. O teor dessa rotina e os valores que serão atribuídos aos parâmetros geométricos dos casos analisados estão descritos nos subitens a seguir.

\subsubsection{Sistematização e execução da análise numérica}

A rotina preparada em Matlab (anexo $A$ ) recebe todos os dados necessários à execução do programa, traduz para a linguagem exigida, isto é cria pasta com os arquivos de entrada de dados e de execução, e executa sem a necessidade de se utilizar a interface (utilização do modo Batch), o que acelera muito o processo.

A geometria do propulsor, dado de entrada para o programa, é baseada na série B-Troost, a fim de se realizar uma série de análise sistematizada, variando-se apenas alguns parâmetros de projeto de um propulsor.

Os dados provenientes da série B-troost, obtidos em Kuiper (1992), abrangem os mesmos conceitos apresentados no item 3.1. Consistem de algumas tabelas que descrevem relações adimensionalizadas das propriedades geométricas da pá, tanto as que variam radialmente como as internas a cada uma das seções radiais (fólios) que constituem a pá.

A rotina recebe os valores de $A_{E} / A_{O}, Z, P / D, D$, rake e skew, a partir destes e dos dados da série, fornece 3 arquivos-chave para a execução do 
programa:main.2, que apresenta os dados gerais do propulsor para cada seção radial da pá (comprimento da corda, skew, máxima espessura, rake, passo, máximo camber e alguns dados do hub); cam_lin.2, que fornece a Camber line de cada seção radial; e thi_lin.2, que contém a distribuição da espessura ao longo da seção do fólio.

Definidos os dados geométricos de entrada, a rotina citada também recebe os parâmetros que definem a discretização da malha de painéis do propulsor, os dados de operação, isto é, rotação e coeficiente de avanço (J), e as condições da análise numérica, que compreendem o número de voltas que o propulsor rotaciona (determinando o comprimento da folha de vórtices), o timestep, que determina a discretização dessa folha de vórtice, e o número de harmônicos envolvidos na solução do escoamento. Estas informações são enviadas através da criação dos arquivos ppbgeo.ctr e ppb.bat.

Além desses, são formados os arquivos que descrevem o escoamento incidente, isto é, a esteira na qual o propulsor está operando. São três arquivos referentes às componentes axial (wakefile.vx), tangencial (wakefile.vt) e radial (wakefile.vr) da velocidade incidente.

\subsubsection{Definição das variações geométricas}

Conforme já citado, deseja-se identificar a influência da variação dos parâmetros geométricos de projeto na performance do propulsor. São então estipulados valores chaves que tenham a possibilidade de cobrir uma grande superfície de análise ao mesmo tempo de onerar menos os recursos computacionais, mesmo tratando-se de um método computacional relativamente rápido.

Os valores referentes a número de pás $(Z)$, relação de área expandida $\left(A_{E} / A_{O}\right)$ e relação de passo $(P / D)$ foram fixados dentro da abrangência da própria série $\mathrm{B}$-Troost, de forma igualmente espaçada.

As propriedades rake e skew não são explicitamente parametrizadas na série B-Troost, pois não é previsto que elas sejam livremente alteradas. O skew do propulsor da série é determinado por uma distribuição padronizada que varia 
com os valores de $Z$ e $A_{E} / A_{O}$, e o rake varia linearmente ao longo do raio segundo um ângulo de $15^{\circ}$. Todavia, esses parâmetros são objetos do presente estudo, portanto foram parametrizados respeitando as definições apresentadas no item 2.1: o skew ainda seguindo a distribuição da série $B-$ Troost que o relaciona a $Z$ e $A_{E} / A_{O}$, mas atendendo a um ângulo máximo estipulado (em \% relativa ao ângulo $360 \%$ Z); e o rake também variando linearmente, mas com dois ângulos maiores e outros dois menores do que 0 estipulado. A Tabela 5 resume os valores adotados para definir todos os casos de propulsor a serem mapeados.

Tabela 5 - Valores para variação dos parâmetros geométricos de projeto de propulsor

\begin{tabular}{|c|c|}
\hline Parâmetros Geométrico de Projeto & Valores adotados \\
\hline $\mathrm{P} / \mathrm{D}$ & $0.70 ; 0.85 ; 1.00 ; 1.15 ; 1.30$ \\
\hline $\mathrm{A}_{\mathrm{E}} / \mathrm{A}_{\odot}$ & $0.45 ; 0.60 ; 0.75 ; 0.90 ; 1.05$ \\
\hline $\mathrm{Z}$ & $3 ; 4 ; 5 ; 6 ; 7$ \\
\hline Ângulo Máximo de Skew & $0 \% ; 10 \% ; 20 \% ; 30 \% ; 40 \% ; 50 \% ; 60 \%$ \\
\hline Ângulo de Rake & $0^{\circ} ; 8^{\circ} ; 15^{\circ} ; 22^{\circ} ; 30^{\circ}$ \\
\hline
\end{tabular}

Ao todo são 4375 propulsores, no que diz respeito às configurações geométricas. Este número ainda deve ser multiplicado pelo número de esteiras representativas definidas no item 4.1 e pela quantidade de valores de coeficiente de avanço, que será explicada no item 4.4.1, para resultar em 52500 casos executados no total.

\subsection{Processamento dos resultados}

As análises computacionais se dão em duas etapas: antes e depois da integração casco-hélice. O modo como são processados os resultados vindos da segunda etapa é determinado em função dos critérios estipulados para avaliar os atributos de eficiência e indução de vibração. 


\subsubsection{Processo de integração casco-hélice}

$\mathrm{Na}$ primeira etapa, todos os propulsores compreendidos pela seleção descrita no subitem 5.3.2 são analisadas sob diferentes esteiras, em 3 coeficientes de avanço.

Os valores de $\mathrm{J}$ utilizados nessa etapa são escolhidos de forma racional com referência à relação $P / D$ do propulsor em questão. No ponto a $\mathrm{J}=0.1 \mathrm{P} / \mathrm{D}$, se verifica a região próxima à condição de bollard pull, onde o valor de KT é máximo para $\mathrm{J}=0$. Em $\mathrm{J}=1 \mathrm{P} / \mathrm{D}$, o ângulo de passo do propulsor se aproxima ao ângulo de geração de força de sustentação nula, portanto, ao menos nas curvas de água aberta, KT é baixo, já próximo a zero. Um terceiro valor intermediário é determinado em $\mathrm{J}=0.5 \mathrm{P} / \mathrm{D}$, para se obter um polinômio de segundo grau que representa a função $\mathrm{KT}(\mathrm{J})$.

Portanto, para cada configuração de propulsor, se obtém uma curva de KT x J específica para cada esteira incidente, ou seja, não se utiliza a curva de água aberta, o que diminuirá a imprecisão do processo de integração casco-hélice. A curva de resistência adimensionalizada do navio é calculada de acordo com o método tradicional, em posse dos dados dos navios típicos de cada esteira. Conforme visualizado na Figura 31, a intersecção destas curvas descritas conclui o processo de integração, fornecendo um valor de $\mathrm{J}$ mais adequado para a análise computacional da segunda etapa.

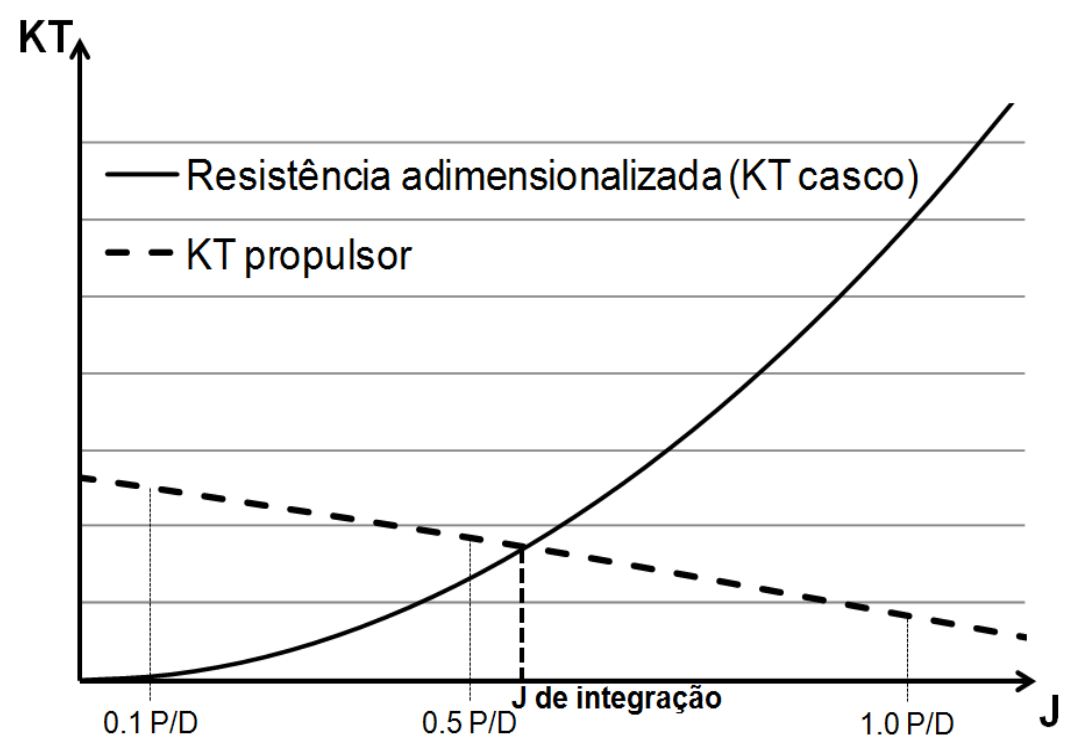

Figura 31 - Processo de integração casco-hélice utilizando curva KT em esteira aproximada 
Vale observar que foi, de fato, verificado que o KT obtido pela análise da segunda etapa, já com o coeficiente $\mathrm{J}$ de integração, correspondeu de forma precisa ao valor previsto durante o processo de integração, isto é, pertencente simultaneamente tanto ao polinômio interpolado de $\mathrm{KT}(\mathrm{J})$ do propulsor como pela função quadrática de resistência adimensionalizada do casco, validando as aproximações feitas pelo polinômio e o processo de integração como um todo.

\subsubsection{Definição dos critérios de avaliação}

Após a integração casco-hélice, o mesmo caso de propulsor é analisado pela última vez, já com o $\mathrm{J}$ mais próximo do que seria o operacional sob aquele determinado tipo de esteira incidente. Os resultados desta análise são, portanto, submetidos aos critérios de avaliação.

A avaliação leva em consideração aspectos de excitação de vibração e de eficiência. $O$ critério de eficiência é facilmente determinado pela relação entre KT e KQ médios, provenientes da análise, utilizando a equação 6. No entanto, a avaliação da vibração induzida deve ser dividida em três partes, segundo o subitem 2.2.

Como o presente estudo está focado no hélice, não se deseja fazer cálculos estruturais mais complexos, tampouco o dimensionamento do sistema propulsivo completo. Dessa forma, extraiu-se do conteúdo presente na literatura pesquisada uma maneira de se isolar ou mesmo tornar tangível a interferência do propulsor na vibração transmitida através do eixo.

As excitações de vibração horizontal e torcional serão avaliadas diretamente pelas flutuações de $\mathrm{K}_{\mathrm{T}}$ e $\mathrm{K}_{\mathrm{Q}}$ na direção $\mathrm{X}$.

Considerando que vibração transversal é influenciada pelo momento fletor no eixo, podemos citar duas formas do propulsor causar este tipo de esforço (ver Figura 32): através do momento que as forças transversais $\left(F_{Y}\right.$ e $\left.F_{Z}\right)$ realizam segundo o braço relativo à distância entre o propulsor e a bucha (o primeiro apoio do eixo), e através do momento gerado pelo empuxo multiplicado pela sua excentricidade (combinação de $\mathrm{M}_{\mathrm{Y}}$ e $\mathrm{M}_{\mathrm{Z}}$ ). 


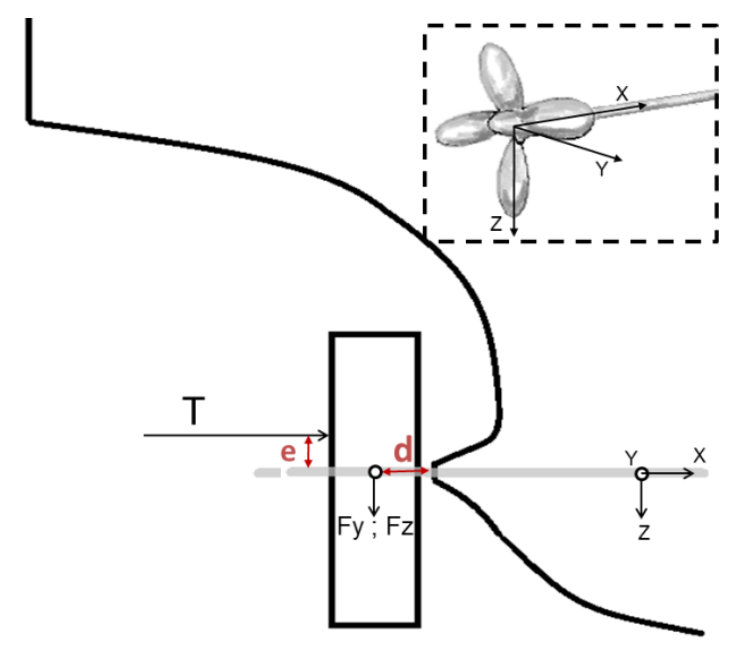

Figura 32 - Componentes do momento fletor do eixo

Em uma análise preliminar dos esforços produzidos pelo propulsor nestes quatro graus de liberdade, com o auxilio da Tabela 1, observa-se que $F_{Y}$ e $F_{Z}$ são de ordem de cem vezes menor que o empuxo. Desta forma, considerando que mesmo que a excentricidade do empuxo fosse da mesma ordem que a distância entre o propulsor e a bucha do eixo, o momento fletor causado pela excentricidade do empuxo já teria relevância muito maior que o momento provocado pelas forças transversais. Por essa razão os momentos $M_{Y}$ e $M_{Z}$ foram escolhidos para representarem a excitação de vibração transversal. $O$ critério para esta componente pode ser, então, combinado pela excentricidade (e) do empuxo, utilizada sob a forma adimensionalizada pelo diâmetro.

\subsubsection{Restrição de cavitação}

Para a escolha dos propulsores mais adequados a cada tipo de esteira, dentre os resultados obtidos pelo estudo paramétrico, uma restrição relativa à ocorrência de cavitação é aplicada. Devido à limitação do software de se obter os esforços gerados por cada uma das seções radiais do propulsor, não foi possível adotar um método de se estimar a cavitação mais precisamente, utilizando os cálculos em cada um dos fólios seccionais. Portanto, adota-se a formulação de Burril, utilizando o critério para navios mercantes presente em Harvald (1980), que corresponde a uma cavitação ao redor de 5\% (anexo C). 


\section{RESULTADOS}

O objetivo central do estudo paramétrico consiste na leitura e interpretação dos resultados obtidos pelo desenvolvimento da metodologia descrita no capítulo anterior. Foram analisadas 4375 configurações geométricas de hélices definidas pelo subitem 4.3.2 em cada um dos três tipos de esteiras incidentes, compondo uma amostra satisfatória para abranger um campo de cinco variáveis de projeto.

Inicialmente, aplica-se a restrição de cavitação para os propulsores compreendidos na seleção, para indicar os casos viáveis. Em seguida, apresentam-se os resultados referentes ao estudo paramétrico, que procura identificar as influências das variáveis geométricas do projeto de propulsor nos critérios especificados para eficiência e excitação de vibração no subitem 4.4.2.

\subsection{Cavitação}

O fenômeno da cavitação se mostrou intimamente ligado ao parâmetro geométrico de área expandida. Como pode se observar na Tabela 6, quanto maior a área, menor é a ocorrência de cavitação. Tal fato indica que a distribuição dos esforços em uma área maior melhora o desempenho relativo a este fenômeno. Isso ocorre pois os fólios seccionais da pá apresentam maiores comprimentos de corda, diminuindo a vorticidade emitida no escoamento, durante a geração do lift.

Em segundo lugar, a relação de passo influencia também no fenômeno, porém de maneira diretamente proporcional. O número de pás já apresenta uma influência bem discreta, enquanto que rake e skew não apresentaram praticamente nenhuma significância para o critério de cavitação, frente a dominância dos outros parâmetros citados.

Pode-se concluir da Tabela 6, que o critério adotado se mostra bastante rigoroso para o navio série 60 , por se tratar do navio mais rápido, de menor calado, cujos pontos de integração se deram às rotações mais elevadas, resultando na permanência de apenas $4 \%$ dos propulsores, como soluções viáveis. Essa redução impediu que, para essa esteira, os efeitos de passo e 
atrito, ou seja, a relação entre a força propulsora e o torque resistivo irá aumentar. Se considerarmos uma mesma área do propulsor total, um maior número de pás irá distribuir mais o carregamento entre elas, o que diminuirá a intensidade de vórtices, portanto, menores serão as velocidades induzidas, portanto a eficiência irá aumentar. Dessa forma, os parâmetros mais determinantes para caracterizar tal atributo são a relação de área expandida e o número de pás do propulsor.

Os gráficos a seguir elucidam essa tendência, em que a eficiência do propulsor é diretamente proporcional ao número de pás e inversamente proporcional em relação à área expandida.

Na prática, a tendência de aumento de número de pás e diminuição da área expandida se contrapõe à restrição de resistência estrutural, pois a diminuição da pá leva a falhas estruturais, sendo necessário o aumento da corda da pá. Dessa forma, em um projeto de propulsor, deve-se encontrar o equilíbrio do menor valor de área possível para proporcionar maior eficiência e do valor que garanta a integridade estrutural da pá, além da restrição de cavitação que também impacta nesse parâmetro.

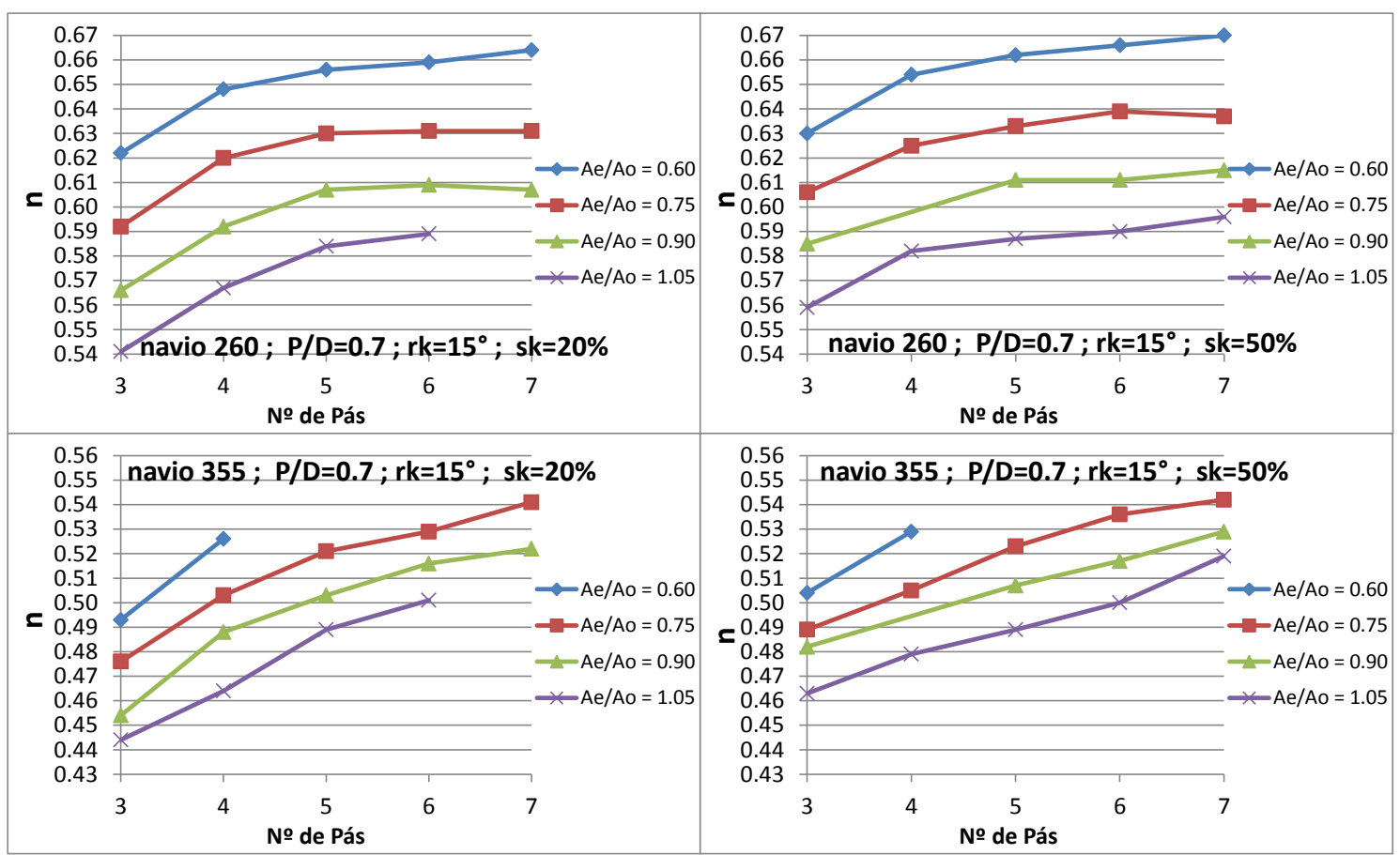

Figura 33 - Eficiência em função de № de pás, para diferentes Ae/Ao (skew de 20\% e 50\% esteiras 260 e 355) 


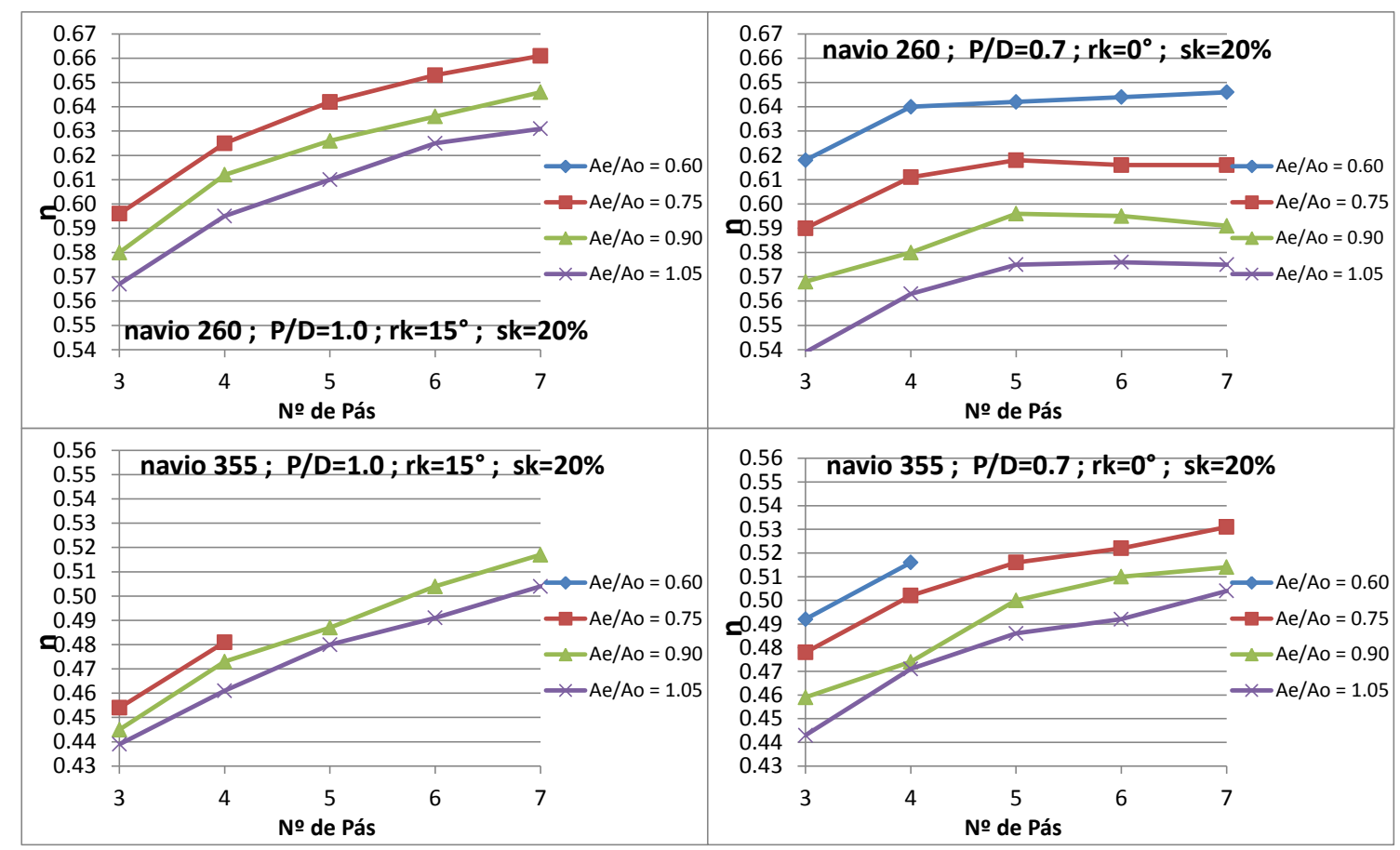

Figura 34 - Eficiência em função de № de pás, para diferentes Ae/Ao (rake 0ํe 15ำ - esteiras 260 e 355)

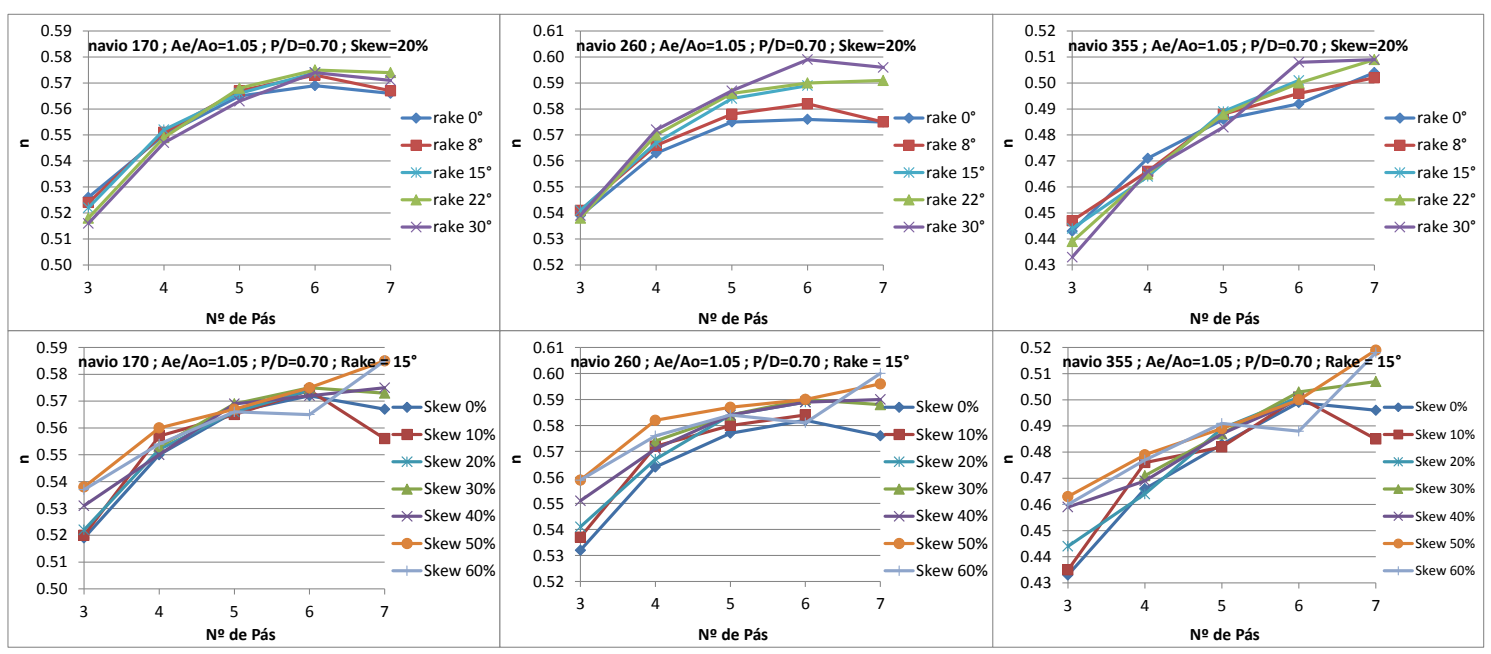

Figura 35 - Eficiência em função de № de pás, para diferentes valores de rake e skew (esteiras 170,260 e 355)

O parâmetro P/D não apresenta tendências diretas com a eficiência, de forma que cada configuração de propulsor apresentará uma relação $P / D$ mais adequada, dependendo da esteira em que está atuando. Como pode ser observado nos gráficos da Figura 38, formam-se parábolas, que indicam a presença de um ponto de máximo. Esse comportamento se deve à relação íntima entre o ângulo de passo geométrico de uma seção e o ângulo de passo 
hidrodinâmico, determinado pela velocidade da esteira e de rotação do propulsor. Existe, portanto, um ângulo de ataque ideal, que otimiza a relação das decomposições de lift e drag gerada pelos fólios seccionais: maior ou menor do que tal, a eficiência diminuirá.
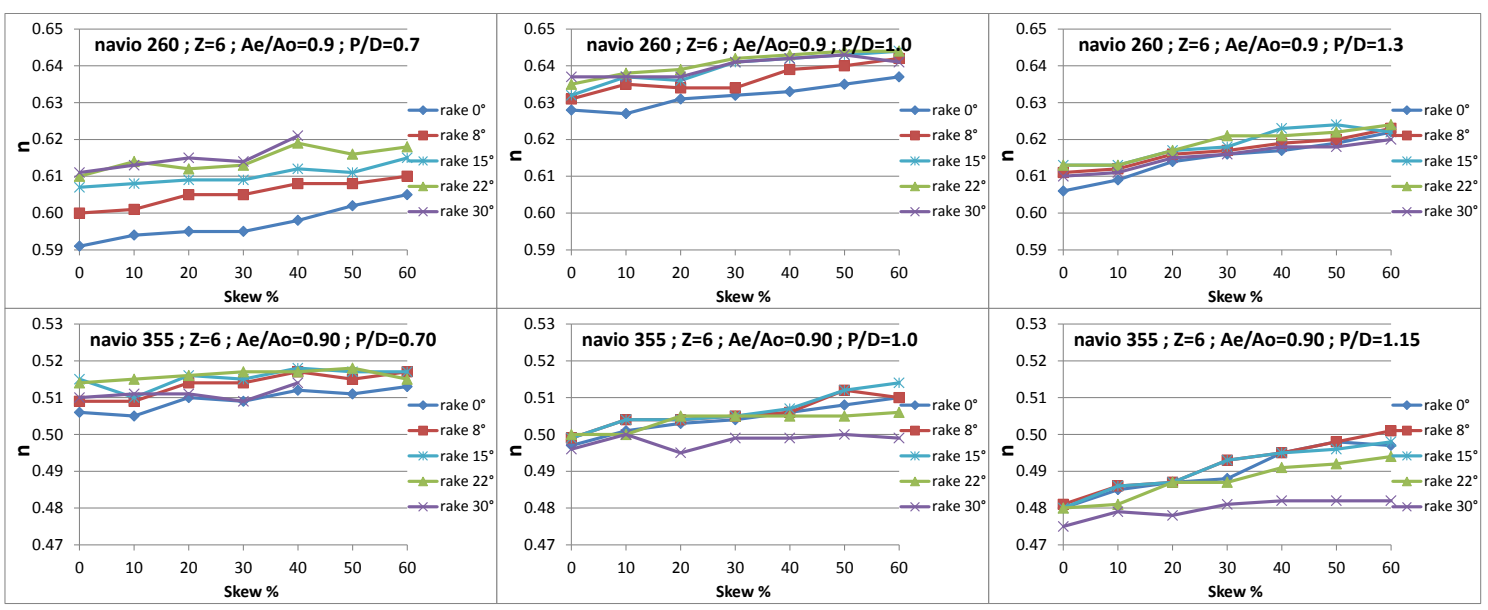

Figura 36 - Eficiência em função de skew, para diferentes valores de rake (P/D 0.7 a 1.3 esteiras 260 e $355-Z=6$ )
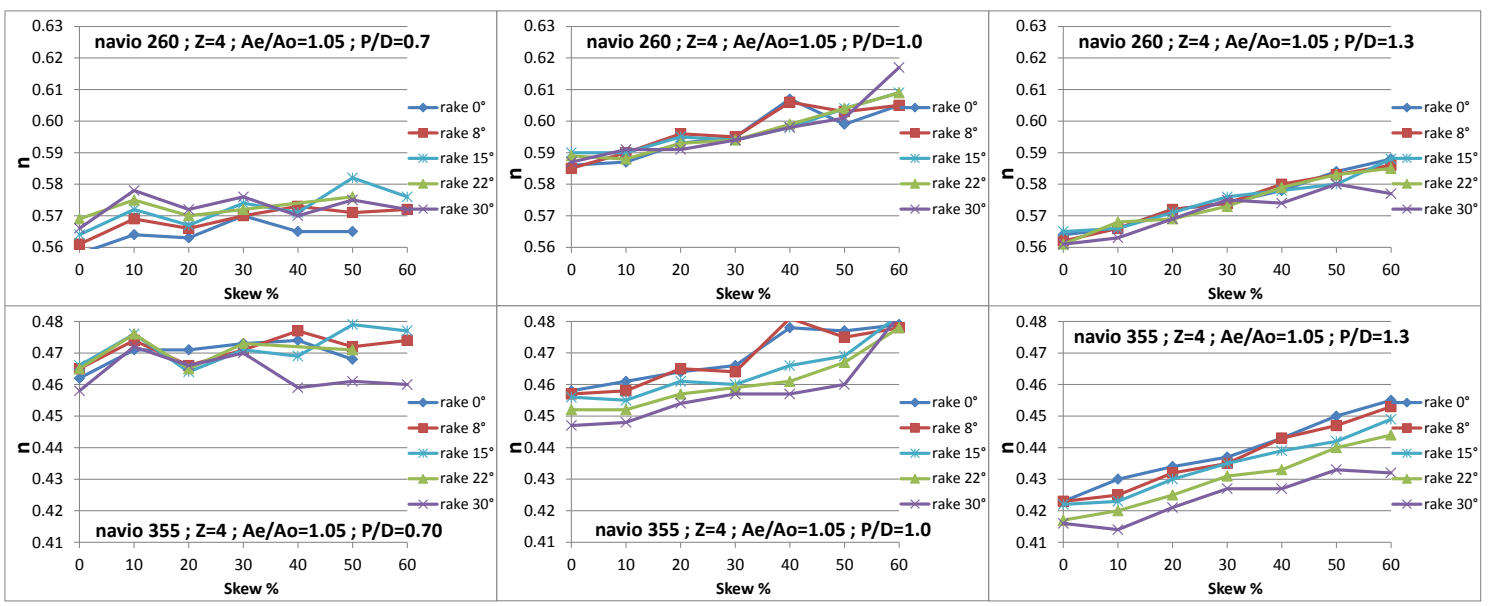

Figura 37 - Eficiência em função de skew, para diferentes valores de rake (P/D 0.7 a 1.3 esteiras 260 e $355-Z=4$ ) 


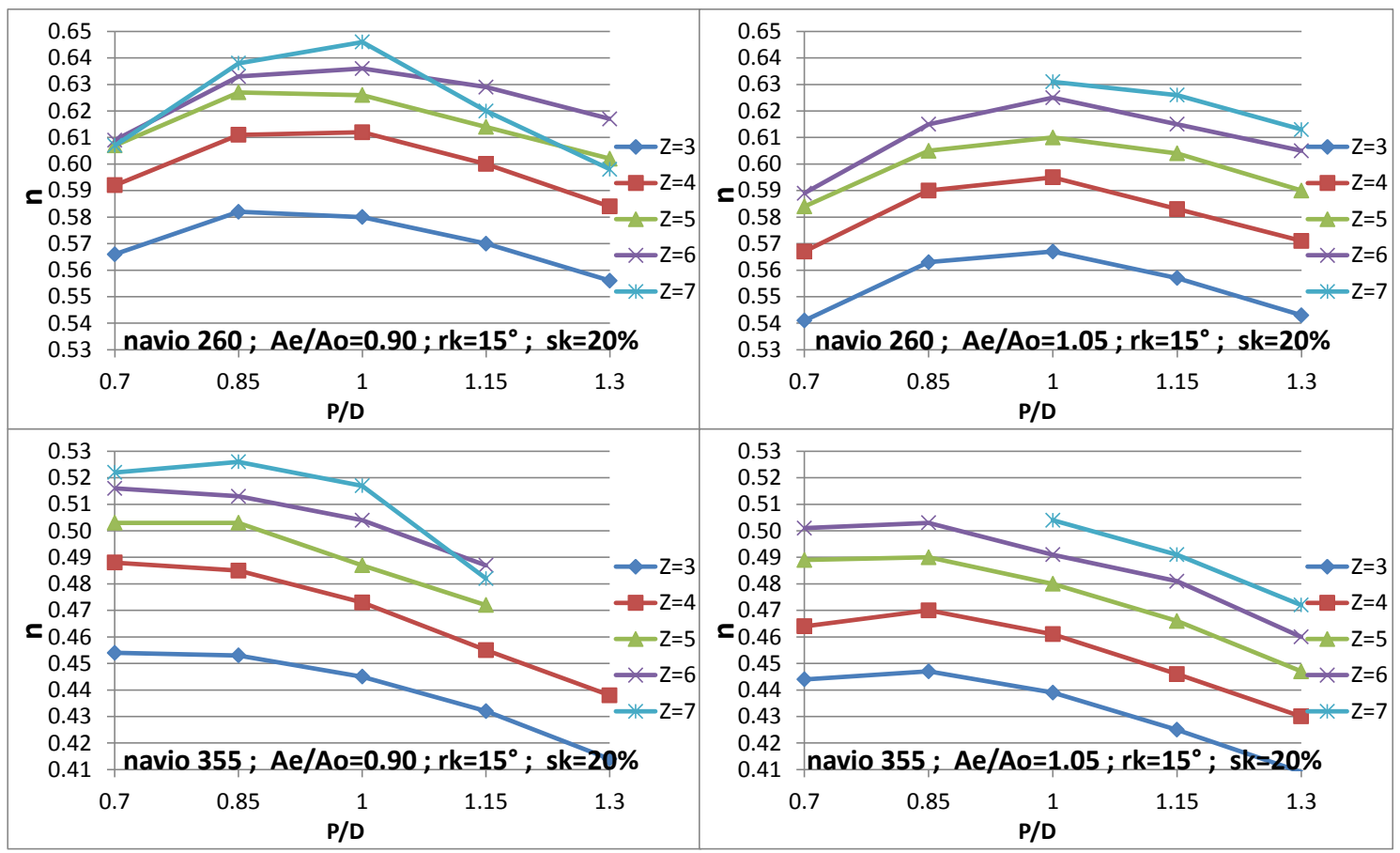

Figura 38 - Eficiência em função de P/D, para diferentes valor de Z (Ae/Ao 0.90 e 1.05 esteiras 260 e 355)

Os parâmetros de skew e rake, muitas vezes, não apresentam influência significativa sobre a eficiência, ou, em alguns casos, tendências leves. Como pode se observar nos gráficos a seguir, o aumento do skew, principalmente para os menores números de pás, e do rake revelam uma leve tendência de aumento de eficiência, porém em apenas alguns casos.

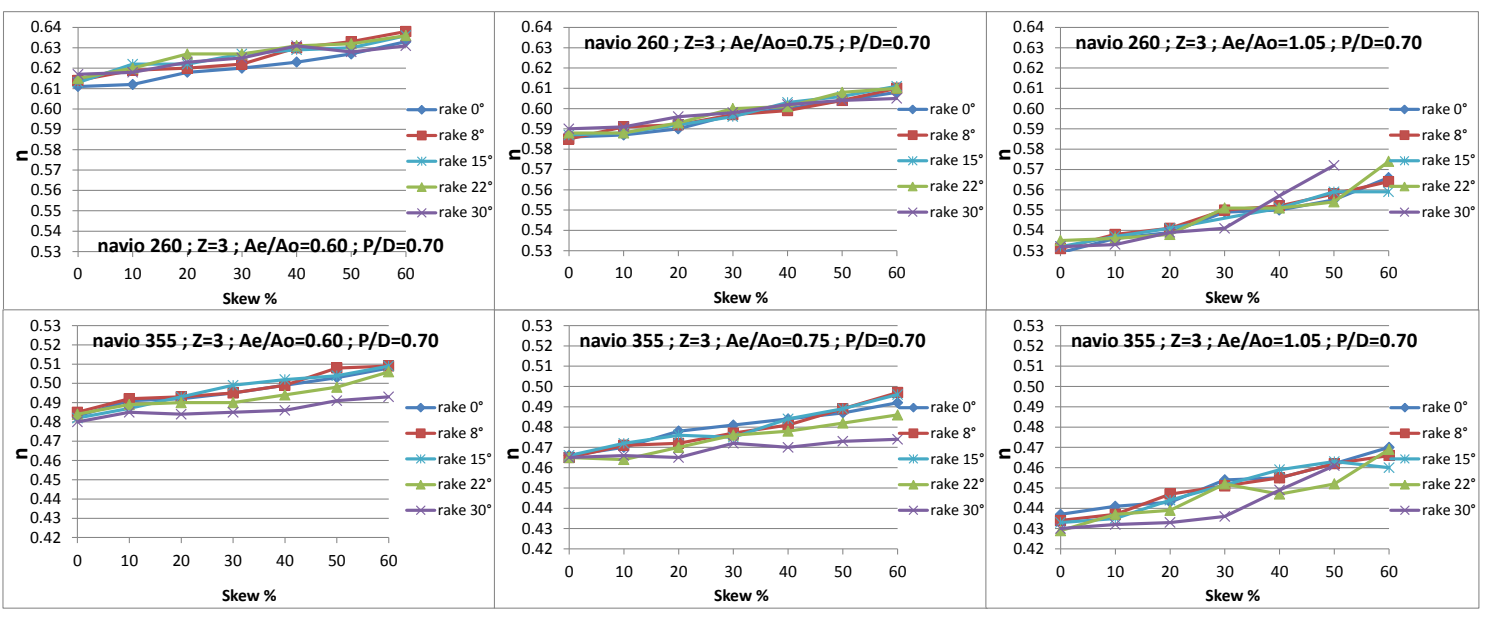

Figura 39 - Eficiência em função de skew, para diferentes valores de rake (Ae/Ao 0.60; 0.75; 1.05 - esteiras 260 e $355-Z=3$ ) 


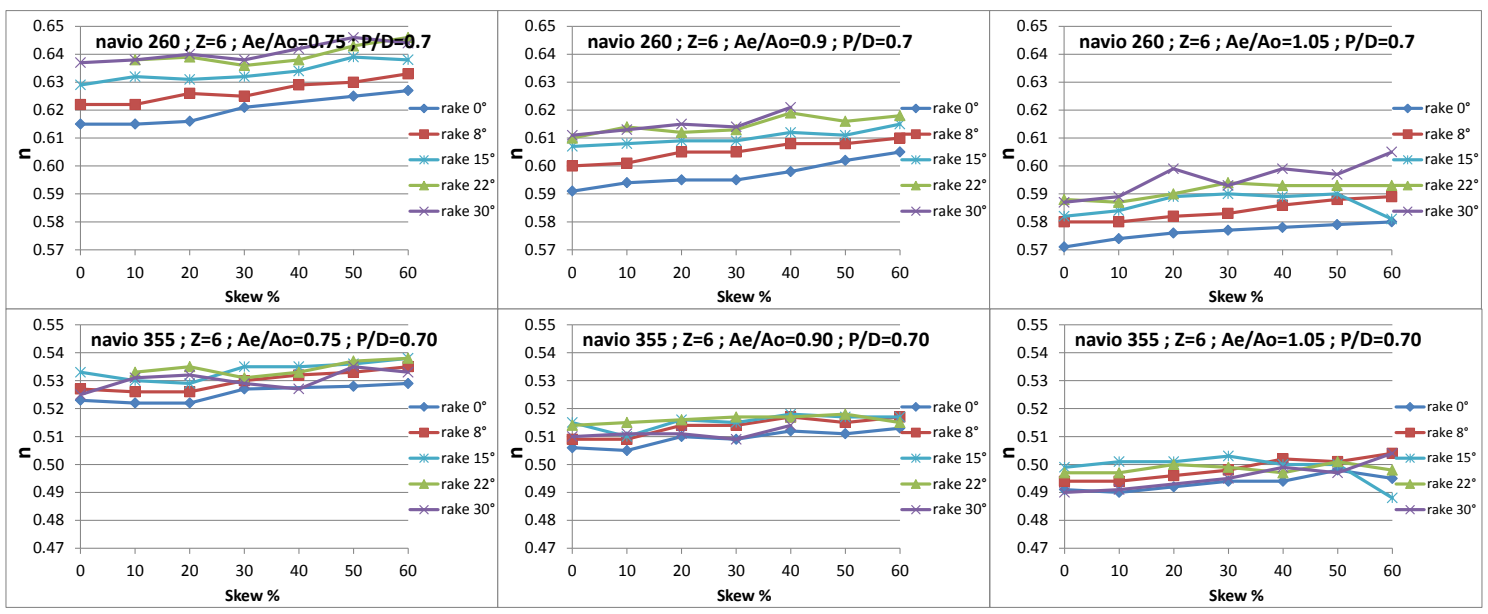

Figura 40 - Eficiência em função de skew, para diferentes valores de rake (Ae/Ao 0.75; 0.90; 1.05 - esteiras 260 e 355 $\mathrm{Z}=6$ )

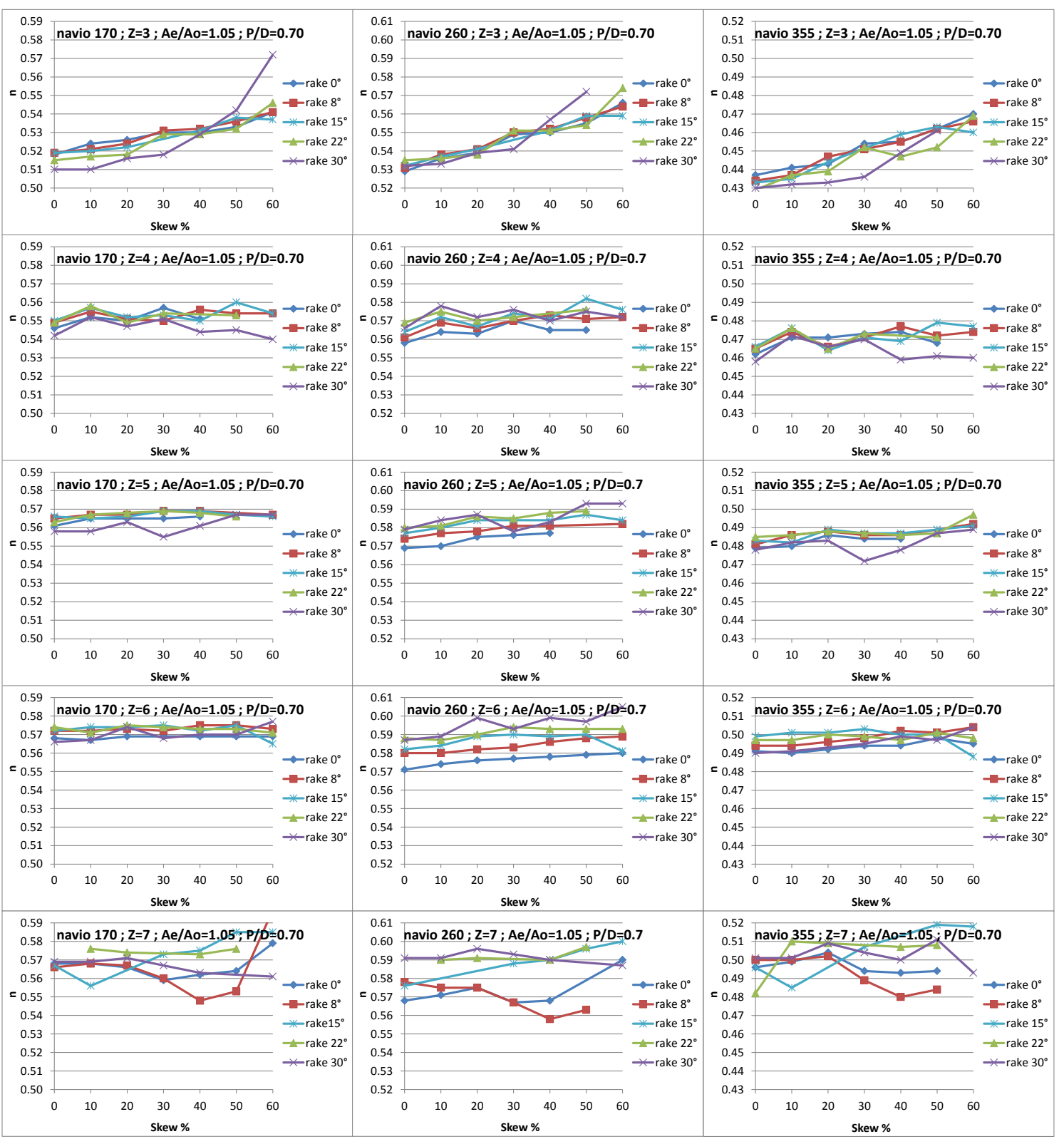

Figura 41 - Eficiência em função de skew, para diferentes valores de rake (esteiras 170, 260 e 355) 


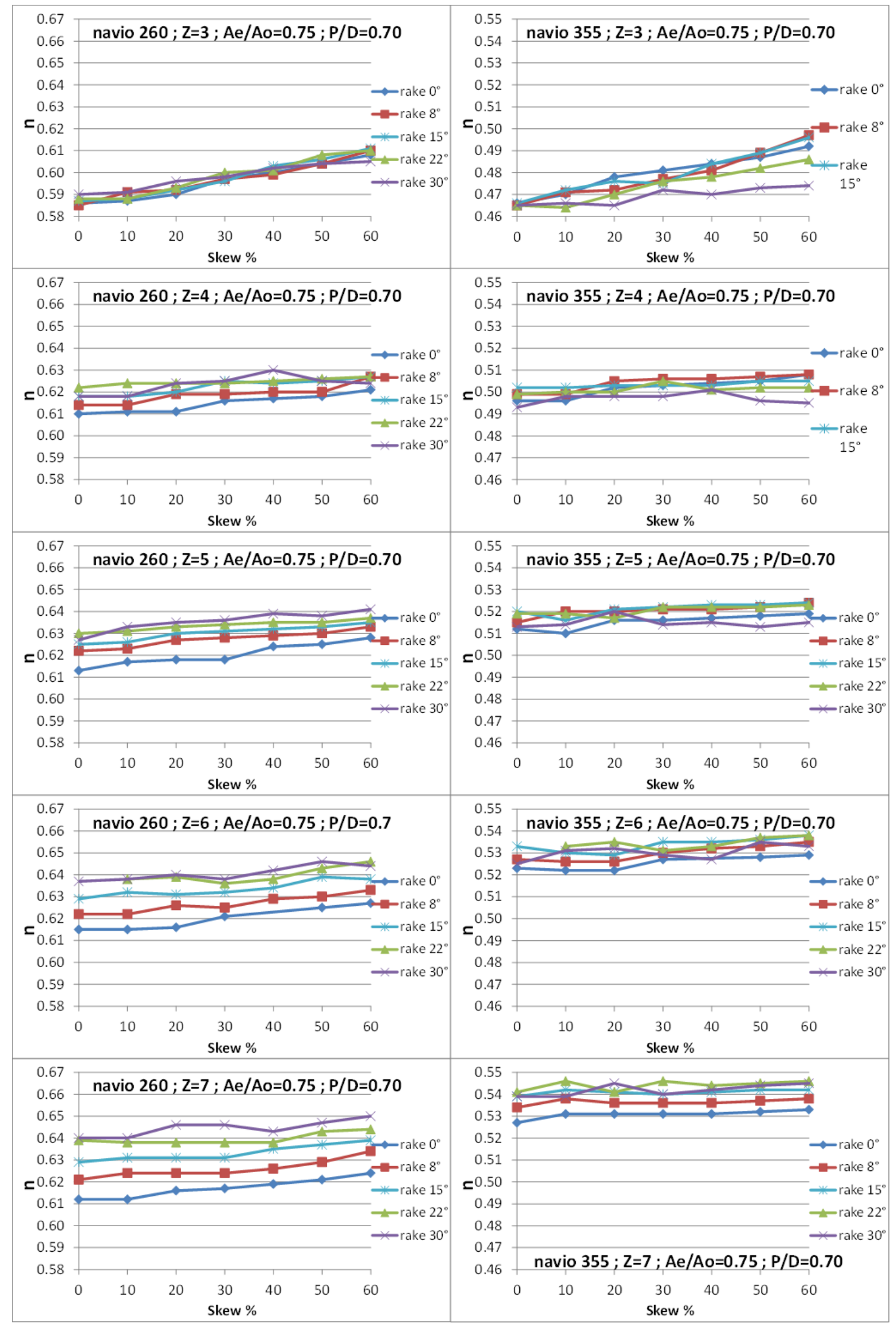

Figura 42 - Eficiência em função de skew, para diferentes valores de rake (esteiras 260 e 355) 
A baixa relação do skew com a eficiência explica-se pela sua função ser ligada à vibração, já que influencia na defasagem em que cada fólio seccional da pá irá incidir sob determinado ponto da esteira. Por exemplo: em um propulsor sem skew, todos os fólios seccionais estão posicionados em uma mesma posição angular, incidindo sobre a mesma região da esteira; quando se impõe um ângulo de skew, esses fólios ficarão em diferentes posições angulares, criando uma defasagem na geração dos esforços, mas não uma alteração de intensidade dos mesmos.

\subsubsection{Forças e Momentos Axiais de $1^{\mathrm{a}}$ ordem e $2^{\mathrm{a}}$ ordem}

Devido à geração de empuxo estar diretamente ligada à geração de torque resistivo, as excitações de vibração horizontal e torcional na direção axial apresentaram proporcionalidade entre si, ou seja, uma linearidade de comportamento, como pode se observar nas figuras 43 e 44 . Tal fato possibilitou uma simplificação muito grande na análise dos resultados, uma vez que o comportamento dos parâmetros geométricos frente às amplitudes de força é análogo ao comportamento frente às amplitudes de momento. Dessa forma, os gráficos que ilustram as conclusões sobre a excitação de vibração longitudinal e torcional se resumem aos referentes às amplitude de oscilação da força axial de primeira ( $F x 1)$ e segunda ordem (Fx2).

Fx1 vs. Mx1 on 260

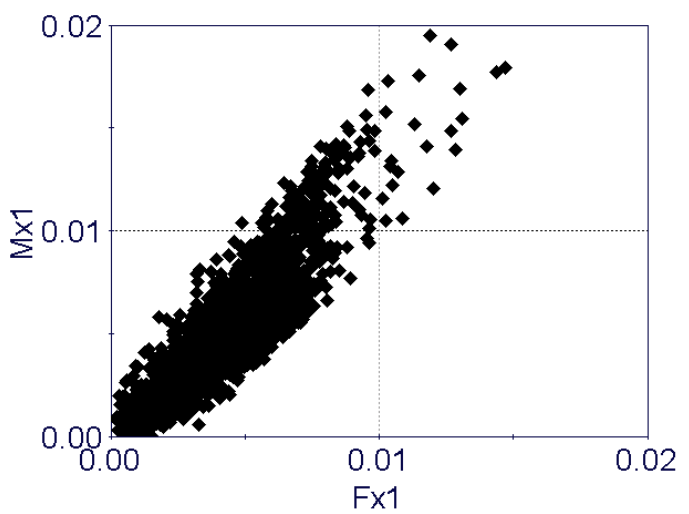

Fx1 vs. Mx1 on 170

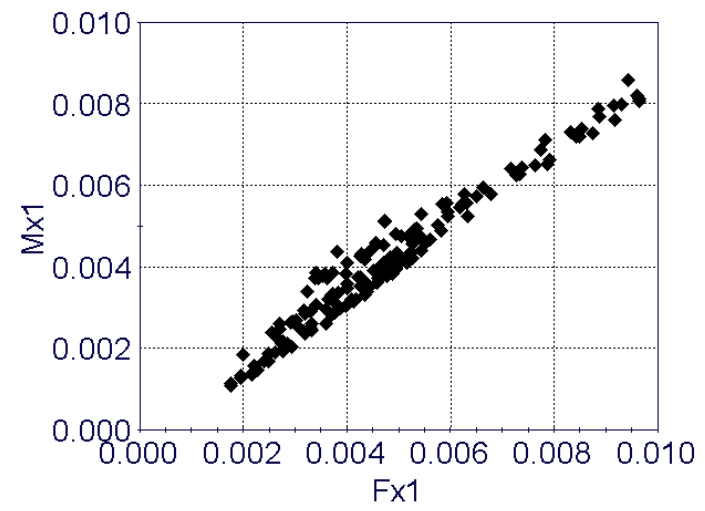

Figura 43 - Amplitudes de $1^{\text {a }}$ ordem de força ( $\left.F \times 1\right)$ vs momento (Mx1) (axial) 
Fx2 vs. Mx2 on 260

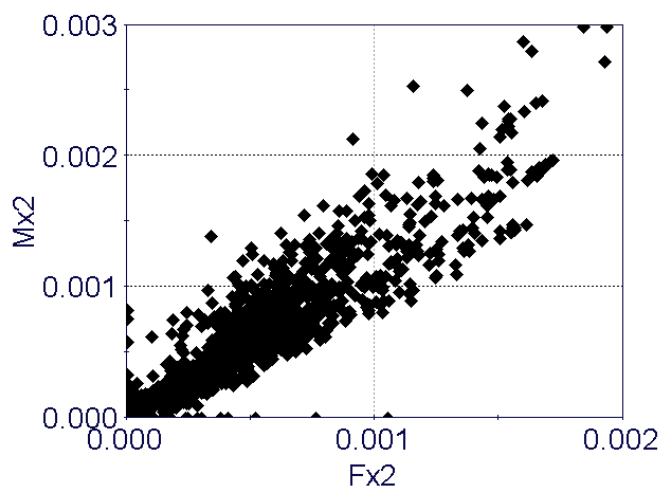

Fx2 vs. Mx2 on 355

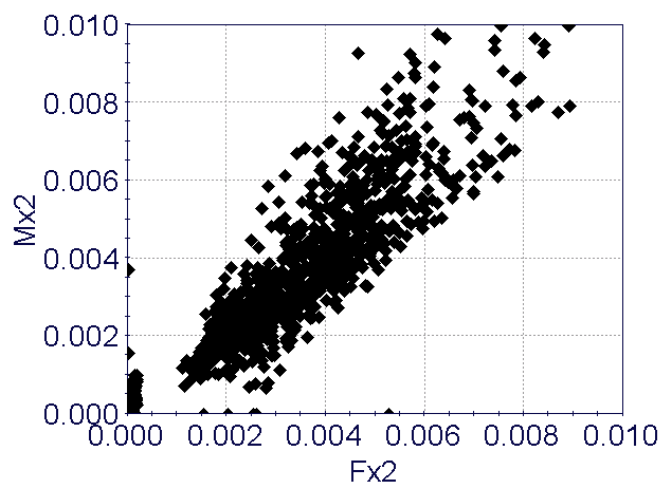

Figura 44 - Amplitudes de $2^{\mathrm{a}}$ ordem de força (Fx2) vs momento (Mx2) (axial)

Nos navios série 60 e porta-containers, verificam-se amplitudes de vibração em escalas muito inferiores às apresentadas pelo navio-tanque, como se pode observar nos gráficos das figuras 45 a 48 .

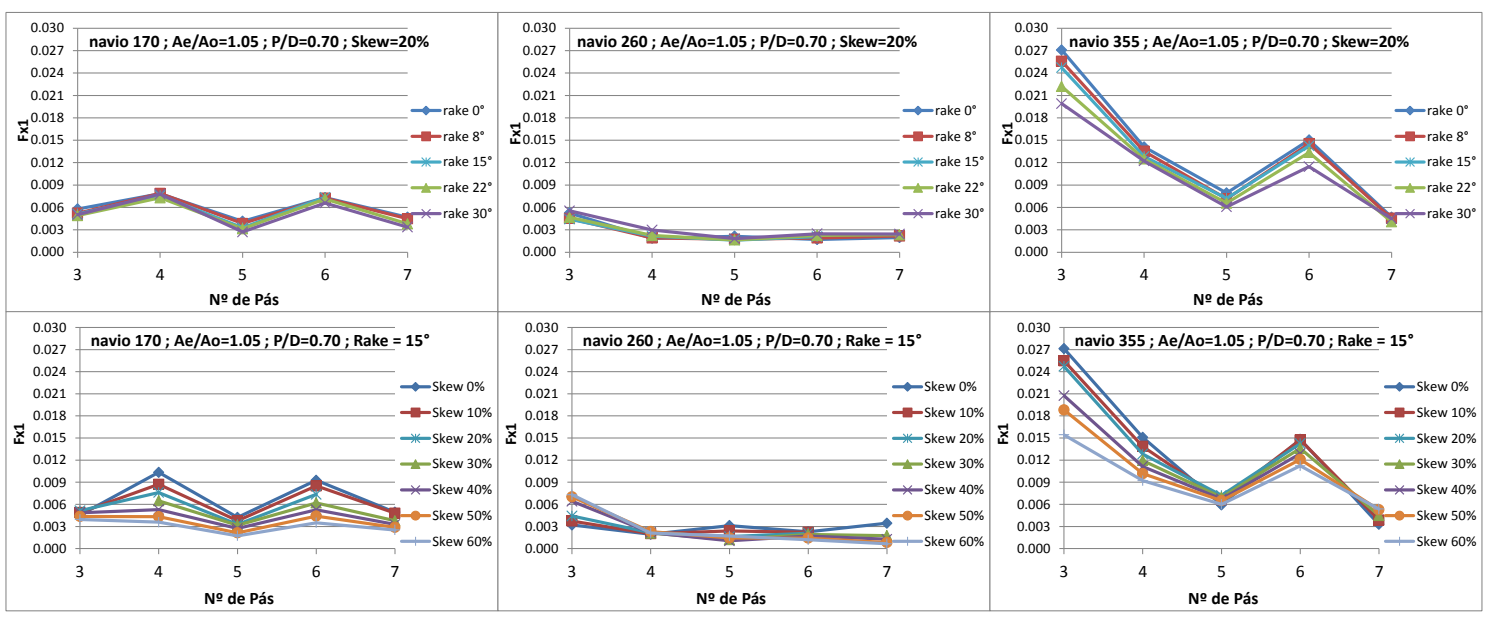

Figura 45 - Amplitude de 1a ordem de força axial (Fx1) em função do número de pás para diferentes valores de rake e skew (esteiras 170, 260 e 355)
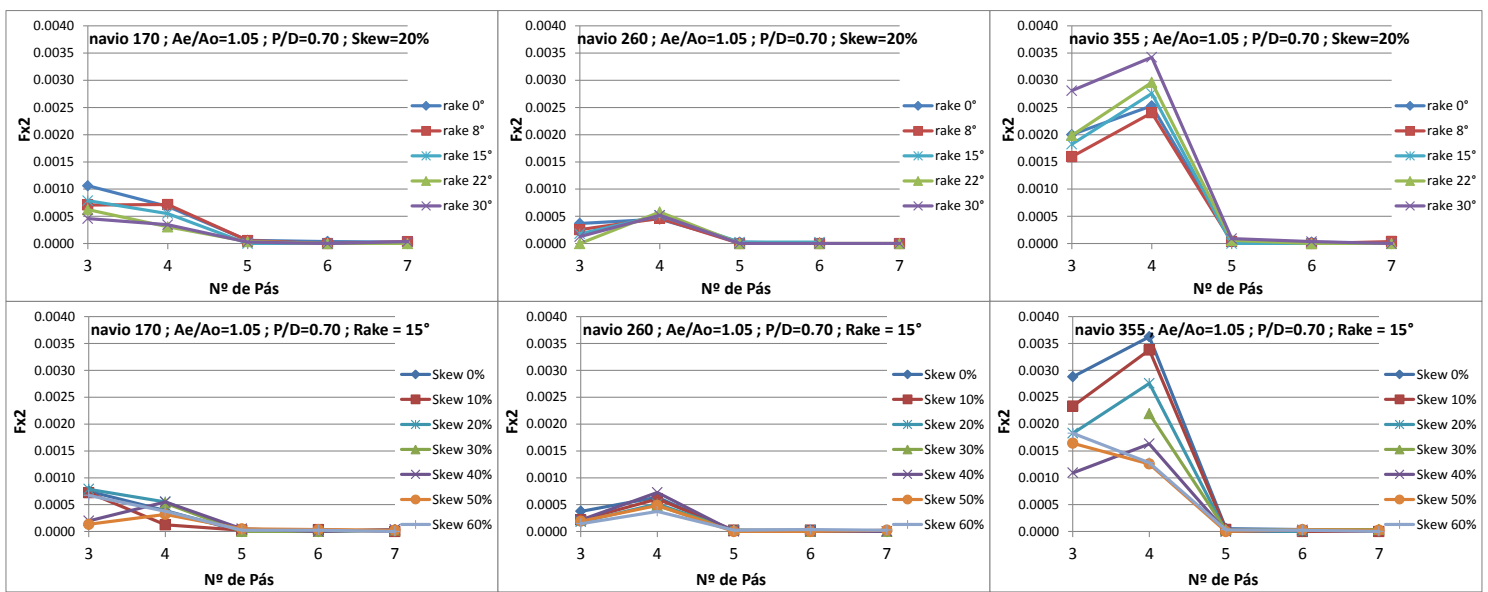

Figura 46 - Amplitude de 2a ordem de força axial (Fx2) em função do número de pás para diferentes valores de rake e skew (esteiras 170, 260 e 355) 


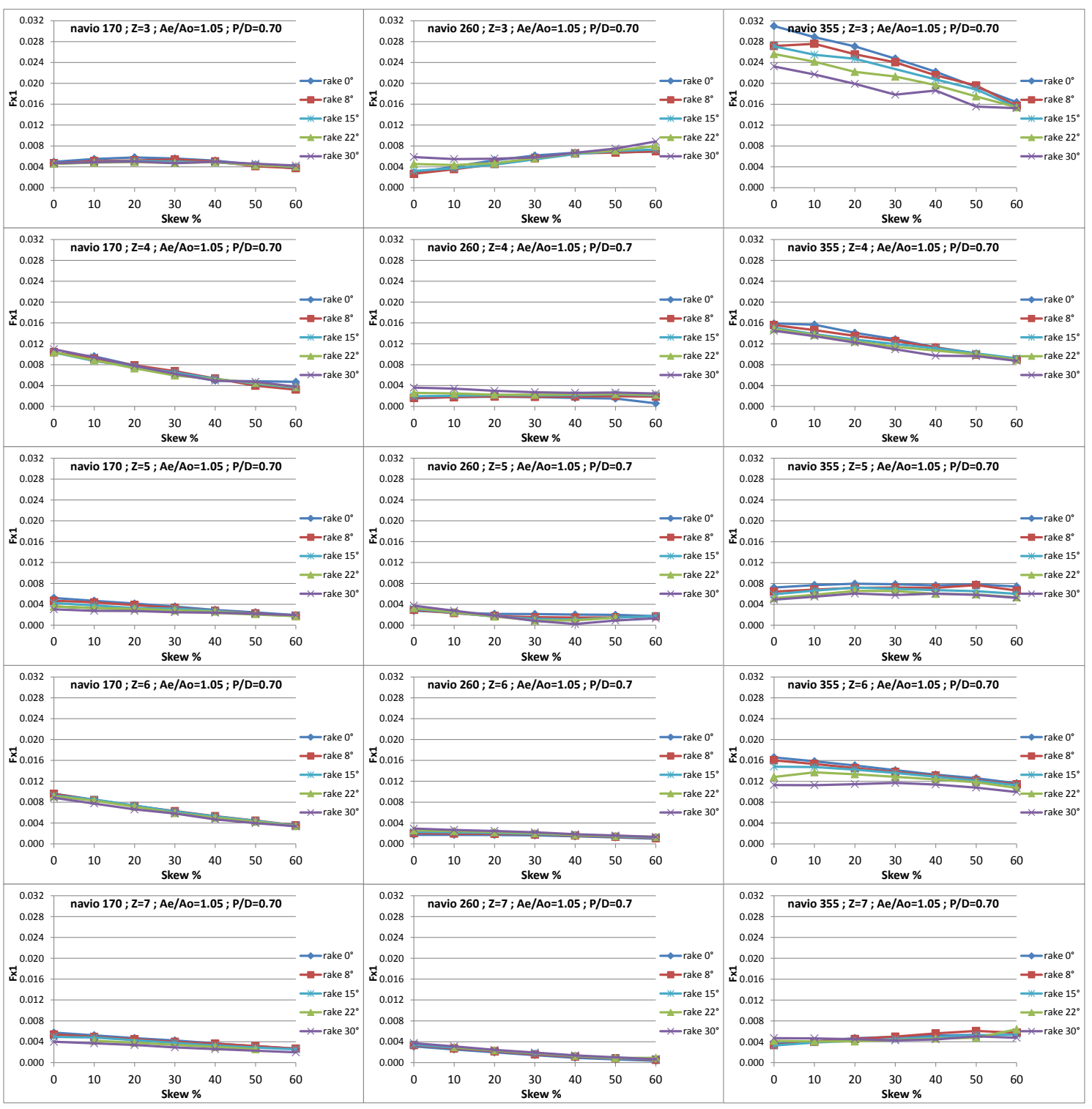

Figura 47 - Amplitude de $1^{\text {a }}$ ordem de força axial (Fx1) em função do skew, para diferentes valores de rake (esteiras 170, 260 e 355)

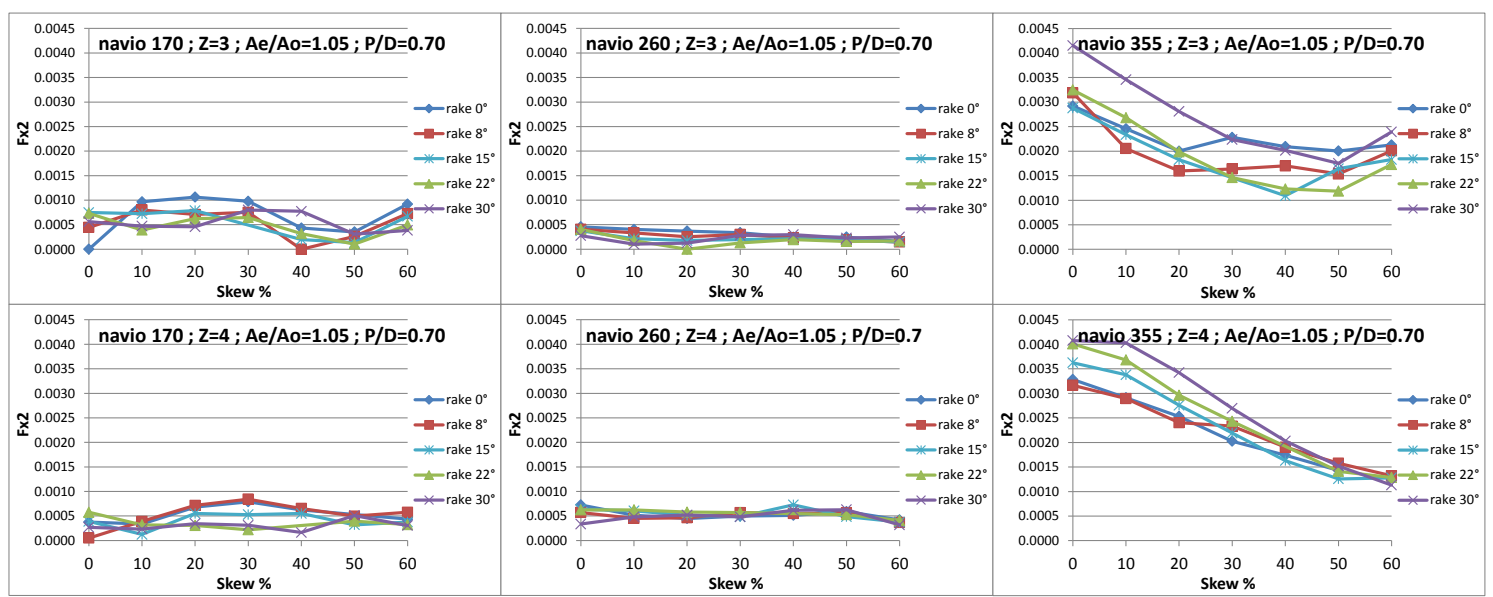

Figura 48 - Amplitude de $2^{a}$ ordem de força axial (Fx2) em função do skew, para diferentes valores de rake (esteiras 170, 260 e 355) 
Para os esforços de primeira ordem, o rake apresentou interferências contrárias entre os navios tanque e porta-containers, já para o série 60 , não houve nenhuma influência. Mesmo sendo tendências leves, para o naviotanque, o aumento do rake levou à diminuição das amplitudes de $1^{\text {a }}$ ordem, e o contrário ocorreu no caso do porta-container. Para os esforços de segunda ordem, o rake não mostrou influência alguma.

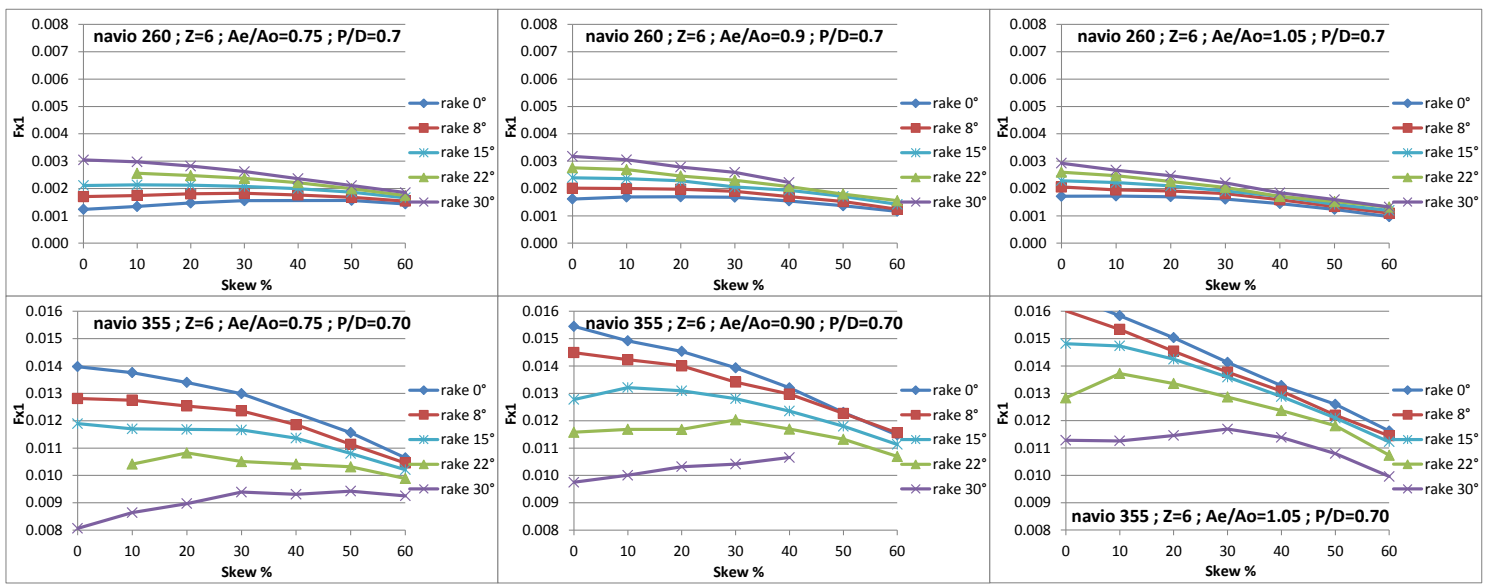

Figura 49 - Amplitude de $1 \underline{\text { a }}$ ordem de força axial (Fx1) em função do skew, para diferentes valores de rake (Ae/Ao 0.750 .901 .05 esteiras 260 e $355-Z=6$ )

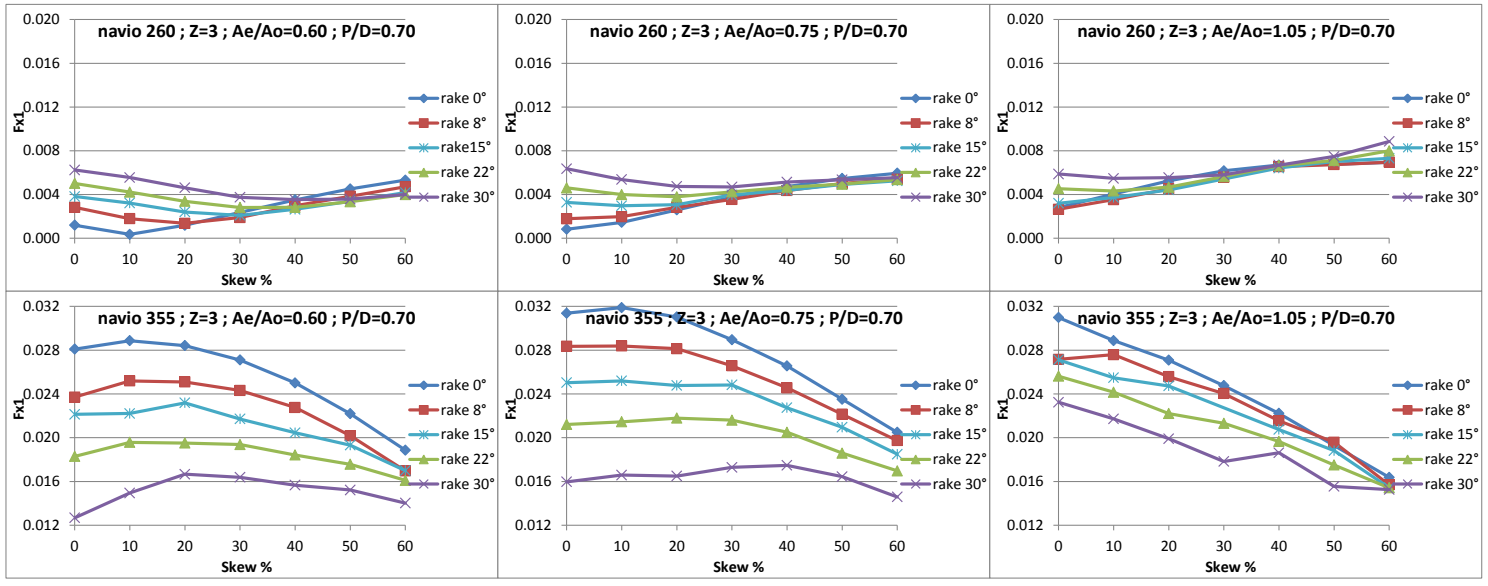

Figura 50 - Amplitude de $1^{\text {a }}$ ordem de força axial ( $\left.F x 1\right)$ em função do skew, para diferentes valores de rake (Ae/Ao 0.60; 0.75; 1.05 esteiras 260 e $355-Z=3$ ) 


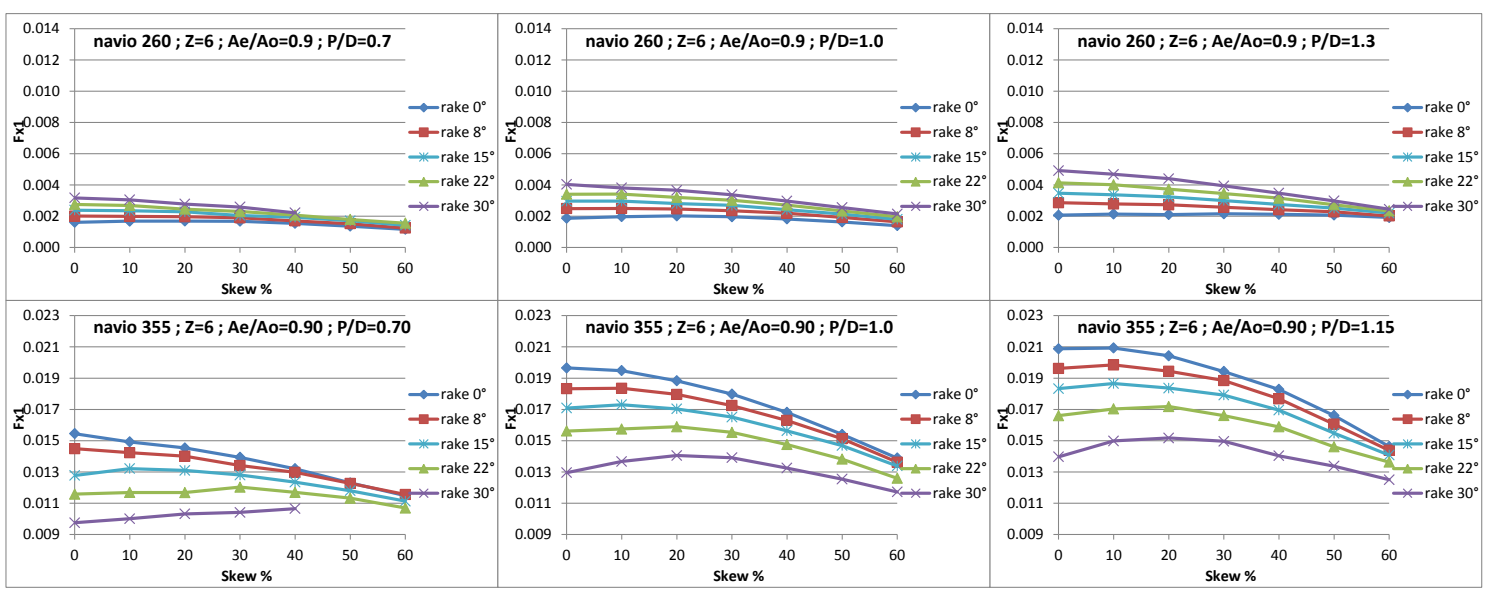

Figura 51 - Amplitude de $1^{\text {a }}$ ordem de força axial (Fx1) em função do skew, para diferentes valores de rake (variação de P/D 0.7 a 1.3 - esteiras 260 e 355 - Z=4)

Com base no que foi descrito sobre a propriedade do skew no subítem 5.2.1, pode-se observar nos gráficos a seguir que as curvas dos esforços axiais frente à variação do skew não indicam tendências positivas ou negativas, mas sim valores mínimos em que o grau de defasagem da produção de esforços entre as seções radiais é ótimo, e que portanto, minimiza a geração de vibração torcional e longitudinal. Este comportamento se torna claro nos gráficos referentes às amplitudes de segunda ordem do navio porta-containers, nas Figuras 52, 53 e 54 .

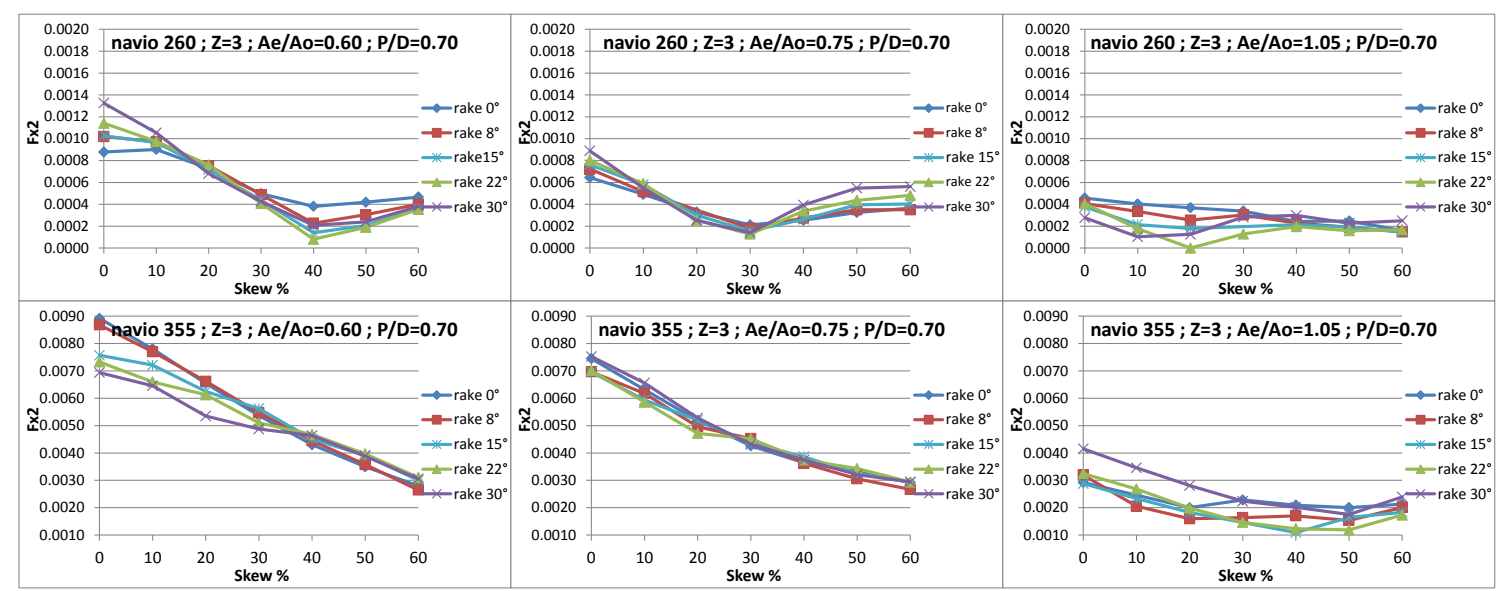

Figura 52 - Amplitude de $2^{\text {a }}$ ordem de força axial (Fx2) em função do skew, para diferentes valores de rake (Ae/Ao 0.60; 0.75; 1.05 esteiras 260 e $355-Z=3$ ) 


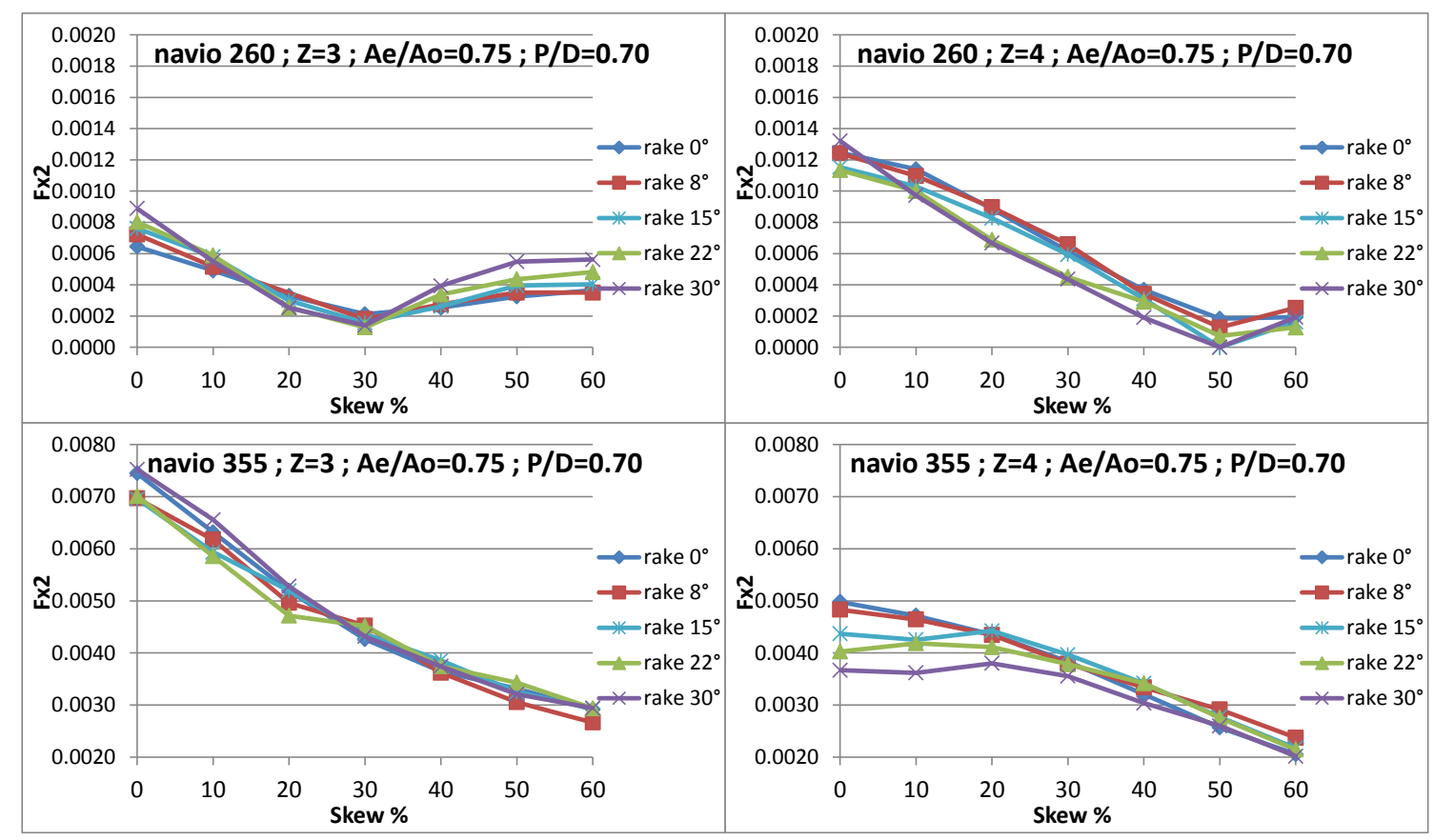

Figura 53 - Amplitude de $2^{\underline{a}}$ ordem de força axial (Fx2) em função do skew, para diferentes valores de rake $(Z=3 ; 4$ - esteiras 260 e $355-\mathrm{Ae} / \mathrm{Ao}=0.75)$

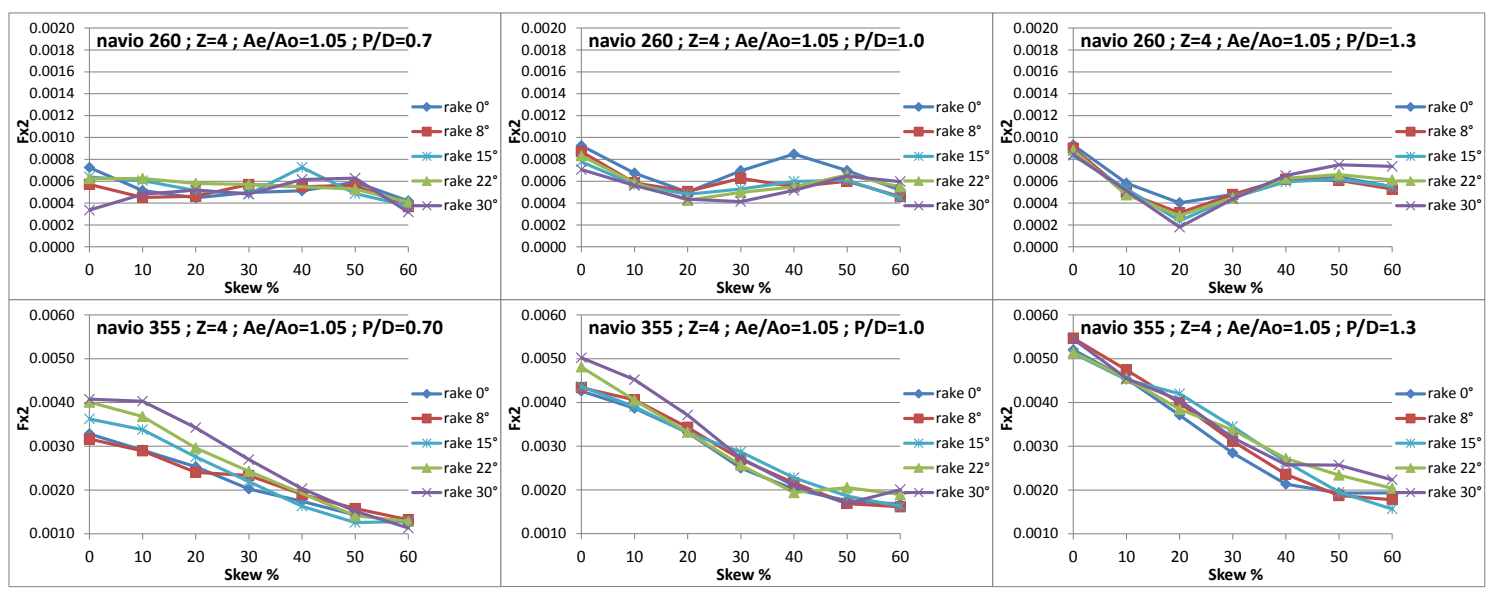

Figura 54 - Amplitude de $2^{\underline{a}}$ ordem de força axial (Fx2) em função do skew, para diferentes valores de rake (P/D 0.7; 1.0; 1.3 - esteiras 260 e 355 - Ae/Ao=1.05 )

O aumento do passo (P/D) do propulsor sugere que a força gerada durante uma revolução aumente também. Os gráficos a seguir ilustram que as oscilações dos esforços axiais também aumentam para um propulsor mais carregado, tanto em relação aos harmônicos de $1^{\underline{a}}$ ordem como de $2^{\underline{a}}$ ordem, a exceção das amplitudes de $2^{\mathrm{a}}$ ordem do porta-container. 


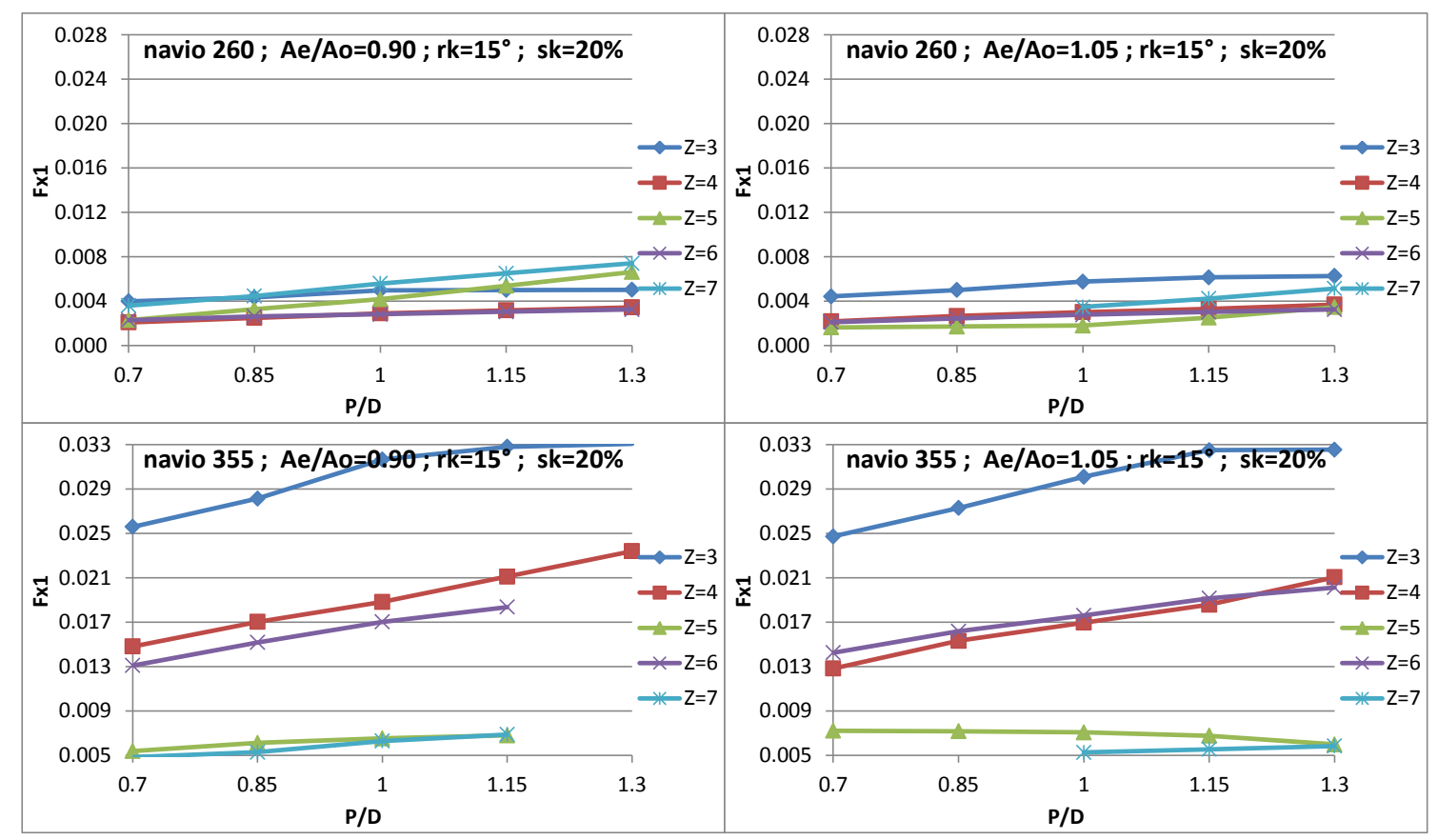

Figura 55 - Amplitude de $1^{\text {a }}$ ordem de força axial (Fx1) em função de P/D, para diferentes valores de $Z$ (esteiras 260 e 355)

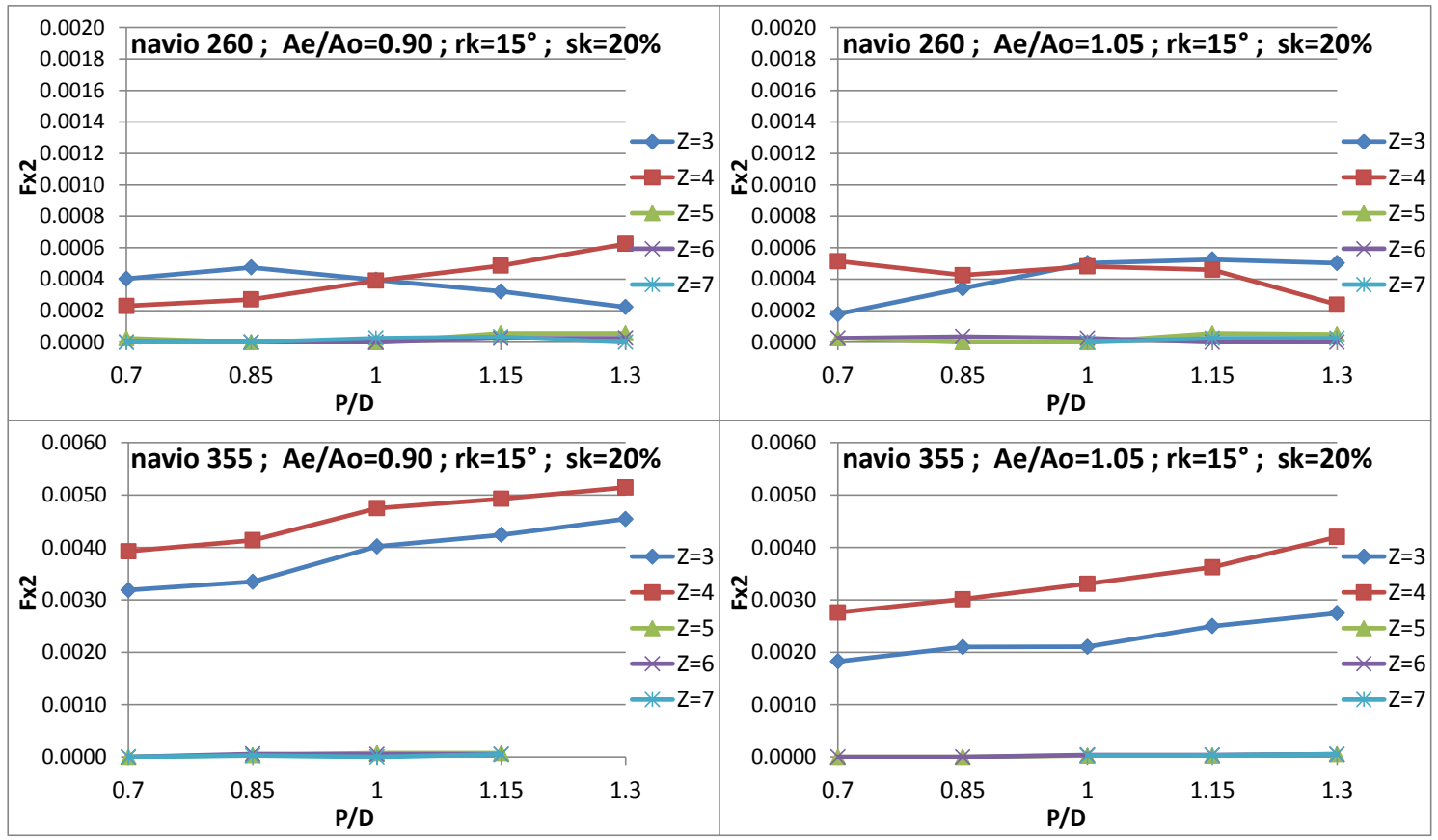

Figura 56 - Amplitude de $2^{-a}$ ordem de força axial (Fx2) em função de P/D, para diferentes valores de $Z$ (esteiras 260 e 355 )

O número de pás apresenta ligação direta com a excitação de vibração. Através dos gráficos presentes nas figuras a seguir, é possível detectar que a as amplitudes de vibração axial apresentam patamares diferentes entre número 
de pás par e ímpar. Dentro desses patamares, essas amplitudes diminuem em função do aumento de número de pás.

Como se observa na maioria dos casos, os propulsores de número par de pás geram maior excitação axial, possivelmente por estarem entrando em fase com os harmônicos da esteira. Em número ímpar de pás, coloca-se a pá em defasagem com tais harmônicos.

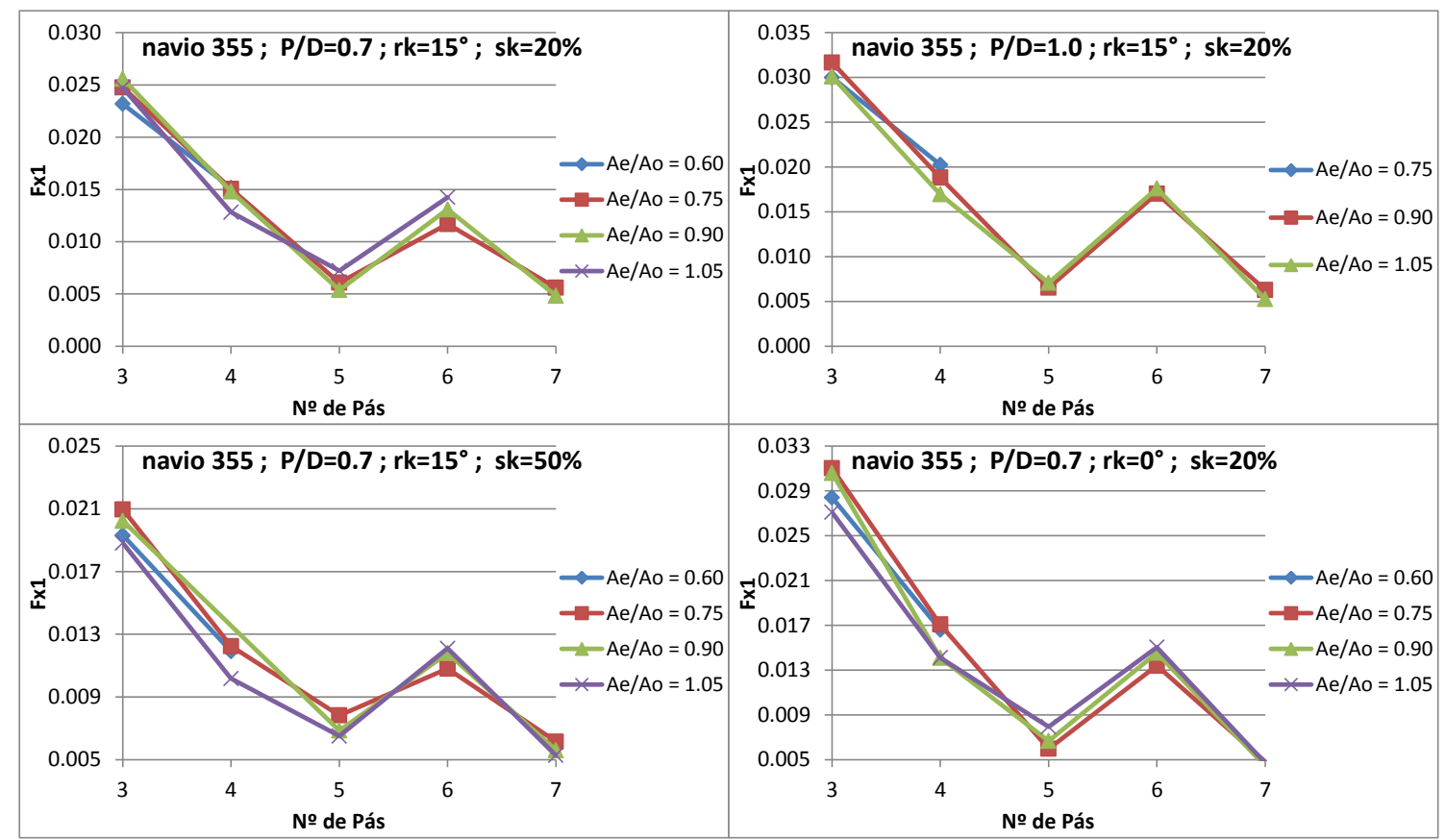

Figura 57 - Amplitude de $1^{\text {a }}$ ordem de força axial (Fx1) em função de $Z$, para diferentes valores de Ae/Ao (esteiras 260 e 355)

Os efeitos da diminuição do número de pás e da ressonância ou defasagem com a esteira medem forças em alguns casos, por isso, os propulsores de 3 e 4 pás se alternam na posição de maiores excitadores de esforços axiais. 


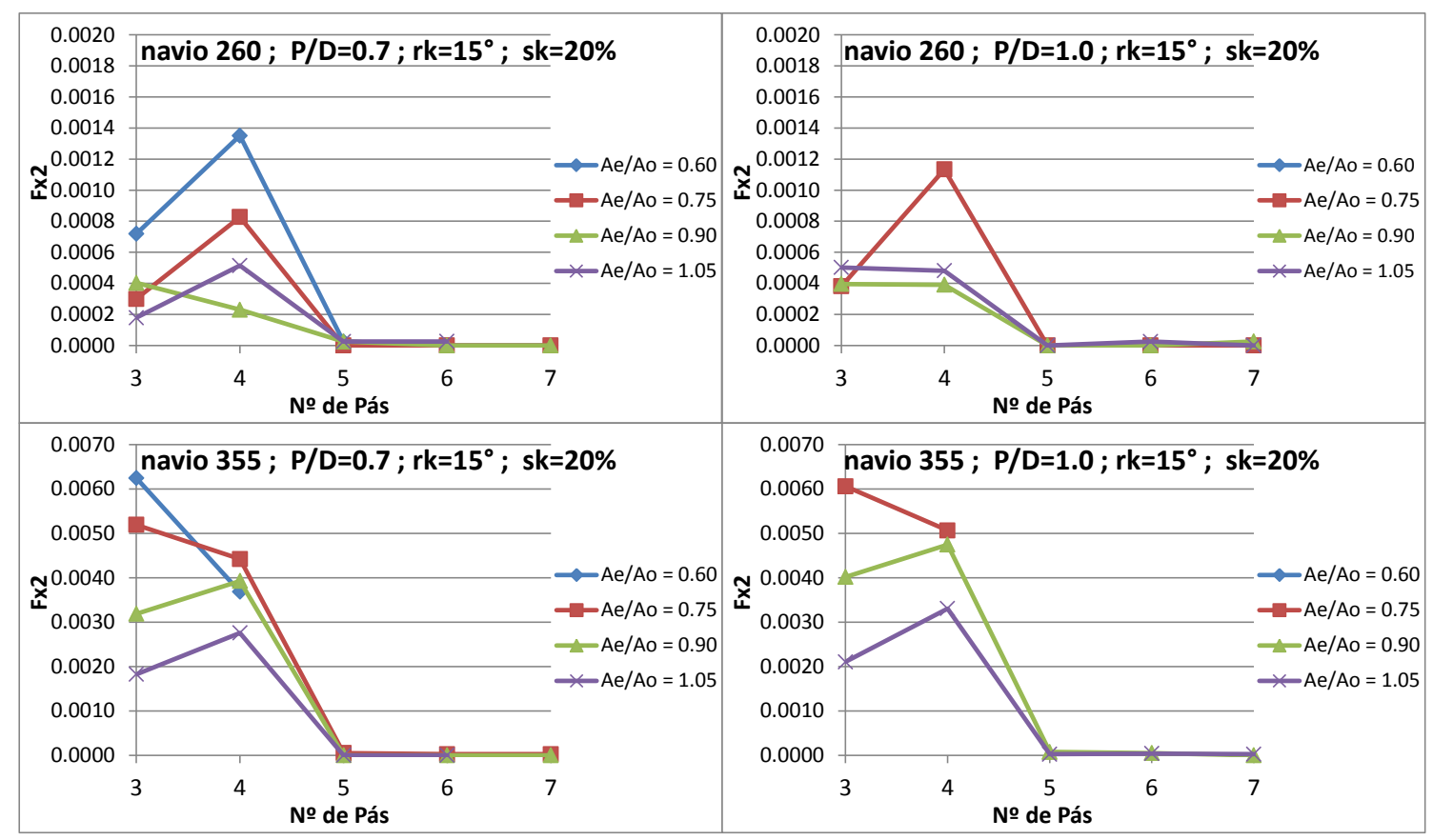

Figura 58 - Amplitude de $2^{\text {a }}$ ordem de força axial (Fx2) em função de Z, para diferentes valores de Ae/Ao (P/D 0.7 e 1.0 - esteiras 260 e 355)

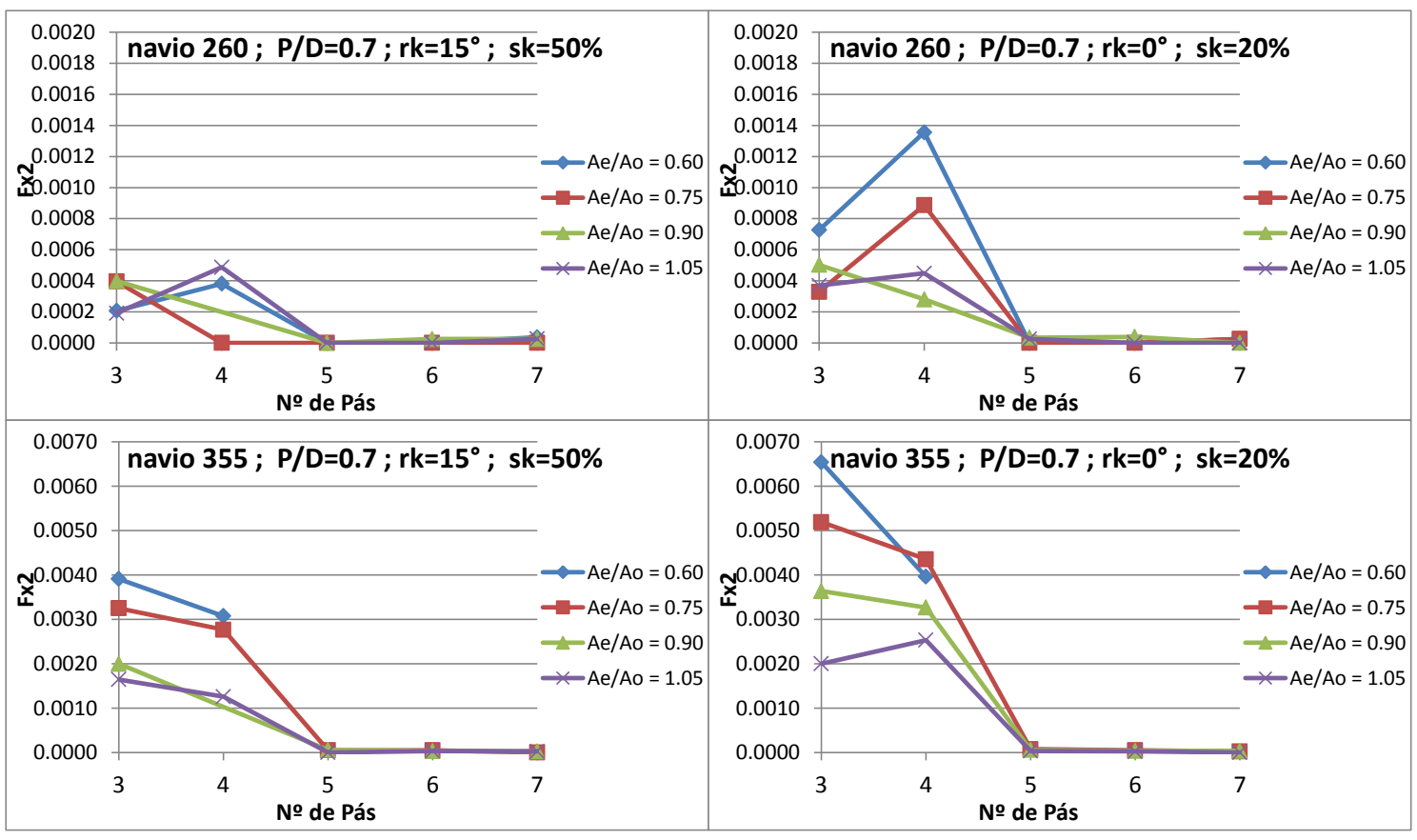

Figura 59 - Amplitude de $2^{\mathrm{a}}$ ordem de força axial (Fx2) em função de Z, para diferentes valores de $\mathrm{Ae} / \mathrm{Ao}$ (skew $20 \%$ e $50 \%$ - esteiras 260 e 355 ) 
Propulsores com número de pás maior ou igual a 5 reduzem as amplitudes de segunda ordem a valores praticamente nulos. Em um projeto específico de propulsor, deve-se avaliar, portanto, a frequência natural do casco para se escolher o número de pás mais adequado, cuja frequência de pá não seja múltipla da mesma, de forma que as amplitudes desses esforços não entrem em ressonância e causem problemas estruturais sérios no casco.

O parâmetro geométrico relacionado à área expandida não demonstrou influência sobre a excitação de vibração axial de $1^{\text {a }}$ ordem, como se observa nos gráficos da Figura 57. No entanto, para as amplitudes de $2^{\mathrm{a}}$ ordem, os gráficos da Figura 58 e Figura 59 mostram que o aumento da área atenua a excitação de vibração.

\subsubsection{Excentricidade do Empuxo}

O atributo da excentricidade do empuxo representa a geração de momentos fletores sobre o eixo, que impacta diretamente na geração de vibração transversal. Revelam-se tendências claras frente aos parâmetros rake, número de pás e $P / D$, enquanto que os parâmetros de área e skew não mostraram nenhuma influência. $O$ mesmo comportamento se repetiu para os três tipos de navios.

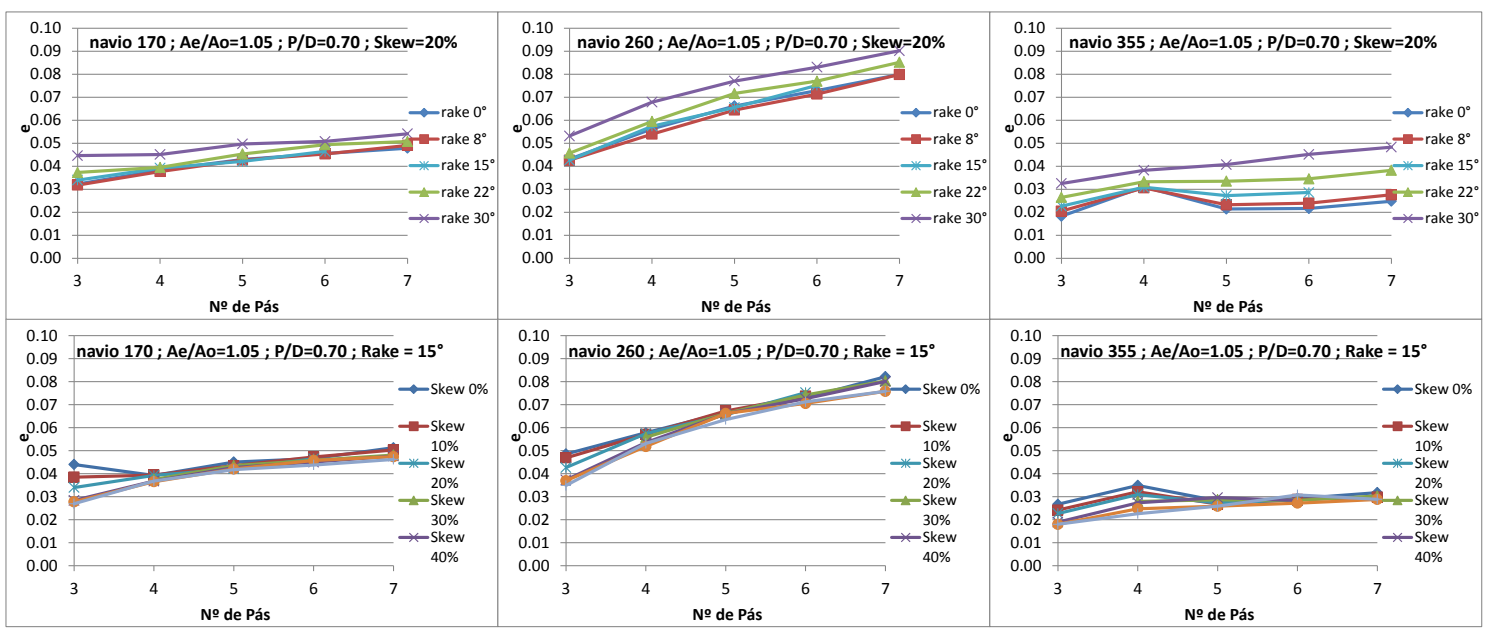

Figura 60 - Excentricidade do Empuxo em função de Z, para diferentes valores de rake e skew (esteiras 170, 260 e 355) 


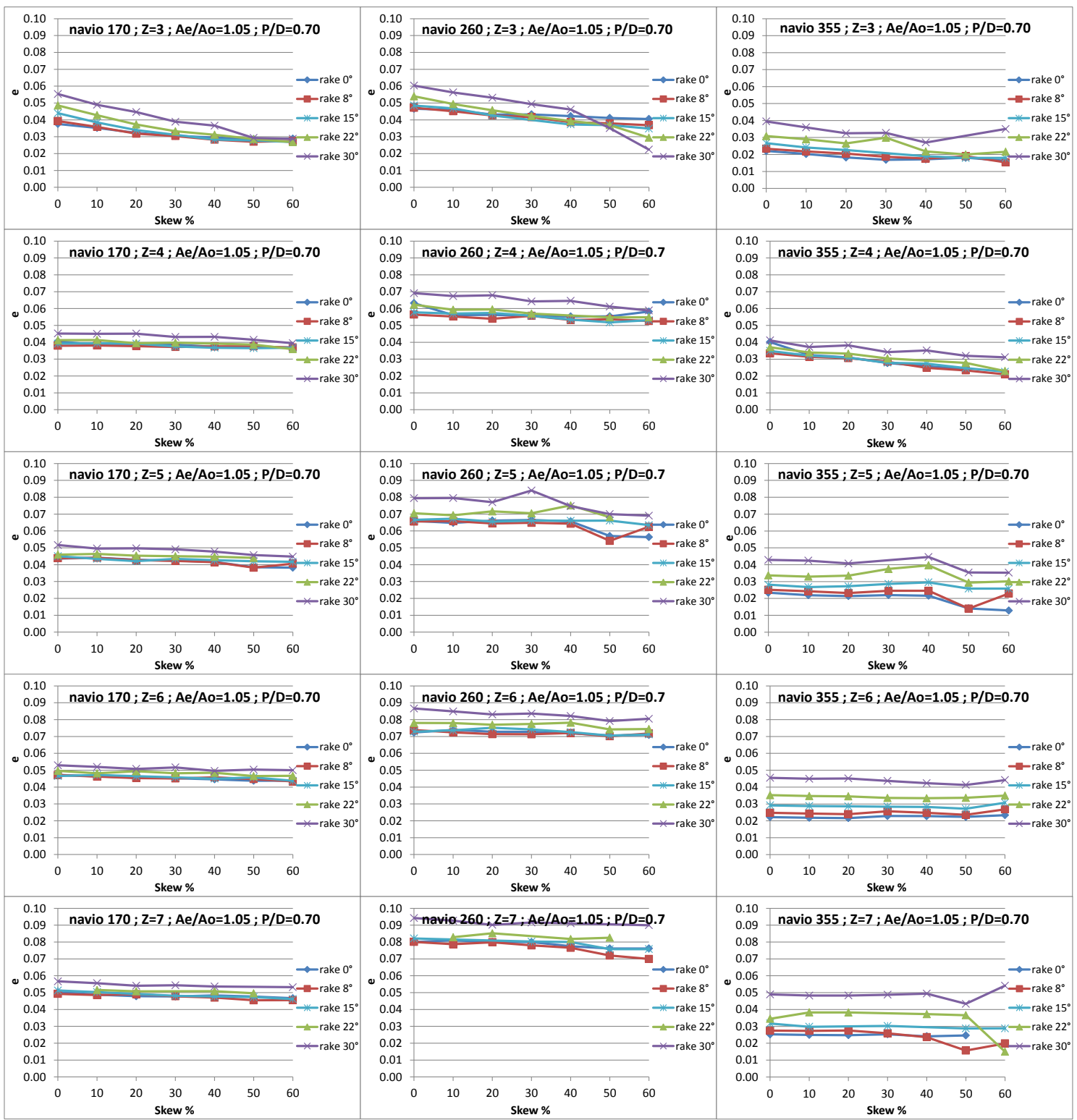

Figura 61 - Excentricidade do Empuxo em função de skew, para diferentes valores de rake (esteiras 170, 260 e 355)

A inclinação das pás em relação ao plano do propulsor, isto é, o aumento do rake, demonstrou ser desfavorável sob o ponto de vista de vibração transversal. Os gráficos a seguir mostram que a excentricidade do empuxo atinge valores mais altos com os maiores valores de rake. Da mesma forma ocorreu para o número de pás. 


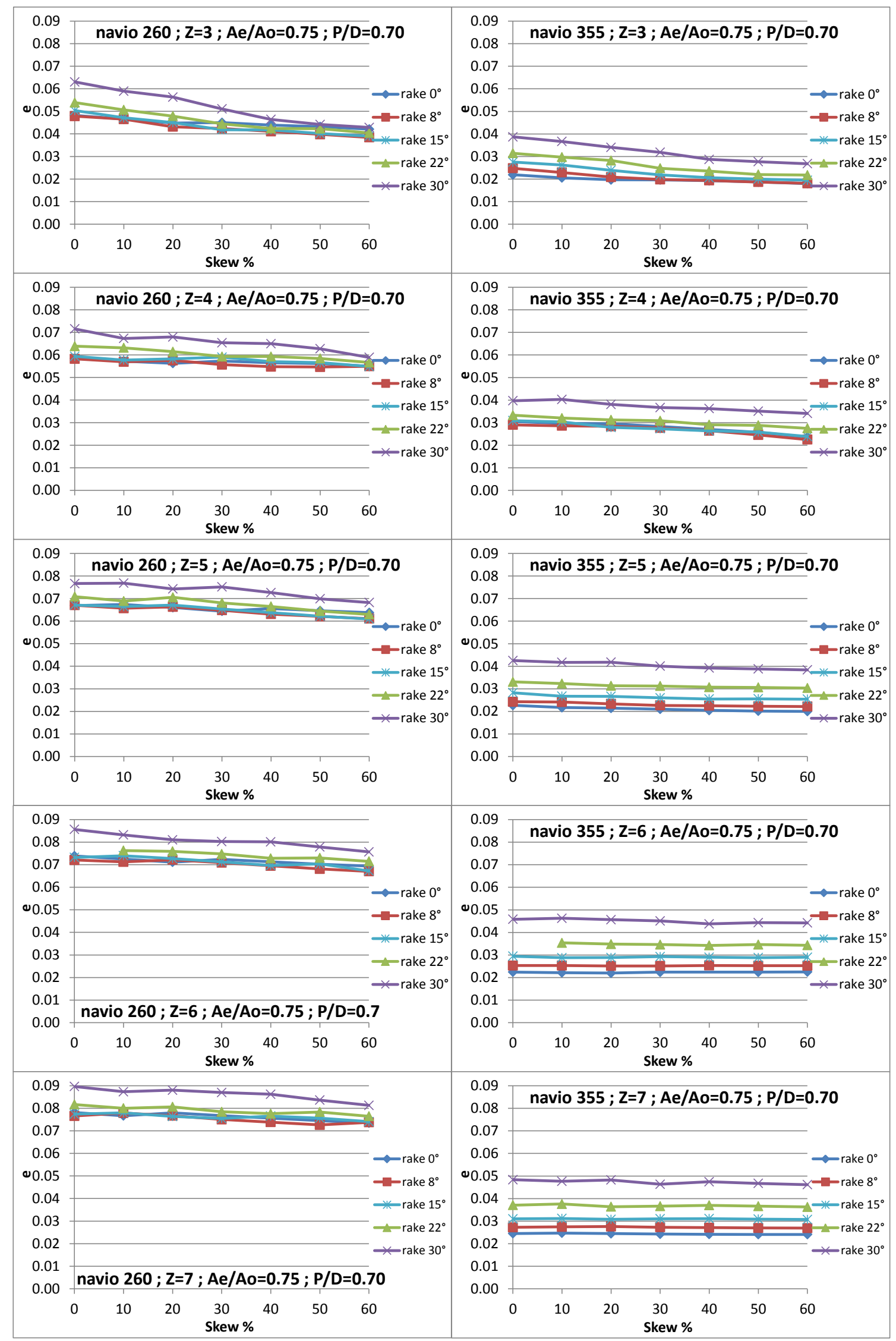

Figura 62 - Excentricidade do Empuxo em função de skew, para diferentes valores de rake (esteiras 260 e 355) 


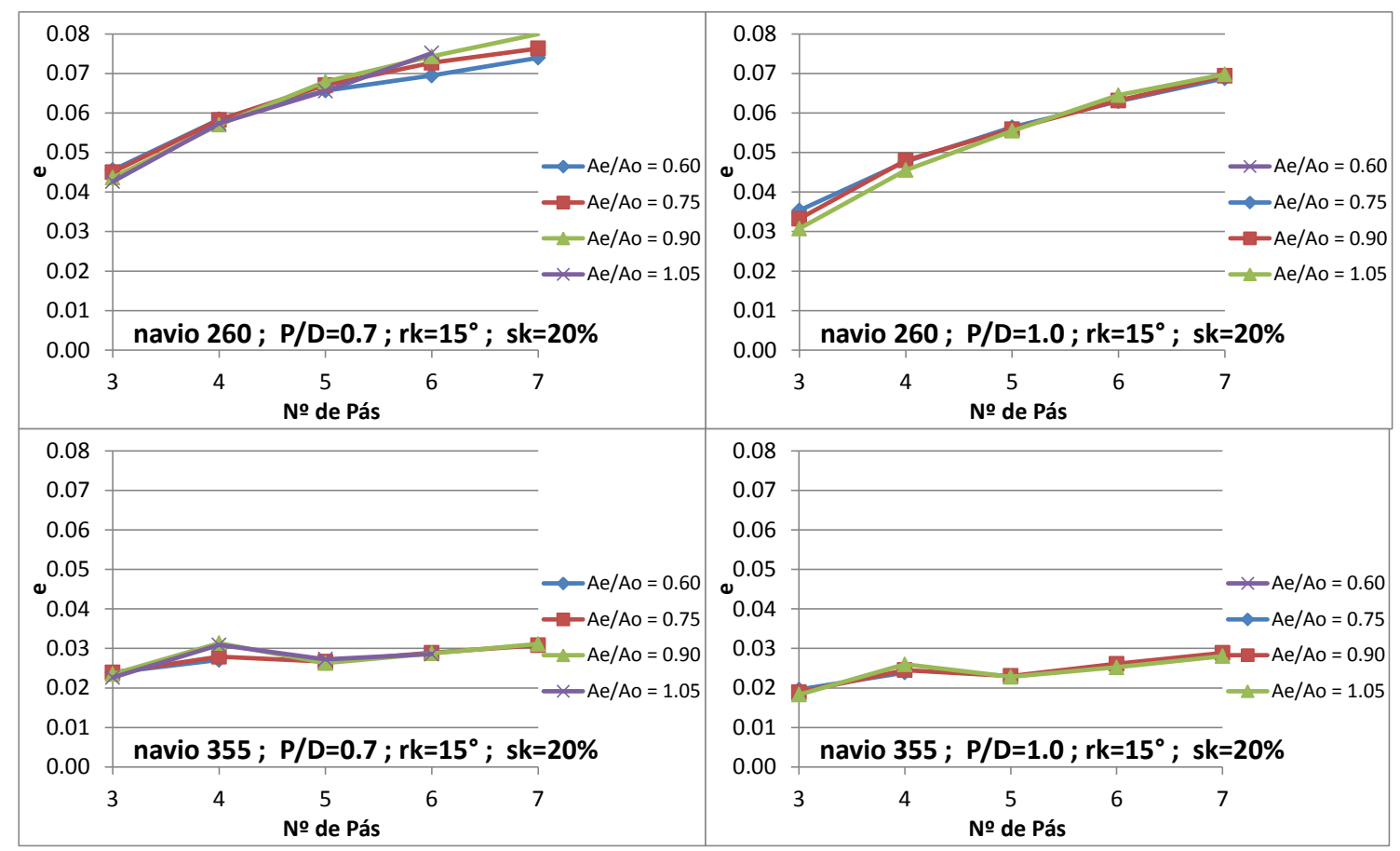

Figura 63 - Excentricidade do empuxo em função de Z, para diferentes valores de Ae/Ao (P/D 0.7 e 1.0 - esteiras 260 e 355)

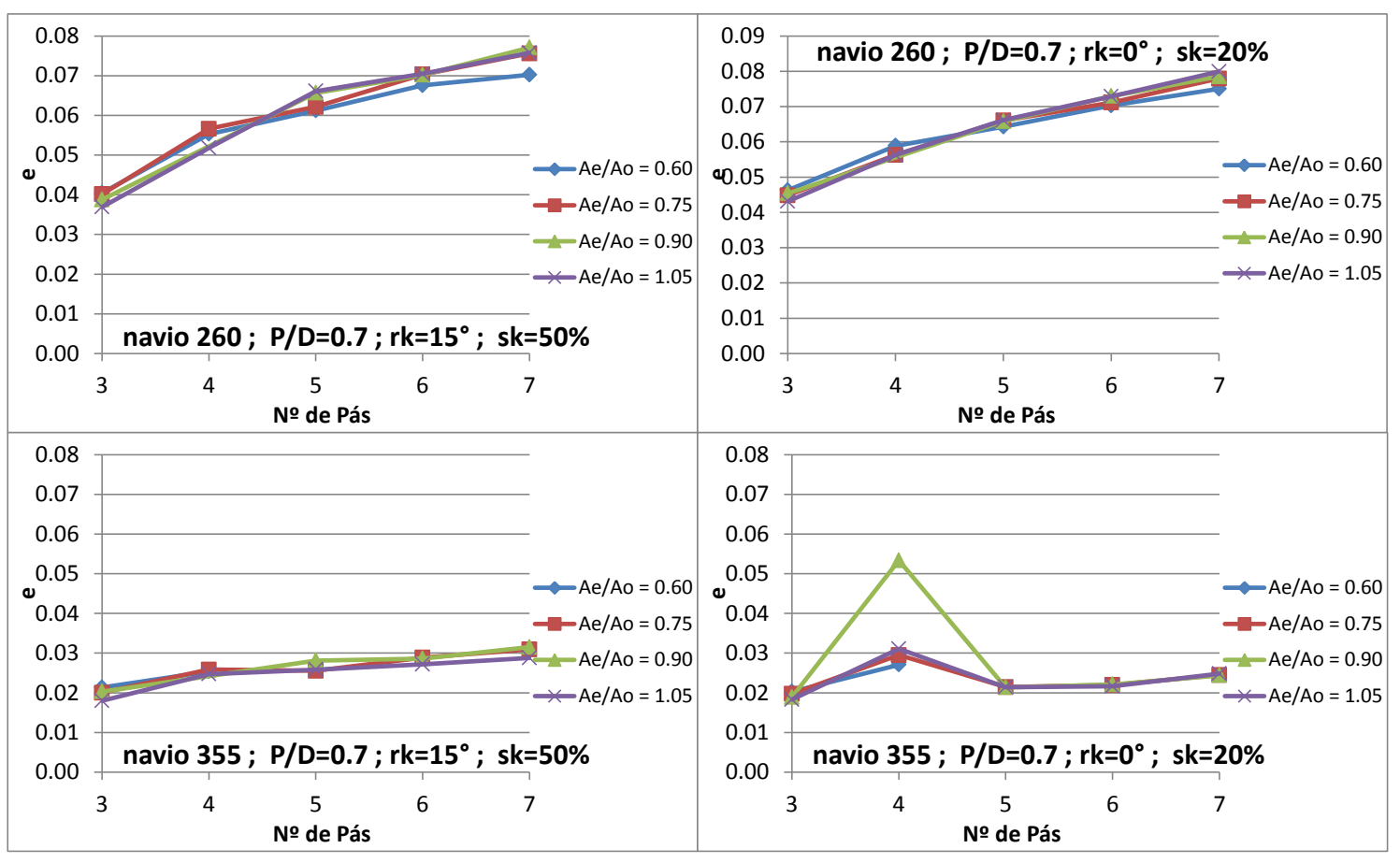

Figura 64 - Excentricidade do empuxo em função de Z, para diferentes valores de Ae/Ao (skew $20 \%$ e $50 \%$ - esteiras 260 e 355 ) 
A relação de $P / D$ foi o único parâmetro que apresentou um comportamento inversamente proporcional à excentricidade do empuxo, como se observa na Figura 65.

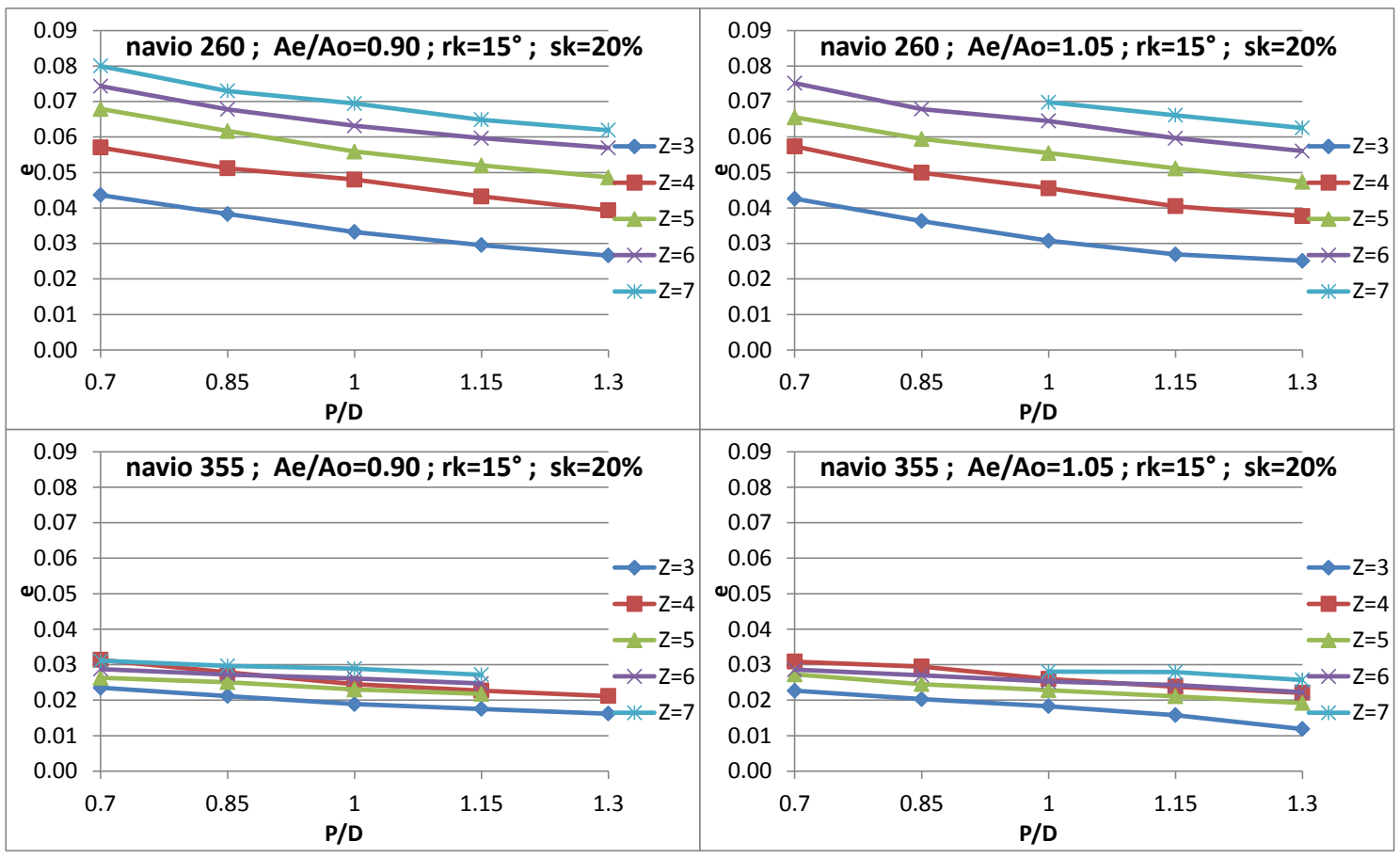

Figura 65 - Excentricidade do empuxo em função de P/D, para diferentes valores de Z (esteiras 260 e 355) 


\section{CONCLUSÃO}

O estudo se iniciou com as primeiras análises numéricas, utilizando o software PPB, referentes ao exercício padrão proposto pela ITTC. Com o mesmo propulsor e esteira incidente, os resultados numéricos apresentaram semelhança com os experimentais no que diz respeito à amplitude harmônica de $1^{\text {a }}$ ordem para oscilação da força e do momento axiais produzidos pelo propulsor, o que colaborou para a validação do uso do software adotado.

A metodologia utilizada enfrentou seus primeiros desafios ao estudar as esteiras dos navios. Conforme desejado inicialmente, seria muito bem-vinda a introdução de esteiras parametrizadas às análises realizadas pelo estudo paramétrico, pois permitiria uma gradativa alteração do campo de velocidade incidente, colaborando para que os resultados referentes à diversificação do comportamento do propulsor pela alteração de esteiras incidentes fossem mais "contínuos" e indicassem de fato tendências. Apesar de abrangente, a forma discreta e pontual como foram escolhidas as esteiras dificultou muito na percepção da maneira e das possíveis razões da variação do comportamento do propulsor em esteiras distintas, nos casos em que havia de fato variação. Ao menos, para os casos em que não houve interferência e o propulsor se comportou de forma igual para as diferentes esteiras, tem-se um bom indicativo de que realmente a esteira não influencia nestes determinados comportamentos do propulsor, dada a grande diferença entre os campos utilizados. Além disso, a dificuldade de se obter a distribuição radial dos esforços ao longo da pá do propulsor a partir dos resultados fornecidos pelo software impossibilitou a utilização de critérios elaborados para a cavitação e resistência estrutural.

O estudo paramétrico cumpriu com os objetivos de se buscar tendências ou apenas confirmá-las. A relação de área expandia confirmou a interferência inversamente proporcional à eficiência prevista pela teoria, assim como a íntima relação com a ocorrência de cavitação. A relação $P / D$, por exemplo, mostrou comportamentos claros em todos os critérios e iguais nos três tipos de esteira, abrindo a possibilidade de previsões ou simplesmente confirmando sua significância para a otimização do propulsor sob tais atributos. O skew se 
confirmou parâmetro influente para o controle de vibração longitudinal e torcional. $\mathrm{O}$ número de pás $\mathrm{Z}$ mostrou tendências esperadas referentes à eficiência e à interação de ressonância e defasagem com a esteira, relacionada à vibração axial. Outra conclusão que se confirmou foi a pouca ou aleatória influência do rake para tais critérios, exceto para vibração transversal.

As conclusões feitas a partir do estudo paramétrico podem ser aproveitadas para um posterior processo otimizatório, indicando quais são os parâmetros mais relevantes para cada um dos atributos e que, portanto, valem à pena serem inseridos na otimização. Por outro lado, não são possíveis de serem extrapoladas às outras séries sistemáticas de propulsores, uma vez que a série B-Troost possui peculiaridades geométricas distintas, a exemplo da distribuição de passo ser constante ao longo do raio (exceto para 4 pás). Peculiaridades como essa podem afetar não só o comportamento do parâmetro em questão como a maneira de interação com os demais. Fato este que não desconsidera a aplicação do mesmo procedimento para os estudos de outras séries.

A relevância da metodologia se dá pela possibilidade de abordar de maneira simples e objetiva a excitação de vibração, na medida em que interpreta os esforços gerados nos seis graus de liberdade pelo propulsor em critérios intimamente relacionados à maneira como tais esforços serão transmitidos através do eixo para toda a embarcação, além de contrapô-los ao critério tão importante da eficiência propulsora.

Outro ponto a se destacar foi o conhecimento teórico, relativo às definições geométricas, e prático adquirido para utilização do software, assim como o de todo procedimento computacional empregado, que é útil aos demais pesquisadores ou interessados por este tema. 


\section{REFERÊNCIAS}

ABS. Guidance Notes on Ship Vibration. Houston, 2006

BALTAZAR, J., CAMPOS, J.A.C. On the Modelling of the Flow in Ducted Propeller With Panel Method.Norway, 2009.

BERTRAM, V. Practical Ship Hydrodynamics.Oxford, 2000.

CARLTON, J. S. Marine Propellers and Propulsion.Butterworth-Heinemann Ltd. Oxford, 2007.

FERNANDES, J. C.Segurança nas Vibrações sobre o Corpo Humano. UNESP, 2000.

GRIM, O. Propeller and Vane Wheel.J.S.R, 1980

HANAOKA, T. Hydrodynamics of an Oscillating Propeller. Fourth Symposium on Naval Hydrodynamics, 1962.

HIRATA, K. Uma Metodologia de Análise de Vibração em Propulsores devido à Esteira Não Uniforme. Universidade de São Paulo, 1983.

HOSHINO, T. Hydrodynamics Analysis of Propellers in Steady Flow using Surface Panel Method.Japan, 1989.

HSVA.Manual for Graphical User Interface driven PPB Program System. 2010

ITTC.International Towing Tank Conference - 14ํㅜ Proceedings Propeller Committee.Otawa, 1975

JOHANNESSEN, H., SKARR, K.T. Guidelines for Prevention of excessive Ship Vibration. SNAME, 1980

KERWIN, J.E., LEE, C.S. Prediction of Steady and Unsteady Marine Propellers Performance by Numerical Lifting-Surface Theory.SNAME, 1978.

KUIPER, G.TheWageningen Propeller Series.Netherlands, 1992.

LERBS, H. W. Moderately Loaded Propellers With a Finite Number of Blades and an Arbitrary Distribution of Circulation. SNAME, 1952.

LEWIS, E.V. Principles of Naval Architecture.The Society of Naval Architects and Marine Engineers.New York, 1988. 
LEWIS, F. M. PropellerVibration. SNAME vol.43, 1935

PANAGOPULOS, E. Design-Stage Calculations of Torsional, Axial and Lateral Vibrations o Marine Shafting. SNAME, 1950

PNV - Departamento de Engenharia Naval e Oceânica. Métodos Computacionais para Engenharia I, 2006.

SEARS, W.R. Some Aspects of Non Stationary Airfoil Theory and its Practical Application. 1941

SBRAGIO, Ricardo. Projeto Racional de Propulsores de Alto Skew. São Paulo, 1995.

SNAME.Ship Vibration Symposium .1980

SNAME.Marine Engineering. Jersey City, 1992

STRECKWALL, H. Hydrodnamic Analysis of three Propellers using Surface Painel Method for Steady and Unsteady Inflow Conditions. 22 ${ }^{\mathrm{a}}$ ITTC Propulsion Committee.Grenoble, 1998.

VAZ, G.N.V.B. Modelling of Sheet Cavitation of Sheet Cavitation on Hydrofoils and Marine Propellers using Boundary Element Method. Lisboa, 2005.

VERITEC.Vibration Control in Ships.Oslo, 1985

WARD, G.; WILLSHARE, G.T. Propeller-excited Vibration with Particular Reference to Full-scale Measurements.The Royal Institutionof Naval Architects.London, 1975. 


\section{ANEXO A - ESTEIRA DO EXERCÍCIO PADRÃO PROPOSTO}

\section{PELA 14믄 ITTC}

\begin{tabular}{|c|c|c|c|c|c|c|c|c|c|}
\hline PHI & .300 & .400 & .500 & .600 & .700 & .800 & .900 & .950 & 1.000 \\
\hline .000 & .667 & .772 & .848 & .907 & .928 & .925 & .939 & .932 & .934 \\
\hline 10.000 & .672 & .761 & .849 & .910 & .918 & .930 & .936 & .938 & .935 \\
\hline 20.000 & .618 & .721 & .827 & .904 & .917 & .926 & .937 & .928 & .930 \\
\hline 30.000 & .560 & .668 & .783 & .897 & .923 & .928 & .930 & .925 & .921 \\
\hline 40.000 & .505 & .630 & .768 & .899 & .906 & .914 & .917 & .920 & .914 \\
\hline 50.000 & .516 & .652 & .785 & .900 & .900 & .902 & .912 & .910 & .905 \\
\hline 60.000 & .545 & .674 & .809 & .913 & .916 & .902 & .907 & .912 & .910 \\
\hline 70.000 & .541 & .555 & .810 & .884 & .902 & .900 & .900 & .910 & .901 \\
\hline 80.000 & .490 & .641 & .774 & .874 & .889 & .888 & .911 & .901 & .897 \\
\hline 90.000 & .417 & .588 & .722 & .545 & .879 & .876 & .891 & .893 & .892 \\
\hline 100.000 & .384 & .538 & .678 & .812 & .862 & .865 & .890 & .884 & .885 \\
\hline 110.000 & .321 & .467 & .608 & .761 & .836 & .846 & .865 & .872 & .870 \\
\hline 120.000 & .270 & .409 & .548 & .684 & .773 & .804 & .827 & .829 & .623 \\
\hline 130.000 & .252 & .353 & .484 & .607 & .718 & .756 & .778 & .786 & .774 \\
\hline 140.000 & .261 & .353 & .457 & .580 & .658 & .691 & .729 & .729 & .721 \\
\hline 150.000 & .286 & .343 & .429 & .553 & .576 & .617 & .650 & .650 & .660 \\
\hline 160.000 & .268 & .335 & .401 & .461 & .509 & .564 & .581 & .579 & .576 \\
\hline 170.000 & .268 & .314 & .324 & .379 & .430 & .444 & .486 & .481 & .474 \\
\hline 180.000 & .236 & .275 & .290 & .302 & .303 & .308 & .316 & .315 & .311 \\
\hline 190.000 & .249 & .292 & .335 & .374 & .417 & .460 & .475 & .485 & .498 \\
\hline 200.000 & .278 & .342 & .410 & .471 & .508 & .570 & .584 & .585 & .584 \\
\hline 210.000 & .283 & .369 & .441 & .531 & .583 & .612 & .633 & .652 & .654 \\
\hline 220.000 & .292 & .390 & .489 & .572 & .653 & .691 & .722 & .734 & .739 \\
\hline 230.000 & .280 & .404 & .531 & .648 & .719 & .771 & .778 & .790 & .786 \\
\hline 240.000 & .299 & .449 & .592 & .722 & .800 & .829 & .830 & .849 & .851 \\
\hline 250.000 & .358 & .520 & .670 & .783 & .851 & .870 & .873 & .883 & .878 \\
\hline 260.000 & .421 & .596 & .733 & .846 & .891 & .905 & .896 & .908 & .909 \\
\hline 270.000 & .514 & .665 & .804 & .586 & .912 & .925 & .922 & .931 & .930 \\
\hline 280.000 & .557 & .711 & .847 & .908 & .916 & .930 & .931 & .933 & .938 \\
\hline 290.000 & .590 & .736 & .876 & .910 & .931 & .936 & .931 & .941 & .937 \\
\hline 300.000 & .606 & .738 & .867 & .914 & .926 & .933 & .925 & .941 & .941 \\
\hline 310.000 & .569 & .718 & .839 & .915 & .927 & .939 & .929 & .941 & .944 \\
\hline 320.000 & .547 & .662 & .807 & .917 & .934 & .947 & .925 & .945 & .947 \\
\hline 330.000 & .537 & .659 & .817 & .904 & .921 & .938 & .936 & .939 & .945 \\
\hline 340.000 & .569 & .703 & .842 & .905 & .925 & .942 & .936 & .946 & .948 \\
\hline 350.000 & .630 & .749 & .852 & .907 & .924 & .941 & .931 & .940 & .944 \\
\hline
\end{tabular}


TANGENTIAL WAKE (TESTE ITTC)

$$
9
$$

$\begin{array}{llllllllll}\text { PHI } & .300 & .400 & .500 & .600 & .700 & .800 & .900 & .950 & 1.000\end{array}$

$0.000-.030-.014-.015-.016-.018-.013-.016-.011-.016$

$10.000-.001-.004-.002-.003-.004-.003-.003-.003-.005$

$\begin{array}{llllllllll}20.000 & .018 & .018 & .009 & .012 & .010 & .010 & .009 & .009 & .008\end{array}$

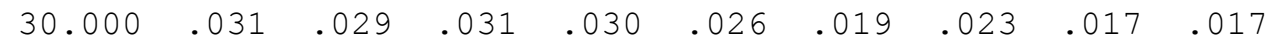

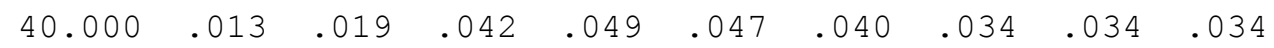

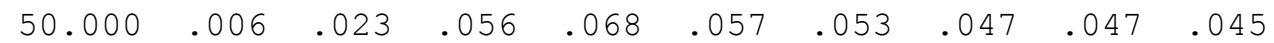

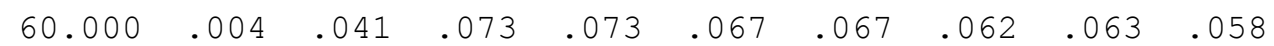

$\begin{array}{llllllllll}70.000 & .021 & .058 & .091 & .097 & .090 & .083 & .080 & .074 & .073\end{array}$

$\begin{array}{llllllllll}80.000 & .032 & .067 & .102 & .113 & .105 & .097 & .087 & .089 & .088\end{array}$

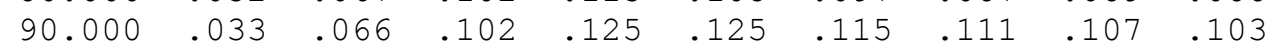

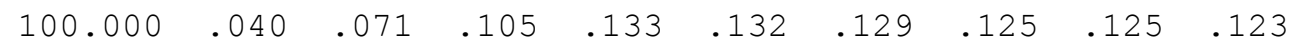

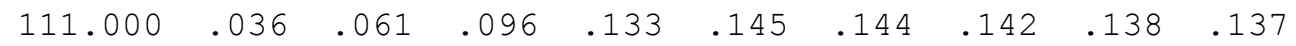

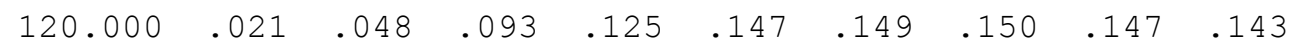

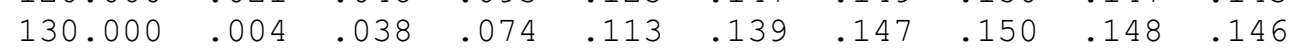

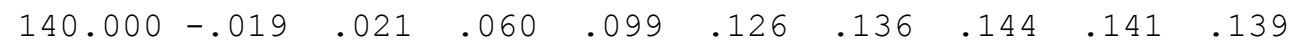

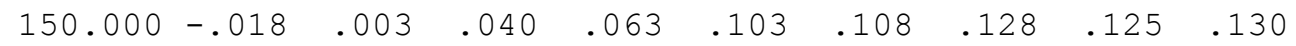

$\begin{array}{llllllllll}160.000 & -.024 & .001 & .025 & .050 & .076 & .086 & .104 & .104 & .096\end{array}$

$\begin{array}{llllllllll}170.000 & -.018 & .008 & .014 & .025 & .044 & .047 & .070 & .071 & .072\end{array}$

$180.000-.017-.007 \quad .006 \quad .004-.002 \quad .000 \quad .001 \quad .014-.002$

$190.000 .010-.007-.021-.031-.042-.053-.043-.052-.062$

$200.000 .018-.004-.022-.042-.065-.072-.096-.086-.091$

$210.000 .021-.004-.029-.061-.082-.094-.096-.108-.110$

$220.000 .017-.018-.051-.081-.103-.115-.120-.124-.122$

$230.000-.028-.034-.073-.100-.124-.130-.126-.129-.127$

$240.000-.028-.060-.090-.119-.150-.132-.131-.133-.130$

$250.000-.042-.068-.100-.129-.133-.135-.128-.126-.120$

$260.000-.046-.076-.108-.126-.132-.127-.121-.119-.118$

$270.000-.046-.085-.116-.128-.123-.116-.112-.105-.105$

$280.000-.050-.084-.115-.118-.111-.103-.094-.098-.089$

$290.000-.038-.083-.099-.107-.104-.095-.097-.084-.081$

$300.000-.032-.073-.101-.096-.081-.081-.076-.073-.072$

$310.000-.018-.055-.079-.087-.075-.071-.064-.066-.061$

$320.000-.005-.039-.070-.074-.067-.059-.055-.052-.054$

$330.000-.030-.048-.058-.057-.059-.052-.045-.044-.043$

$340.000-.027-.049-.044-.043-.036-.039-.034-.034-.034$

$350.000-.035-.029-.030-.031-.029-.050-.026-.026-.026$ 


\section{ANEXO B - ROTINA DE EXECUÇÃO PRÉ-INTEGRAÇÃO}

\section{(MATLAB)}

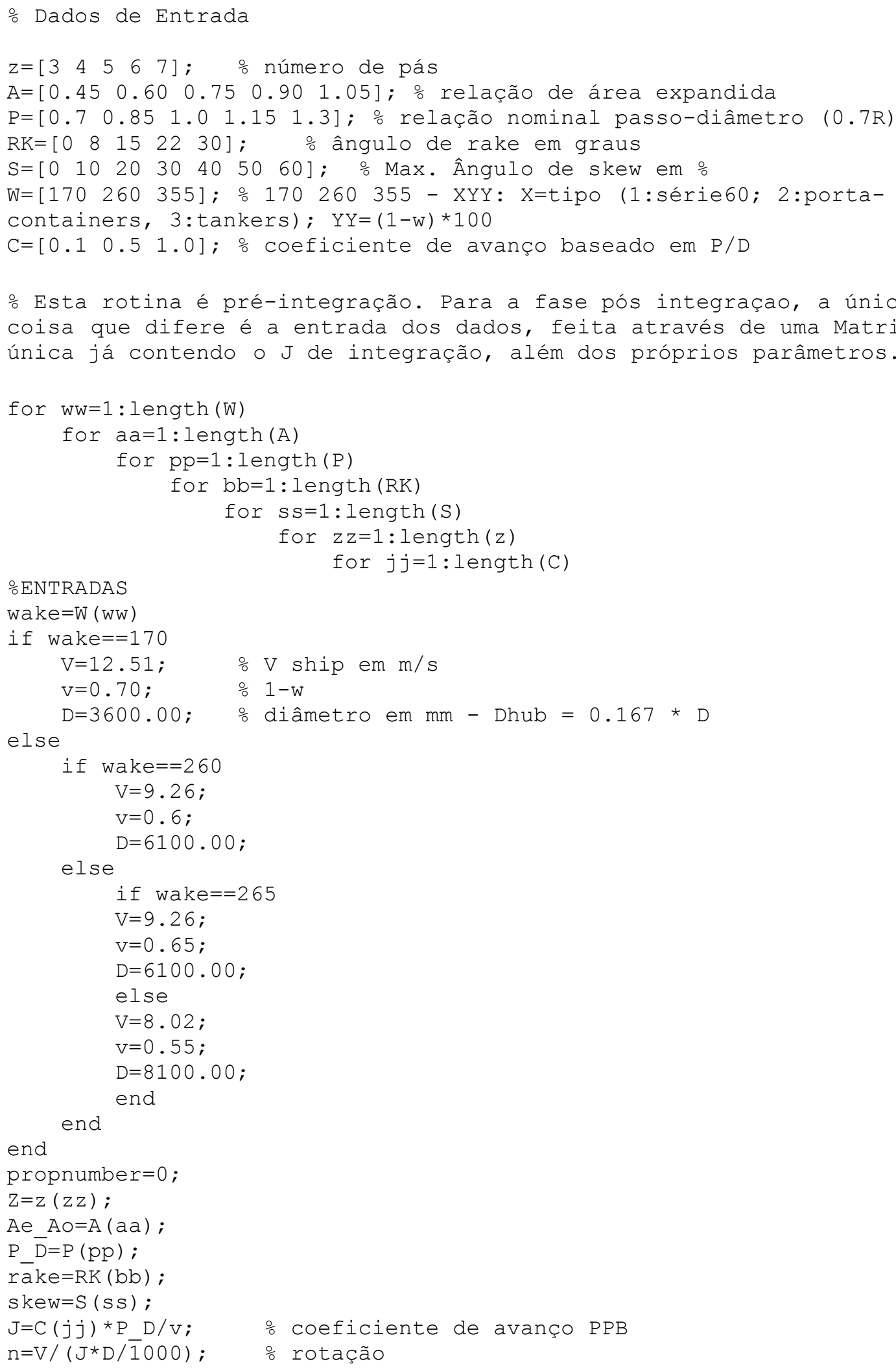


ESTEIRAS

if wake $==170$

$\mathrm{WX}=\left[\begin{array}{llllllllllllll}0.000 & 0.347 & 0.346 & 0.346 & 0.350 & 0.360 & 0.379 & 0.406 & 0.448 & 0.506 & 0.586\end{array}\right.$ $\begin{array}{llllllllllllll}10.000 & 0.352 & 0.353 & 0.363 & 0.387 & 0.431 & 0.508 & 0.644 & 0.796 & 0.849 & 0.858\end{array}$

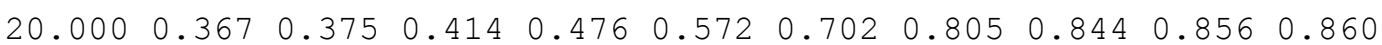
$\begin{array}{llllllllllll}30.000 & 0.390 & 0.405 & 0.471 & 0.564 & 0.682 & 0.783 & 0.834 & 0.852 & 0.858 & 0.862\end{array}$ $\begin{array}{llllllllllll}40.000 & 0.412 & 0.433 & 0.522 & 0.633 & 0.741 & 0.814 & 0.845 & 0.856 & 0.859 & 0.862\end{array}$ $\begin{array}{lllllllllllll}50.000 & 0.431 & 0.458 & 0.563 & 0.678 & 0.773 & 0.827 & 0.849 & 0.857 & 0.860 & 0.862\end{array}$ $\begin{array}{lllllllllllll}60.000 & 0.447 & 0.476 & 0.590 & 0.703 & 0.787 & 0.832 & 0.850 & 0.857 & 0.859 & 0.862\end{array}$ $\begin{array}{lllllllllllll}70.000 & 0.458 & 0.488 & 0.605 & 0.713 & 0.789 & 0.834 & 0.848 & 0.857 & 0.859 & 0.861\end{array}$ $\begin{array}{lllllllllllll}80.000 & 0.462 & 0.494 & 0.608 & 0.711 & 0.783 & 0.826 & 0.843 & 0.856 & 0.858 & 0.860\end{array}$

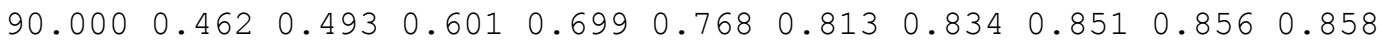

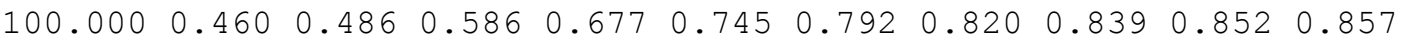

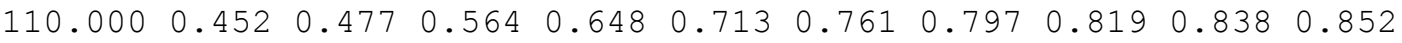

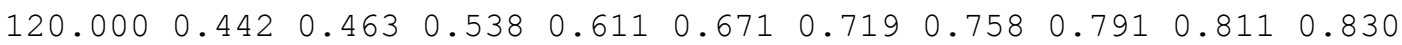

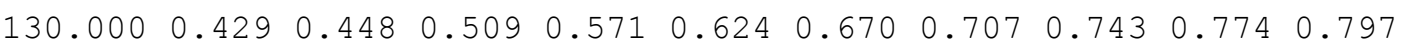

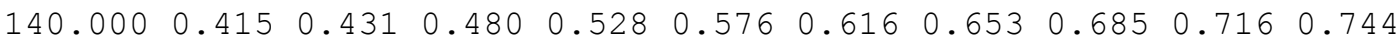

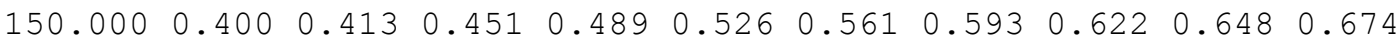

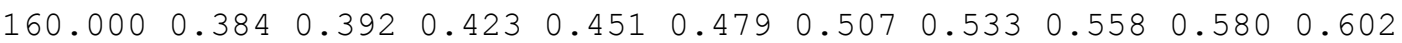
$\begin{array}{llllllllllll}170.000 & 0.372 & 0.376 & 0.391 & 0.410 & 0.429 & 0.449 & 0.467 & 0.485 & 0.501 & 0.517\end{array}$

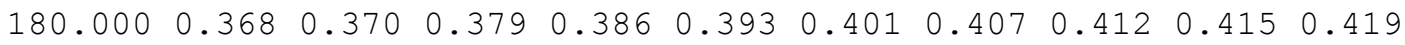

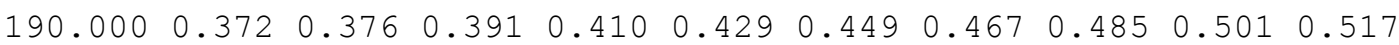
$\begin{array}{llllllllllll}200.000 & 0.384 & 0.392 & 0.423 & 0.451 & 0.479 & 0.507 & 0.533 & 0.558 & 0.580 & 0.602\end{array}$

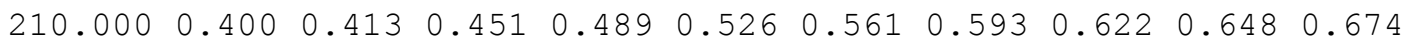

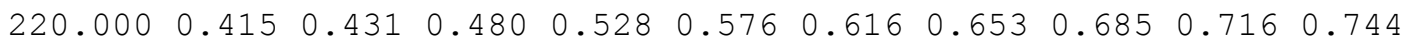

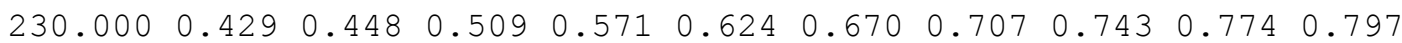
$\begin{array}{lllllllllllll}240.000 & 0.442 & 0.463 & 0.538 & 0.611 & 0.671 & 0.719 & 0.758 & 0.791 & 0.811 & 0.830\end{array}$

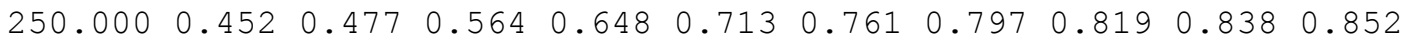
$\begin{array}{lllllllllllll}260.000 & 0.460 & 0.486 & 0.586 & 0.677 & 0.745 & 0.792 & 0.820 & 0.839 & 0.852 & 0.857\end{array}$ $\begin{array}{lllllllllllll}270.000 & 0.462 & 0.493 & 0.601 & 0.699 & 0.768 & 0.813 & 0.834 & 0.851 & 0.856 & 0.858\end{array}$

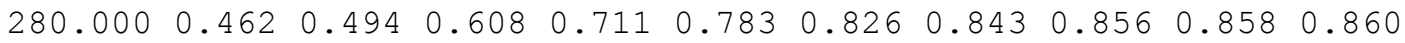

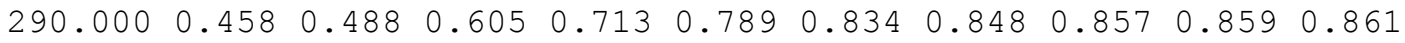

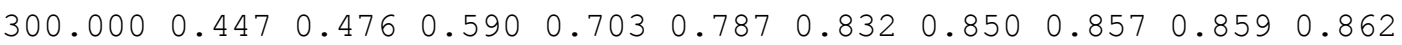
$\begin{array}{llllllllllll}310.000 & 0.431 & 0.458 & 0.563 & 0.678 & 0.773 & 0.827 & 0.849 & 0.857 & 0.860 & 0.862\end{array}$ $\begin{array}{llllllllllll}320.000 & 0.412 & 0.433 & 0.522 & 0.633 & 0.741 & 0.814 & 0.845 & 0.856 & 0.859 & 0.862\end{array}$

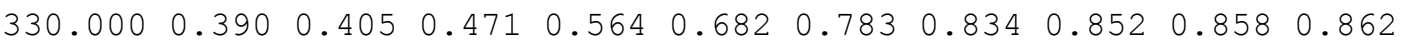
$\begin{array}{lllllllllllll}340.000 & 0.367 & 0.375 & 0.414 & 0.476 & 0.572 & 0.702 & 0.805 & 0.844 & 0.856 & 0.860\end{array}$ $\left.\begin{array}{lllllllllllll}350.000 & 0.352 & 0.353 & 0.363 & 0.387 & 0.431 & 0.508 & 0.644 & 0.796 & 0.849 & 0.858\end{array}\right]$;

$\mathrm{WT}=\left[\begin{array}{llllllllllll}0.000 & 0.000 & 0.000 & 0.000 & 0.000 & 0.000 & 0.000 & 0.000 & 0.000 & 0.000 & 0.000\end{array}\right.$ $10.000-0.014-0.014-0.013-0.012-0.008-0.003 \quad 0.0090 .023 \quad 0.0280 .023$

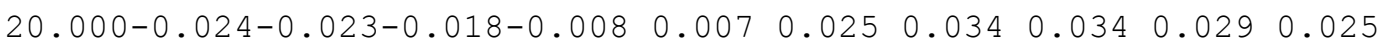

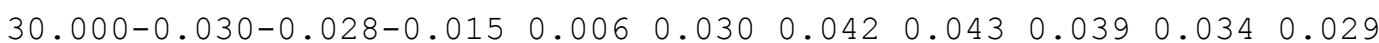
$40.000-0.032-0.027-0.004 \quad 0.026 \quad 0.0460 .053 \quad 0.0490 .043 \quad 0.0390 .035$

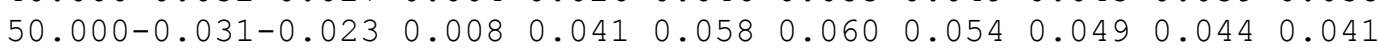
60.000-0.029-0.018 $0.020 \quad 0.053 \quad 0.066 \quad 0.066 \quad 0.061 \quad 0.056 \quad 0.051 \quad 0.047$ $\begin{array}{lllllllll}70.000-0.025-0.014 & 0.029 & 0.062 & 0.073 & 0.074 & 0.068 & 0.064 & 0.058 & 0.054\end{array}$ $80.000-0.022-0.010 \quad 0.034 \quad 0.066 \quad 0.078 \quad 0.0790 .076 \quad 0.071 \quad 0.066 \quad 0.062$ $90.000-0.020-0.007 \quad 0.036 \quad 0.068 \quad 0.082 \quad 0.0850 .083 \quad 0.0790 .075 \quad 0.071$

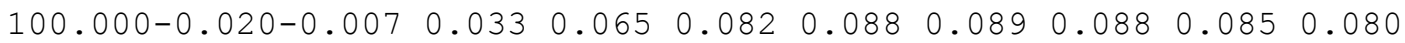

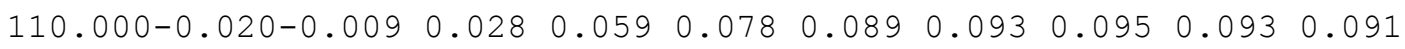

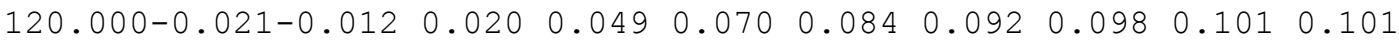

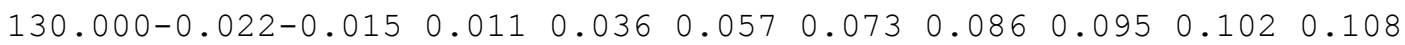

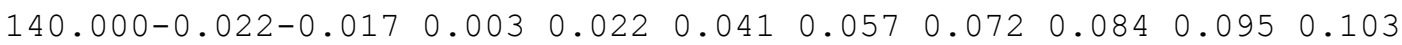
150.000-0.019-0.016-0.003 $0.010 \quad 0.0250 .0390 .053 \quad 0.0650 .077 \quad 0.088$ $160.000-0.016-0.013-0.006 \quad 0.003 \quad 0.0110 .0210 .0310 .042 \quad 0.053 \quad 0.064$

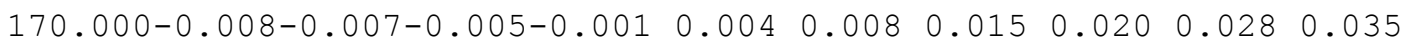
$180.000 \quad 0.000 \quad 0.000 \quad 0.000 \quad 0.000 \quad 0.000 \quad 0.000 \quad 0.000 \quad 0.000 \quad 0.000 \quad 0.000$ $190.000 \quad 0.008 \quad 0.0070 .0050 .001-0.004-0.008-0.015-0.020-0.028-0.035$ 
$200.0000 .0160 .0130 .006-0.003-0.011-0.021-0.031-0.042-0.053-0.064$ $210.0000 .0190 .0160 .003-0.010-0.025-0.039-0.053-0.065-0.077-0.088$ $220.0000 .0220 .017-0.003-0.022-0.041-0.057-0.072-0.084-0.095-0.103$ $230.0000 .0220 .015-0.011-0.036-0.057-0.073-0.086-0.095-0.102-0.108$ $240.0000 .0210 .012-0.020-0.049-0.070-0.084-0.092-0.098-0.101-0.101$ $250.0000 .0200 .009-0.028-0.059-0.078-0.089-0.093-0.095-0.093-0.091$ $260.0000 .0200 .007-0.033-0.065-0.082-0.088-0.089-0.088-0.085-0.080$ $270.0000 .0200 .007-0.036-0.068-0.082-0.085-0.083-0.079-0.075-0.071$ $280.0000 .0220 .010-0.034-0.066-0.078-0.079-0.076-0.071-0.066-0.062$ $290.0000 .0250 .014-0.029-0.062-0.073-0.074-0.068-0.064-0.058-0.054$ $300.0000 .0290 .018-0.020-0.053-0.066-0.066-0.061-0.056-0.051-0.047$ $310.0000 .0310 .023-0.008-0.041-0.058-0.060-0.054-0.049-0.044-0.041$ $320.0000 .0320 .0270 .004-0.026-0.046-0.053-0.049-0.043-0.039-0.035$ $330.0000 .0300 .0280 .015-0.006-0.030-0.042-0.043-0.039-0.034-0.029$ $340.000 \quad 0.0240 .0230 .0180 .008-0.007-0.025-0.034-0.034-0.029-0.025$ $350.000 \quad 0.0140 .0140 .0130 .0120 .008 \quad 0.003-0.009-0.023-0.028-0.023]$;

$\mathrm{WR}=\left[\begin{array}{llllllllllll}0.000 & 0.064 & 0.064 & 0.060 & 0.056 & 0.053 & 0.050 & 0.049 & 0.049 & 0.048 & 0.041\end{array}\right.$ $10.000 \quad 0.0620 .0600 .0530 .0430 .0300 .012-0.016-0.040-0.047-0.045$ $20.000 \quad 0.0530 .0490 .0340 .014-0.011-0.035-0.049-0.051-0.049-0.048$ $30.000 \quad 0.0400 .0340 .013-0.013-0.037-0.049-0.053-0.052-0.050-0.049$ $40.0000 .0270 .019-0.005-0.029-0.045-0.052-0.052-0.051-0.050-0.049$ $50.0000 .0150 .007-0.016-0.036-0.045-0.049-0.050-0.050-0.049-0.049$ $60.0000 .006-0.001-0.021-0.035-0.041-0.045-0.046-0.047-0.047-0.047$ $70.000-0.002-0.006-0.021-0.029-0.035-0.039-0.041-0.042-0.044-0.045$ $80.000-0.007-0.010-0.018-0.022-0.027-0.030-0.034-0.038-0.040-0.041$ 90.000-0.011-0.012-0.014-0.014-0.017-0.021-0.026-0.030-0.034-0.037 $100.000-0.016-0.015-0.009-0.006-0.006-0.010-0.016-0.020-0.026-0.030$ $110.000-0.020-0.018-0.007 \quad 0.001 \quad 0.004 \quad 0.002-0.003-0.008-0.015-0.021$ $120.000-0.026-0.022-0.008 \quad 0.004 \quad 0.0110 .013 \quad 0.010 \quad 0.006-0.001-0.007$ $130.000-0.032-0.029-0.013 \quad 0.002 \quad 0.0120 .018 \quad 0.0200 .0190 .0150 .010$ 140.000-0.041-0.037-0.022-0.007 $0.006 \quad 0.017 \quad 0.023 \quad 0.027 \quad 0.0280 .026$ 150.000-0.051-0.047-0.034-0.021-0.007 $0.006 \quad 0.016 \quad 0.0230 .0290 .033$ $160.000-0.061-0.058-0.048-0.038-0.027-0.015-0.0040 .0070 .0170 .025$ $170.000-0.067-0.066-0.063-0.055-0.047-0.039-0.029-0.018-0.0060 .005$ $180.000-0.069-0.069-0.068-0.064-0.061-0.054-0.047-0.038-0.027-0.014$ $190.000-0.067-0.066-0.063-0.055-0.047-0.039-0.029-0.018-0.0060 .005$ 200.000-0.061-0.058-0.048-0.038-0.027-0.015-0.004 0.0070 .0170 .025 210.000-0.051-0.047-0.034-0.021-0.007 $0.006 \quad 0.0160 .0230 .0290 .033$ 220.000-0.041-0.037-0.022-0.007 $0.006 \quad 0.017 \quad 0.023 \quad 0.027 \quad 0.028 \quad 0.026$ 230.000-0.032-0.029-0.013 $0.002 \quad 0.0120 .0180 .020 \quad 0.0190 .0150 .010$ 240.000-0.026-0.022-0.008 $0.004 \quad 0.0110 .0130 .010 \quad 0.006-0.001-0.007$ $250.000-0.020-0.018-0.007 \quad 0.001 \quad 0.004 \quad 0.002-0.003-0.008-0.015-0.021$ $260.000-0.016-0.015-0.009-0.006-0.006-0.010-0.016-0.020-0.026-0.030$ $270.000-0.011-0.012-0.014-0.014-0.017-0.021-0.026-0.030-0.034-0.037$ $280.000-0.007-0.010-0.018-0.022-0.027-0.030-0.034-0.038-0.040-0.041$ $290.000-0.002-0.006-0.021-0.029-0.035-0.039-0.041-0.042-0.044-0.045$ $300.0000 .006-0.001-0.021-0.035-0.041-0.045-0.046-0.047-0.047-0.047$ $310.0000 .0150 .007-0.016-0.036-0.045-0.049-0.050-0.050-0.049-0.049$ $320.0000 .0270 .019-0.005-0.029-0.045-0.052-0.052-0.051-0.050-0.049$ $330.000 \quad 0.040 \quad 0.0340 .013-0.013-0.037-0.049-0.053-0.052-0.050-0.049$ $340.000 \quad 0.053 \quad 0.0490 .0340 .014-0.011-0.035-0.049-0.051-0.049-0.048$ $350.000 \quad 0.0620 .0600 .0530 .0430 .0300 .012-0.016-0.040-0.047-0.045]$;

else 


\section{if wake $==260$}

$\mathrm{WX}=\left[\begin{array}{llllllllllll}0.000 & 0.093 & 0.122 & 0.203 & 0.292 & 0.423 & 0.587 & 0.766 & 0.900 & 0.938 & 0.951\end{array}\right.$ $\begin{array}{llllllllllll}10.000 & 0.084 & 0.109 & 0.164 & 0.212 & 0.321 & 0.520 & 0.746 & 0.888 & 0.938 & 0.950\end{array}$

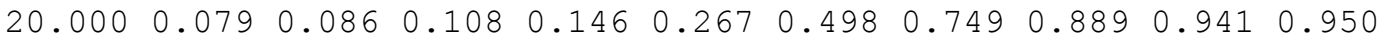

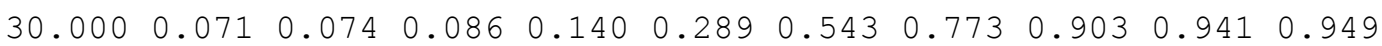
$\begin{array}{lllllllllllll}40.000 & 0.089 & 0.087 & 0.099 & 0.162 & 0.329 & 0.571 & 0.786 & 0.905 & 0.939 & 0.948\end{array}$ $\begin{array}{llllllllllll}50.000 & 0.115 & 0.116 & 0.137 & 0.202 & 0.350 & 0.592 & 0.803 & 0.908 & 0.937 & 0.947\end{array}$ $\begin{array}{lllllllllllll}60.000 & 0.153 & 0.166 & 0.189 & 0.236 & 0.358 & 0.605 & 0.813 & 0.906 & 0.937 & 0.946\end{array}$ $\begin{array}{lllllllllllll}70.000 & 0.198 & 0.213 & 0.229 & 0.257 & 0.371 & 0.603 & 0.807 & 0.906 & 0.937 & 0.942\end{array}$ $\begin{array}{llllllllllll}80.000 & 0.235 & 0.247 & 0.259 & 0.272 & 0.372 & 0.589 & 0.782 & 0.893 & 0.933 & 0.941\end{array}$

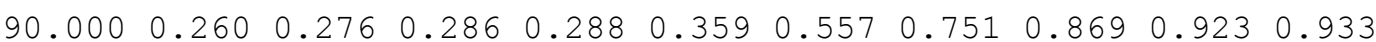

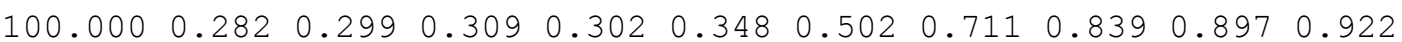

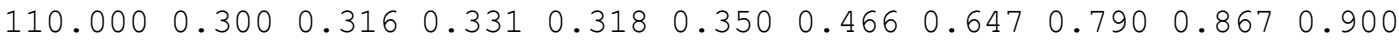

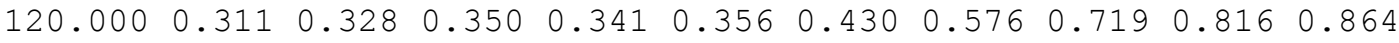
$\begin{array}{llllllllllll}130.000 & 0.317 & 0.335 & 0.364 & 0.366 & 0.371 & 0.416 & 0.517 & 0.639 & 0.741 & 0.802\end{array}$

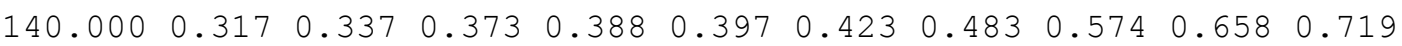

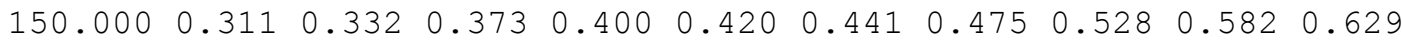

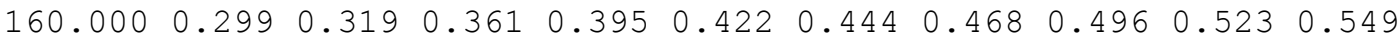

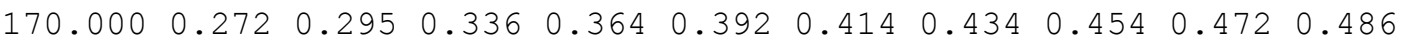

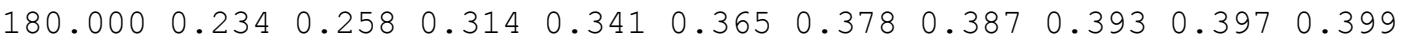

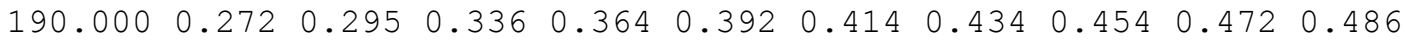
$\begin{array}{llllllllllll}200.000 & 0.299 & 0.319 & 0.361 & 0.395 & 0.422 & 0.444 & 0.468 & 0.496 & 0.523 & 0.549\end{array}$ $\begin{array}{llllllllllll}210.000 & 0.311 & 0.332 & 0.373 & 0.400 & 0.420 & 0.441 & 0.475 & 0.528 & 0.582 & 0.629\end{array}$ $\begin{array}{lllllllllllll}220.000 & 0.317 & 0.337 & 0.373 & 0.388 & 0.397 & 0.423 & 0.483 & 0.574 & 0.658 & 0.719\end{array}$ $\begin{array}{lllllllllllll}230.000 & 0.317 & 0.335 & 0.364 & 0.366 & 0.371 & 0.416 & 0.517 & 0.639 & 0.741 & 0.802\end{array}$

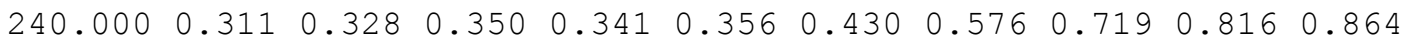
$\begin{array}{lllllllllllll}250.000 & 0.300 & 0.316 & 0.331 & 0.318 & 0.350 & 0.466 & 0.647 & 0.790 & 0.867 & 0.900\end{array}$ $\begin{array}{lllllllllllll}260.000 & 0.282 & 0.299 & 0.309 & 0.302 & 0.348 & 0.502 & 0.711 & 0.839 & 0.897 & 0.922\end{array}$ $\begin{array}{llllllllllll}270.000 & 0.260 & 0.276 & 0.286 & 0.288 & 0.359 & 0.557 & 0.751 & 0.869 & 0.923 & 0.933\end{array}$

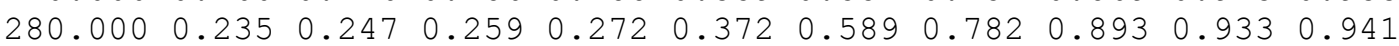

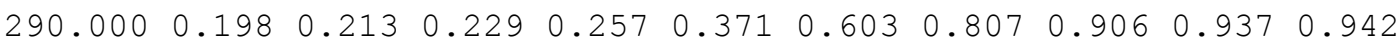
$\begin{array}{llllllllllll}300.000 & 0.153 & 0.166 & 0.189 & 0.236 & 0.358 & 0.605 & 0.813 & 0.906 & 0.937 & 0.946\end{array}$ $\begin{array}{llllllllllll}310.000 & 0.115 & 0.116 & 0.137 & 0.202 & 0.350 & 0.592 & 0.803 & 0.908 & 0.937 & 0.947\end{array}$ $\begin{array}{llllllllllll}320.000 & 0.089 & 0.087 & 0.099 & 0.162 & 0.329 & 0.571 & 0.786 & 0.905 & 0.939 & 0.948\end{array}$

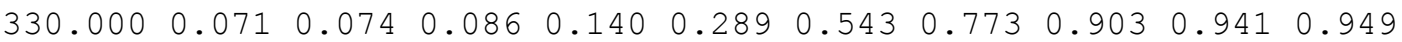
$\begin{array}{llllllllllll}340.000 & 0.079 & 0.086 & 0.108 & 0.146 & 0.267 & 0.498 & 0.749 & 0.889 & 0.941 & 0.950\end{array}$ $\begin{array}{llllllllllll}350.000 & 0.084 & 0.109 & 0.164 & 0.212 & 0.321 & 0.520 & 0.746 & 0.888 & 0.938 & 0.950\end{array}$;

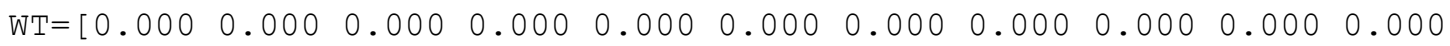
$10.000 \quad 0.0120 .0170 .017-0.001-0.012-0.0100 .003 \quad 0.016 \quad 0.0210 .019$

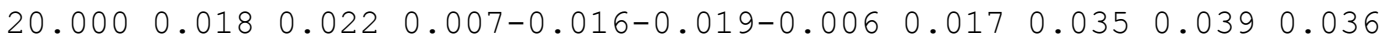

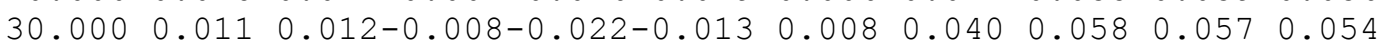
40.000-0.006-0.007-0.024-0.018 $0.003 \quad 0.032 \quad 0.063 \quad 0.077 \quad 0.076 \quad 0.072$ 50.000-0.028-0.030-0.034-0.009 $0.023 \quad 0.053 \quad 0.087 \quad 0.097 \quad 0.096 \quad 0.091$ 60.000-0.054-0.055-0.043 $0.000 \quad 0.040 \quad 0.0790 .1110 .1190 .116 \quad 0.110$ 70.000-0.079-0.079-0.050 $0.007 \quad 0.053 \quad 0.100 \quad 0.132 \quad 0.141 \quad 0.137 \quad 0.130$

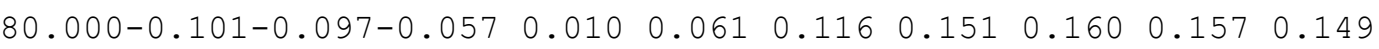
90.000-0.119-0.114-0.064 $0.007 \quad 0.062 \quad 0.122 \quad 0.164 \quad 0.1790 .176 \quad 0.169$

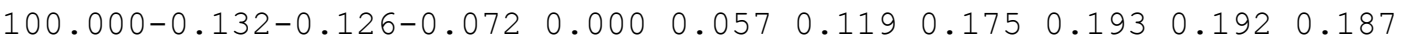

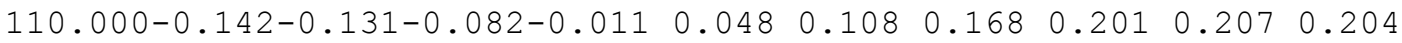

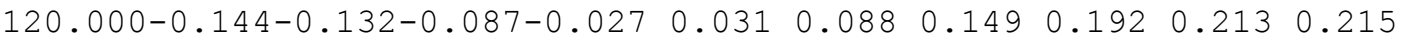

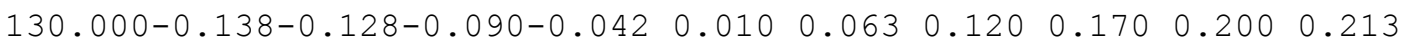

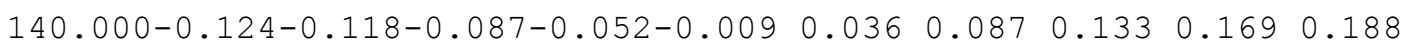
150.000-0.102-0.099-0.078-0.055-0.024 $0.0120 .053 \quad 0.0910 .1230 .147$ 160.000-0.072-0.071-0.061-0.047-0.028-0.003 0.0240 .0510 .0740 .096 170.000-0.035-0.036-0.032-0.027-0.019-0.007 $0.006 \quad 0.0210 .0340 .047$

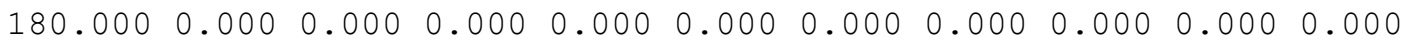
$190.000 \quad 0.0350 .0360 .0320 .0270 .0190 .007-0.006-0.021-0.034-0.047$ $200.000 \quad 0.072 \quad 0.0710 .0610 .0470 .028 \quad 0.003-0.024-0.051-0.074-0.096$ $210.000 \quad 0.1020 .0990 .0780 .0550 .024-0.012-0.053-0.091-0.123-0.147$ 
$220.000 \quad 0.1240 .1180 .0870 .052 \quad 0.009-0.036-0.087-0.133-0.169-0.188$ $230.000 \quad 0.138 \quad 0.128 \quad 0.090 \quad 0.042-0.010-0.063-0.120-0.170-0.200-0.213$ $240.000 \quad 0.144 \quad 0.1320 .087 \quad 0.027-0.031-0.088-0.149-0.192-0.213-0.215$ $250.0000 .1420 .1310 .0820 .011-0.048-0.108-0.168-0.201-0.207-0.204$ $260.000 \quad 0.1320 .1260 .0720 .000-0.057-0.119-0.175-0.193-0.192-0.187$ $270.000 \quad 0.1190 .1140 .064-0.007-0.062-0.122-0.164-0.179-0.176-0.169$ $280.0000 .1010 .0970 .057-0.010-0.061-0.116-0.151-0.160-0.157-0.149$ $290.000 \quad 0.0790 .0790 .050-0.007-0.053-0.100-0.132-0.141-0.137-0.130$ $300.000 \quad 0.0540 .0550 .0430 .000-0.040-0.079-0.111-0.119-0.116-0.110$ $310.000 \quad 0.028 \quad 0.030 \quad 0.0340 .009-0.023-0.053-0.087-0.097-0.096-0.091$ $320.000 \quad 0.006 \quad 0.0070 .0240 .018-0.003-0.032-0.063-0.077-0.076-0.072$ $330.000-0.011-0.0120 .0080 .0220 .013-0.008-0.040-0.058-0.057-0.054$ $340.000-0.018-0.022-0.0070 .0160 .0190 .006-0.017-0.035-0.039-0.036$ 350.000-0.012-0.017-0.0170.0010.012 0.010-0.003-0.016-0.021-0.019];

$W R=[0.000-0.027-0.044-0.086-0.104-0.102-0.090-0.085-0.094-0.101-0.103$ $10.000-0.020-0.032-0.057-0.053-0.050-0.062-0.080-0.092-0.099-0.101$ $20.0000 .003-0.003-0.002-0.002-0.021-0.048-0.072-0.091-0.097-0.099$ $30.000 \quad 0.028 \quad 0.0280 .0330 .020-0.012-0.043-0.072-0.090-0.095-0.097$ $40.000 \quad 0.0490 .0510 .0500 .026-0.009-0.043-0.070-0.085-0.090-0.093$ $50.000 \quad 0.0610 .0630 .0550 .025-0.008-0.040-0.063-0.078-0.084-0.088$ $60.000 \quad 0.0650 .0670 .0550 .025-0.005-0.032-0.055-0.069-0.077-0.081$ $\begin{array}{lllllll}70.000 & 0.061 & 0.063 & 0.049 & 0.025 & 0.001-0.023-0.044-0.059-0.067-0.073\end{array}$ $80.000 \quad 0.048 \quad 0.0490 .0380 .0240 .005-0.012-0.030-0.046-0.056-0.062$ $90.000 \quad 0.027 \quad 0.0290 .0240 .0190 .009-0.001-0.013-0.029-0.041-0.050$ $100.000 \quad 0.001 \quad 0.003 \quad 0.004 \quad 0.0100 .0110 .007 \quad 0.002-0.010-0.024-0.034$ $110.000-0.030-0.028-0.021-0.0040 .007 \quad 0.0120 .0130 .008-0.003-0.016$ $120.000-0.064-0.061-0.050-0.028-0.0050 .0090 .0190 .0220 .0180 .006$

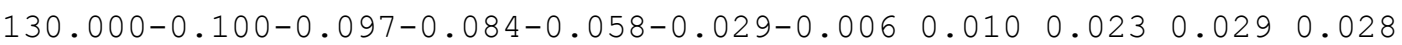
$140.000-0.137-0.134-0.121-0.096-0.067-0.039-0.0140 .0080 .0230 .030$ $150.000-0.170-0.171-0.160-0.140-0.114-0.085-0.057-0.029-0.0050 .013$ $160.000-0.197-0.201-0.199-0.184-0.164-0.140-0.113-0.084-0.057-0.031$ $170.000-0.208-0.219-0.231-0.228-0.215-0.196-0.173-0.147-0.119-0.090$ $180.000-0.202-0.217-0.240-0.242-0.240-0.228-0.210-0.188-0.162-0.136$ $190.000-0.208-0.219-0.231-0.228-0.215-0.196-0.173-0.147-0.119-0.090$ $200.000-0.197-0.201-0.199-0.184-0.164-0.140-0.113-0.084-0.057-0.031$ $210.000-0.170-0.171-0.160-0.140-0.114-0.085-0.057-0.029-0.0050 .013$ 220.000-0.137-0.134-0.121-0.096-0.067-0.039-0.014 $0.008 \quad 0.023 \quad 0.030$ 230.000-0.100-0.097-0.084-0.058-0.029-0.006 $0.010 \quad 0.0230 .0290 .028$ 240.000-0.064-0.061-0.050-0.028-0.005 0.0090 .0190 .0220 .0180 .006 250.000-0.030-0.028-0.021-0.004 $0.007 \quad 0.0120 .0130 .008-0.003-0.016$ $260.000 \quad 0.001 \quad 0.003 \quad 0.004 \quad 0.0100 .0110 .007 \quad 0.002-0.010-0.024-0.034$ $270.000 \quad 0.027 \quad 0.0290 .0240 .0190 .009-0.001-0.013-0.029-0.041-0.050$ $280.000 \quad 0.048 \quad 0.0490 .0380 .0240 .005-0.012-0.030-0.046-0.056-0.062$ $290.000 \quad 0.0610 .0630 .0490 .0250 .001-0.023-0.044-0.059-0.067-0.073$ $300.000 \quad 0.0650 .0670 .0550 .025-0.005-0.032-0.055-0.069-0.077-0.081$ $310.000 \quad 0.0610 .0630 .0550 .025-0.008-0.040-0.063-0.078-0.084-0.088$ $320.000 \quad 0.0490 .0510 .0500 .026-0.009-0.043-0.070-0.085-0.090-0.093$ $330.000 \quad 0.028 \quad 0.0280 .0330 .020-0.012-0.043-0.072-0.090-0.095-0.097$ $340.0000 .003-0.003-0.002-0.002-0.021-0.048-0.072-0.091-0.097-0.099$ 350.000-0.020-0.032-0.057-0.053-0.050-0.062-0.080-0.092-0.099-0.101];

else 
$W X=\left[\begin{array}{lllllllllllll}0.000 & 0.330 & 0.326 & 0.314 & 0.301 & 0.288 & 0.275 & 0.263 & 0.249 & 0.236 & 0.339\end{array}\right.$ $\begin{array}{llllllllllll}10.000 & 0.331 & 0.329 & 0.318 & 0.306 & 0.293 & 0.279 & 0.262 & 0.248 & 0.368 & 0.808\end{array}$ $\begin{array}{lllllllllllll}20.000 & 0.337 & 0.335 & 0.330 & 0.318 & 0.292 & 0.253 & 0.261 & 0.470 & 0.817 & 1.045\end{array}$ $\begin{array}{llllllllllll}30.000 & 0.344 & 0.346 & 0.342 & 0.309 & 0.255 & 0.279 & 0.465 & 0.753 & 0.991 & 1.108\end{array}$ $\begin{array}{llllllllllll}40.000 & 0.355 & 0.358 & 0.347 & 0.282 & 0.266 & 0.372 & 0.596 & 0.845 & 1.033 & 1.129\end{array}$ $\begin{array}{lllllllllllll}50.000 & 0.364 & 0.367 & 0.342 & 0.270 & 0.288 & 0.415 & 0.631 & 0.875 & 1.054 & 1.141\end{array}$ $\begin{array}{lllllllllllll}60.000 & 0.373 & 0.376 & 0.337 & 0.268 & 0.289 & 0.423 & 0.636 & 0.866 & 1.032 & 1.124\end{array}$ $\begin{array}{lllllllllllll}70.000 & 0.380 & 0.382 & 0.335 & 0.268 & 0.292 & 0.399 & 0.592 & 0.824 & 0.991 & 1.095\end{array}$

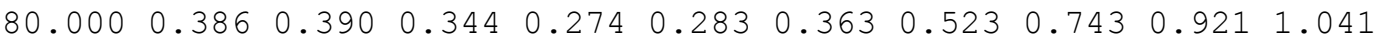

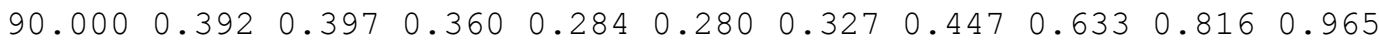

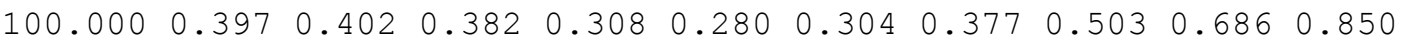

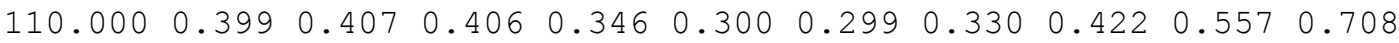

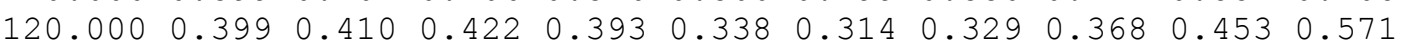

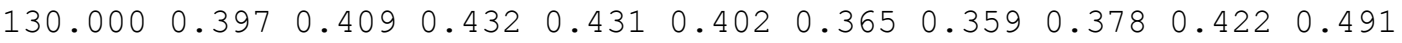

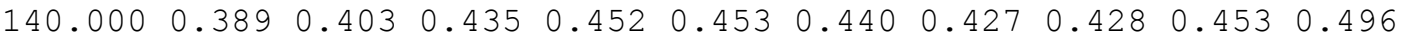
$\begin{array}{llllllllllll}150.000 & 0.380 & 0.392 & 0.426 & 0.453 & 0.473 & 0.485 & 0.491 & 0.500 & 0.513 & 0.534\end{array}$

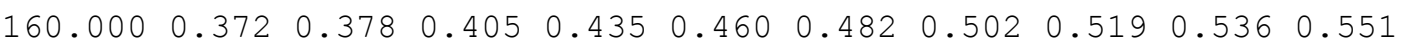

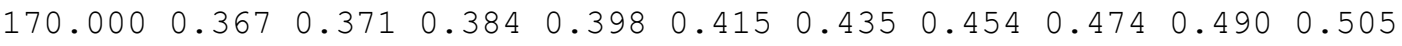
$\begin{array}{llllllllllll}180.000 & 0.365 & 0.368 & 0.377 & 0.384 & 0.390 & 0.397 & 0.402 & 0.406 & 0.409 & 0.410\end{array}$

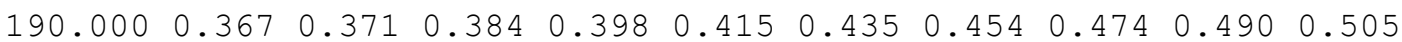

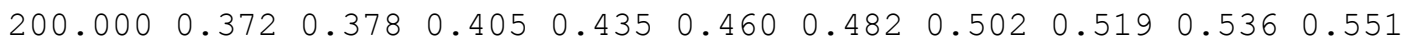

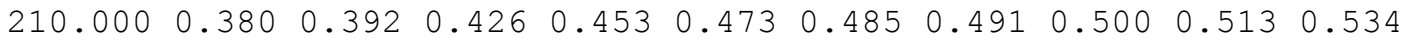

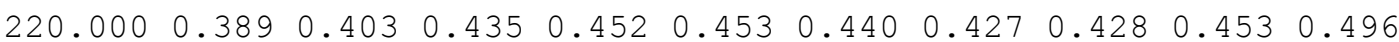
$\begin{array}{lllllllllll}230.000 & 0.397 & 0.409 & 0.432 & 0.431 & 0.402 & 0.365 & 0.359 & 0.378 & 0.422 & 0.491\end{array}$

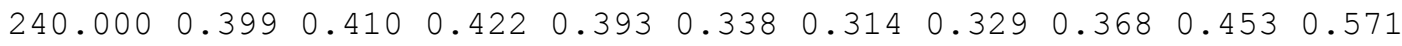
$\begin{array}{llllllllllll}250.000 & 0.399 & 0.407 & 0.406 & 0.346 & 0.300 & 0.299 & 0.330 & 0.422 & 0.557 & 0.708\end{array}$ $\begin{array}{lllllllllllll}260.000 & 0.397 & 0.402 & 0.382 & 0.308 & 0.280 & 0.304 & 0.377 & 0.503 & 0.686 & 0.850\end{array}$

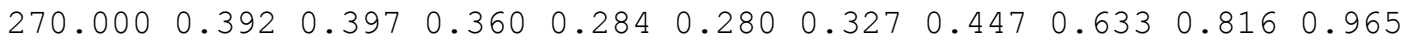

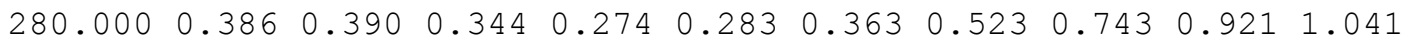

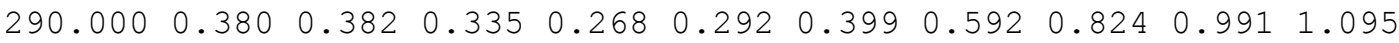
$\begin{array}{lllllllllll}300.000 & 0.373 & 0.376 & 0.337 & 0.268 & 0.289 & 0.423 & 0.636 & 0.866 & 1.032 & 1.124\end{array}$ $\begin{array}{llllllllllll}310.000 & 0.364 & 0.367 & 0.342 & 0.270 & 0.288 & 0.415 & 0.631 & 0.875 & 1.054 & 1.141\end{array}$

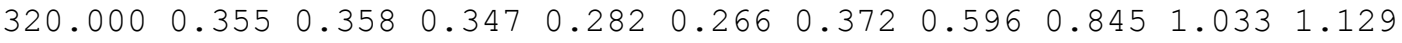

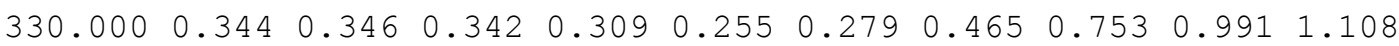
$\begin{array}{lllllllllllll}340.000 & 0.337 & 0.335 & 0.330 & 0.318 & 0.292 & 0.253 & 0.261 & 0.470 & 0.817 & 1.045\end{array}$ $\left.\begin{array}{lllllllllll}350.000 & 0.331 & 0.329 & 0.318 & 0.306 & 0.293 & 0.279 & 0.262 & 0.248 & 0.368 & 0.808\end{array}\right]$;

$\mathrm{WT}=\left[\begin{array}{lllllllllll}0.000 & 0.000 & 0.000 & 0.000 & 0.000 & 0.000 & 0.000 & 0.000 & 0.000 & 0.000 & 0.000\end{array}\right.$ $10.000-0.063-0.063-0.063-0.058-0.047-0.025 \quad 0.004 \quad 0.0350 .0680 .097$ 20.000-0.122-0.120-0.115-0.101-0.069-0.004 $0.076 \quad 0.1410 .166 \quad 0.155$ 30.000-0.172-0.168-0.149-0.110-0.024 $0.075 \quad 0.1550 .1790 .172 \quad 0.158$

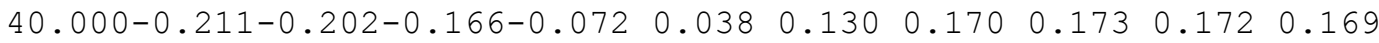
50.000-0.240-0.225-0.160-0.031 $0.073 \quad 0.139 \quad 0.164 \quad 0.174 \quad 0.185 \quad 0.187$ 60.000-0.259-0.241-0.149-0.009 $0.084 \quad 0.134 \quad 0.161 \quad 0.183 \quad 0.199 \quad 0.203$

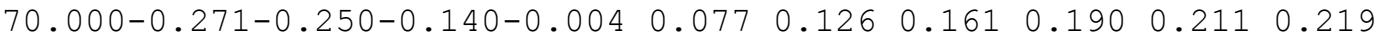

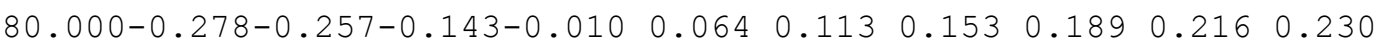

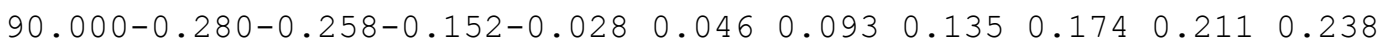

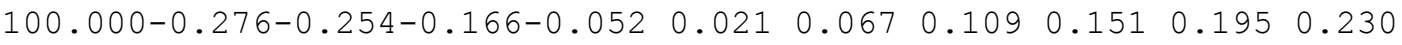

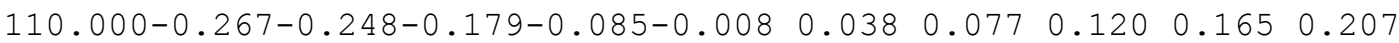
$120.000-0.251-0.236-0.182-0.113-0.042 \quad 0.010 \quad 0.047 \quad 0.0850 .127 \quad 0.172$ $130.000-0.230-0.216-0.175-0.128-0.073-0.022 \quad 0.018 \quad 0.0550 .093 \quad 0.132$ $140.000-0.200-0.190-0.161-0.128-0.092-0.050-0.0090 .0290 .0650 .102$ 150.000-0.161-0.155-0.135-0.114-0.089-0.060-0.0290.004 0.0390.073 $160.000-0.113-0.110-0.098-0.085-0.071-0.052-0.031-0.0080 .0180 .046$ $170.000-0.058-0.056-0.052-0.047-0.039-0.030-0.018-0.0050 .0090 .025$

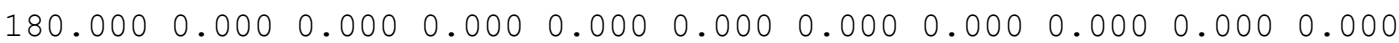

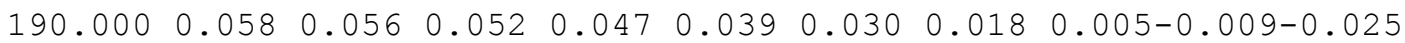

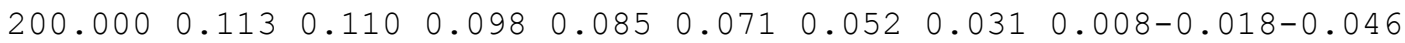

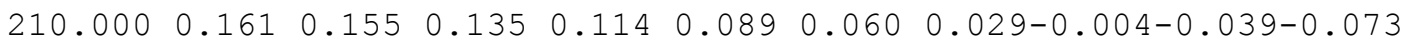

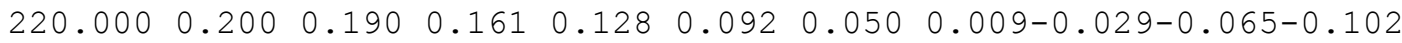
$230.000 \quad 0.230 \quad 0.2160 .175 \quad 0.128 \quad 0.073 \quad 0.022-0.018-0.055-0.093-0.132$ 
$240.000 \quad 0.2510 .2360 .1820 .1130 .042-0.010-0.047-0.085-0.127-0.172$ $250.000 \quad 0.267 \quad 0.248 \quad 0.179 \quad 0.085 \quad 0.008-0.038-0.077-0.120-0.165-0.207$ $260.000 \quad 0.2760 .2540 .1660 .052-0.021-0.067-0.109-0.151-0.195-0.230$ $270.000 \quad 0.280 \quad 0.2580 .1520 .028-0.046-0.093-0.135-0.174-0.211-0.238$ $280.000 \quad 0.278 \quad 0.257 \quad 0.143 \quad 0.010-0.064-0.113-0.153-0.189-0.216-0.230$ $290.000 \quad 0.271 \quad 0.250 \quad 0.1400 .004-0.077-0.126-0.161-0.190-0.211-0.219$ $300.000 \quad 0.2590 .2410 .1490 .009-0.084-0.134-0.161-0.183-0.199-0.203$ $310.000 \quad 0.240 \quad 0.2250 .1600 .031-0.073-0.139-0.164-0.174-0.185-0.187$ $320.000 \quad 0.2110 .2020 .1660 .072-0.038-0.130-0.170-0.173-0.172-0.169$ $330.000 \quad 0.172 \quad 0.1680 .1490 .1100 .024-0.075-0.155-0.179-0.172-0.158$ $340.000 \quad 0.122 \quad 0.120 \quad 0.1150 .1010 .0690 .004-0.076-0.141-0.166-0.155$ $350.000 \quad 0.0630 .0630 .0630 .0580 .0470 .025-0.004-0.035-0.068-0.097]$;

$\mathrm{WR}=\left[\begin{array}{llllllllllll}0.000 & 0.343 & 0.342 & 0.334 & 0.325 & 0.306 & 0.278 & 0.236 & 0.182 & 0.127 & 0.088\end{array}\right.$

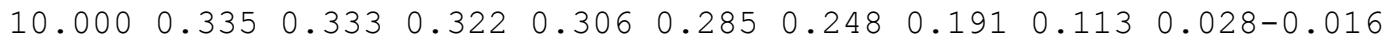
$20.000 \quad 0.313 \quad 0.308 \quad 0.284 \quad 0.255 \quad 0.207 \quad 0.1180 .013-0.062-0.081-0.080$ $30.000 \quad 0.278 \quad 0.267 \quad 0.230 \quad 0.1720 .065-0.034-0.097-0.109-0.105-0.100$ $40.000 \quad 0.2330 .2200 .1720 .081-0.012-0.073-0.094-0.098-0.102-0.105$ $50.000 \quad 0.1830 .1690 .1150 .034-0.026-0.056-0.069-0.081-0.092-0.098$ $60.000 \quad 0.1320 .120 \quad 0.0730 .017-0.016-0.033-0.047-0.063-0.075-0.084$ $70.000 \quad 0.083 \quad 0.073 \quad 0.042 \quad 0.0140 .000-0.012-0.025-0.039-0.052-0.063$ $80.000 \quad 0.033 \quad 0.028 \quad 0.016 \quad 0.0130 .010 \quad 0.005-0.003-0.013-0.025-0.037$ 90.000-0.016-0.017-0.012 $0.007 \quad 0.016 \quad 0.0180 .0180 .0120 .004-0.007$

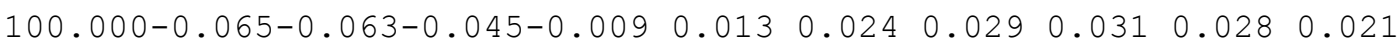

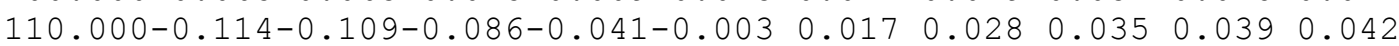

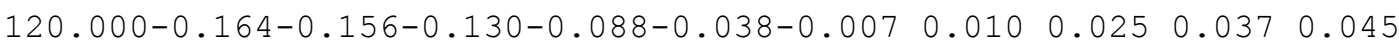
$130.000-0.212-0.204-0.177-0.143-0.098-0.054-0.025-0.0050 .0100 .025$ $140.000-0.259-0.251-0.225-0.198-0.165-0.126-0.090-0.060-0.037-0.018$ $150.000-0.301-0.296-0.274-0.251-0.228-0.200-0.172-0.144-0.115-0.090$ $160.000-0.333-0.331-0.320-0.303-0.284-0.267-0.246-0.224-0.200-0.175$ $170.000-0.352-0.352-0.351-0.346-0.337-0.322-0.305-0.285-0.265-0.242$ $180.000-0.359-0.360-0.360-0.360-0.356-0.348-0.338-0.323-0.304-0.280$ $190.000-0.352-0.352-0.351-0.346-0.337-0.322-0.305-0.285-0.265-0.242$ $200.000-0.333-0.331-0.320-0.303-0.284-0.267-0.246-0.224-0.200-0.175$ $210.000-0.301-0.296-0.274-0.251-0.228-0.200-0.172-0.144-0.115-0.090$ $220.000-0.259-0.251-0.225-0.198-0.165-0.126-0.090-0.060-0.037-0.018$ $230.000-0.212-0.204-0.177-0.143-0.098-0.054-0.025-0.0050 .010 \quad 0.025$ 240.000-0.164-0.156-0.130-0.088-0.038-0.007 $0.010 \quad 0.0250 .037 \quad 0.045$ 250.000-0.114-0.109-0.086-0.041-0.003 $0.017 \quad 0.028 \quad 0.0350 .0390 .042$ 260.000-0.065-0.063-0.045-0.009 $0.013 \quad 0.0240 .0290 .0310 .028 \quad 0.021$ 270.000-0.016-0.017-0.012 $0.007 \quad 0.016 \quad 0.018 \quad 0.0180 .0120 .004-0.007$ $280.000 \quad 0.033 \quad 0.028 \quad 0.0160 .0130 .010 \quad 0.005-0.003-0.013-0.025-0.037$ $290.000 \quad 0.083 \quad 0.073 \quad 0.042 \quad 0.0140 .000-0.012-0.025-0.039-0.052-0.063$ $300.000 \quad 0.1320 .1200 .0730 .017-0.016-0.033-0.047-0.063-0.075-0.084$ $310.000 \quad 0.1830 .1690 .1150 .034-0.026-0.056-0.069-0.081-0.092-0.098$ $320.000 \quad 0.2330 .2200 .1720 .081-0.012-0.073-0.094-0.098-0.102-0.105$ $330.000 \quad 0.278 \quad 0.267 \quad 0.230 \quad 0.172 \quad 0.065-0.034-0.097-0.109-0.105-0.100$ $\begin{array}{lllllllll}340.000 & 0.313 & 0.308 & 0.284 & 0.255 & 0.207 & 0.118 & 0.013-0.062-0.081-0.080\end{array}$ $\begin{array}{lllllllllll}350.000 & 0.335 & 0.333 & 0.322 & 0.306 & 0.285 & 0.248 & 0.191 & 0.113 & 0.028-0.016\end{array}$; end

end 


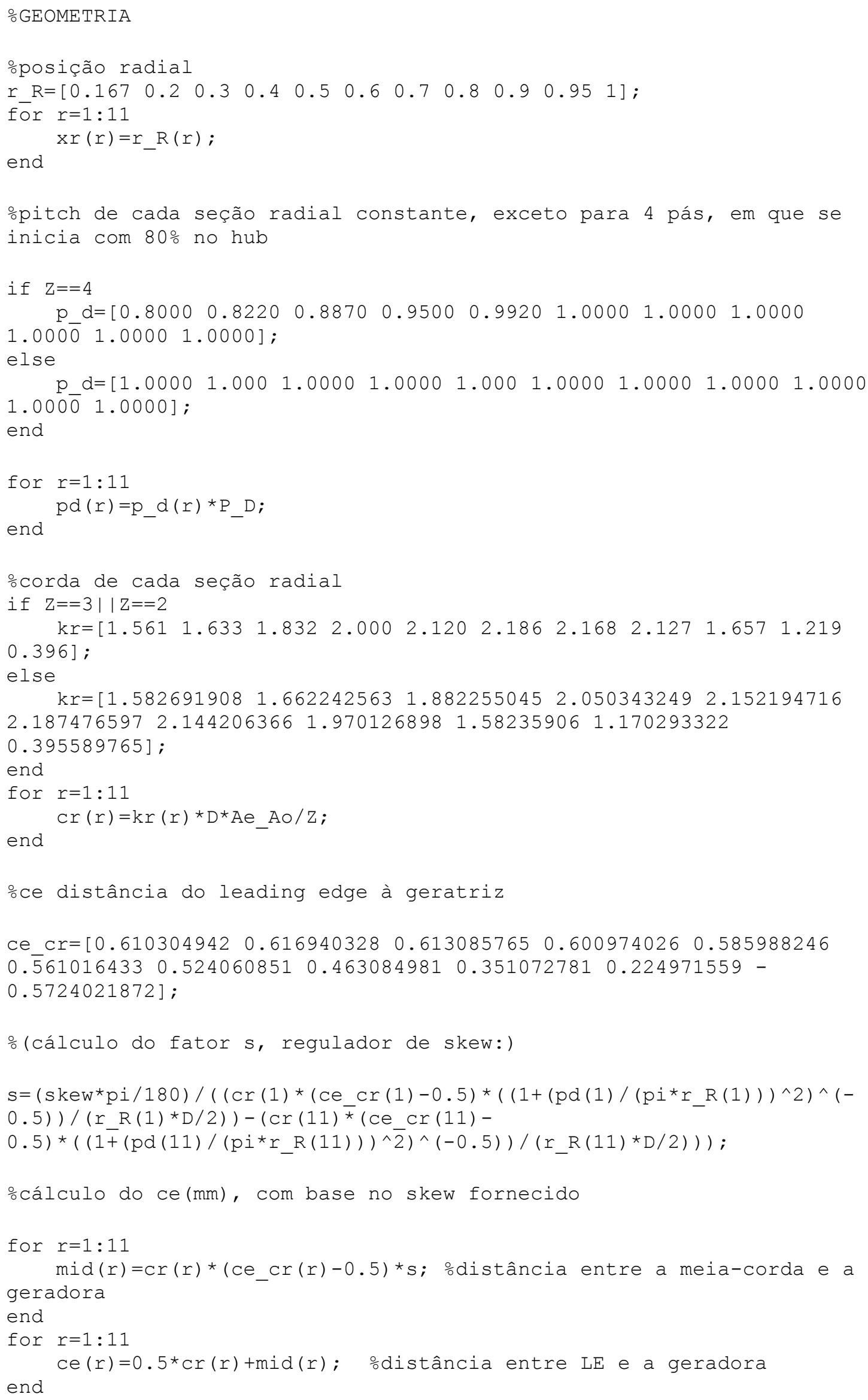




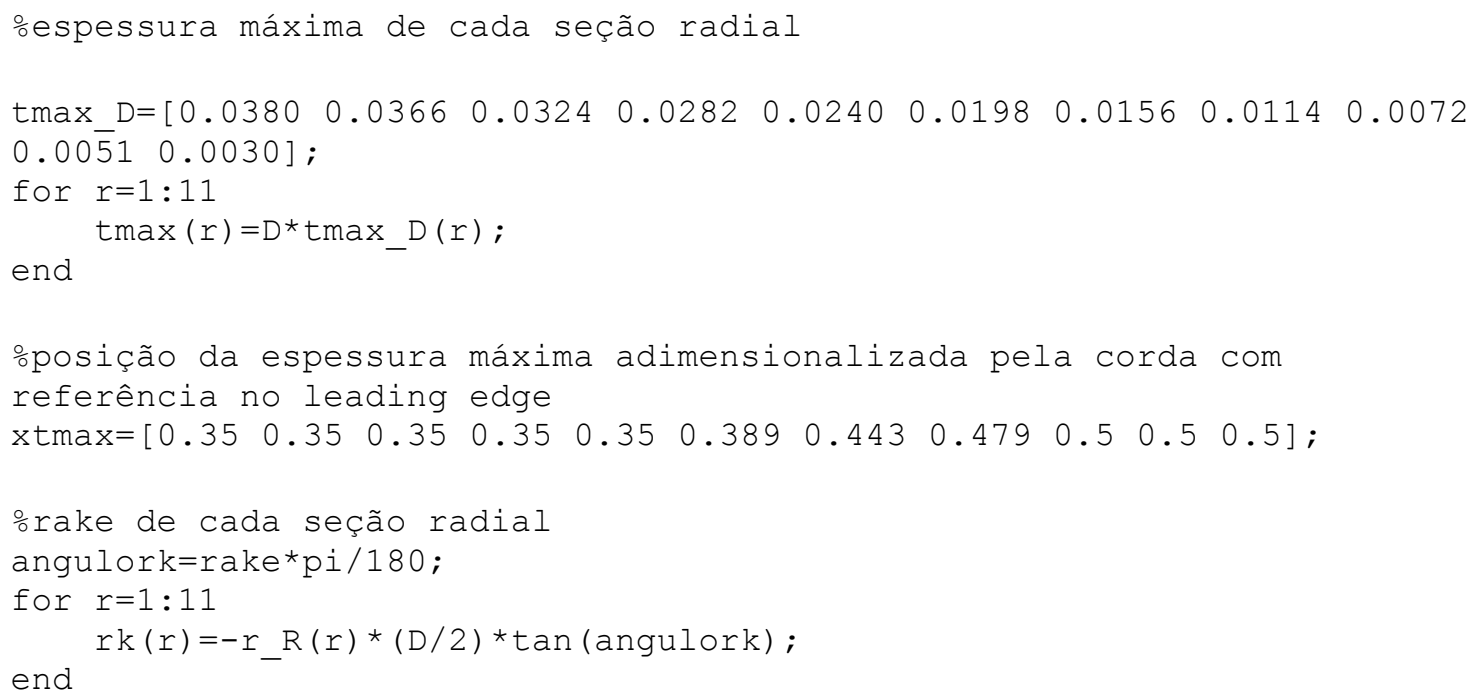

ohub_cone definido como tronco cônico fechando em downstream com tangente 0,05

hub $=\left[\begin{array}{lllllllllll}-0.05 & 0 & 0 & 0 & 0 & 0 & 0 & 0 & 0 & 0 & 0\end{array}\right]$;

ocordwise points fornecidos pela Wageningen com base no ponto de máxima espessura

\subsection{2}

0.0000

0.0045

0.0228

0.0592

0.0000

0.0000

0.0000

0.01290 .0450

0.0000

0.0000

0.0000

$0.0030 \quad 0.0266$

0.0000

0.0000

0.0000

0.0000

0.0000 


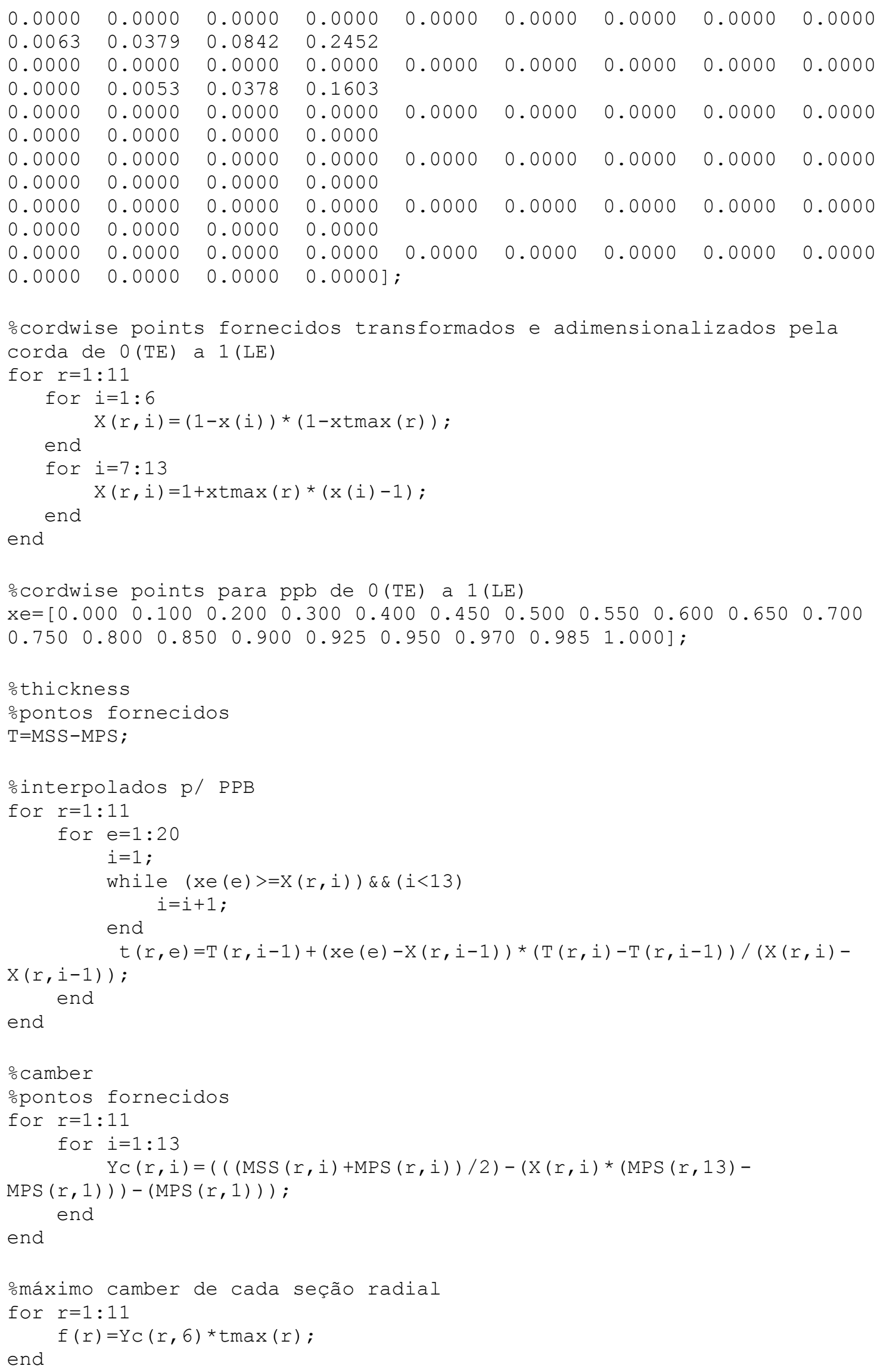




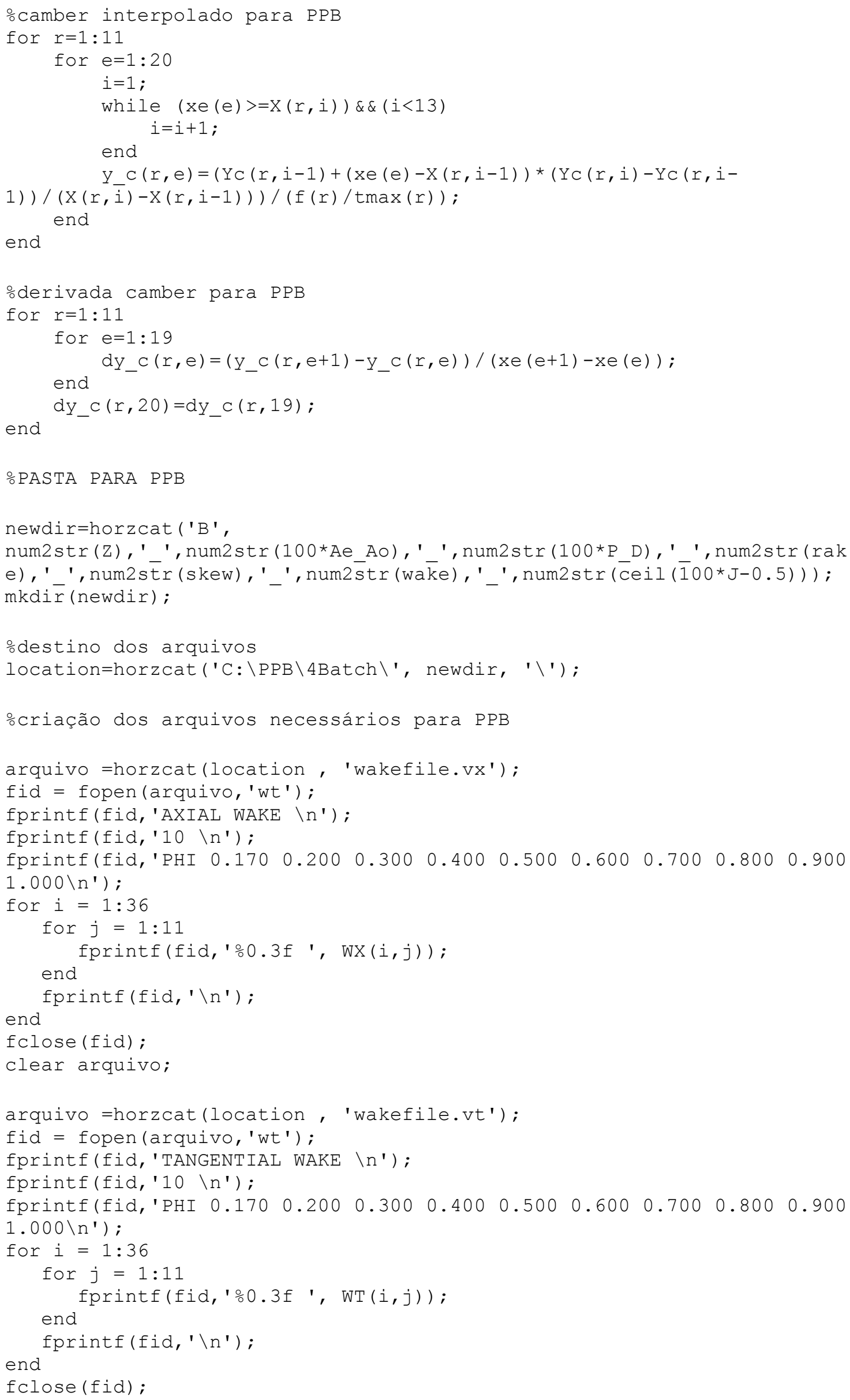




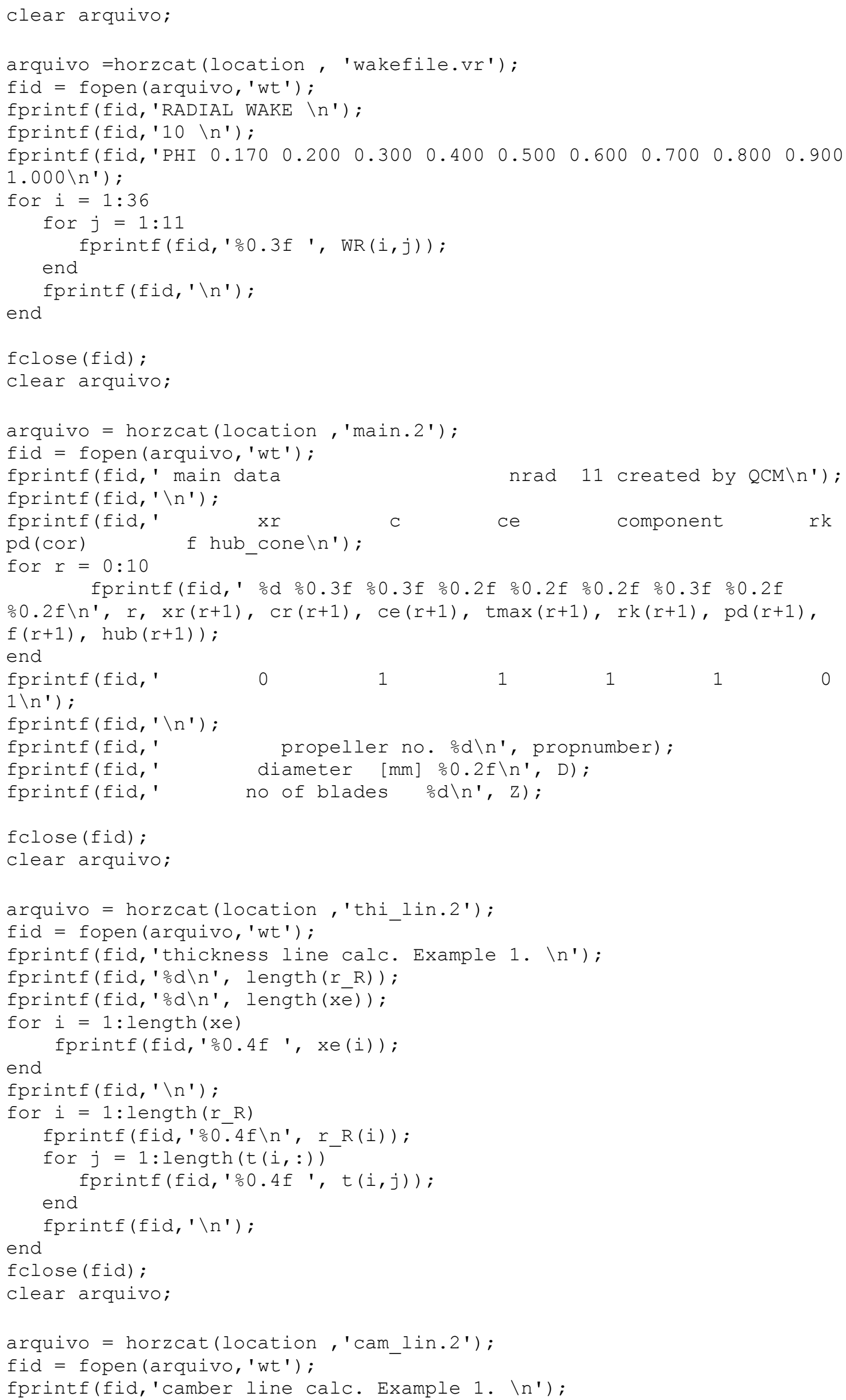




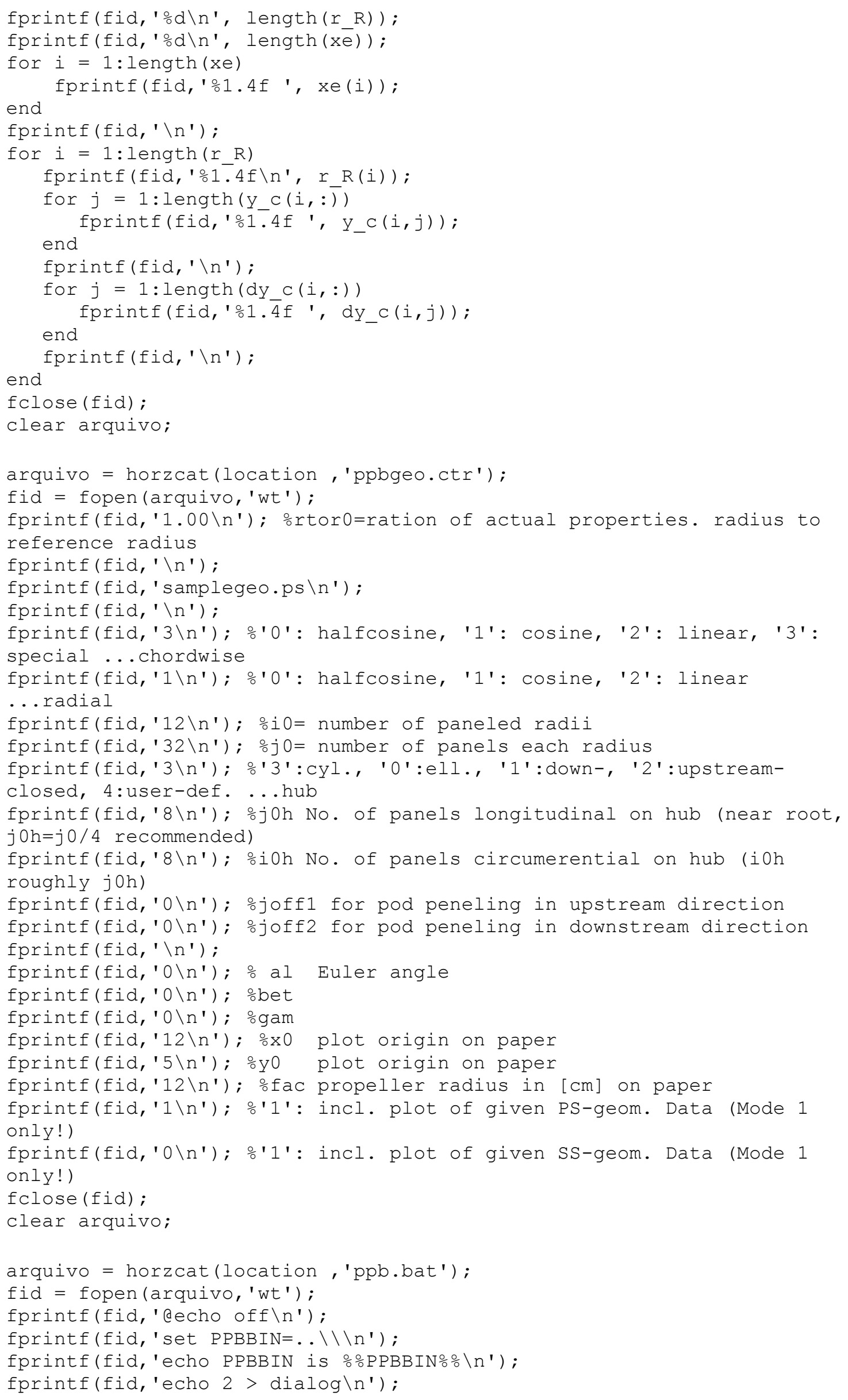




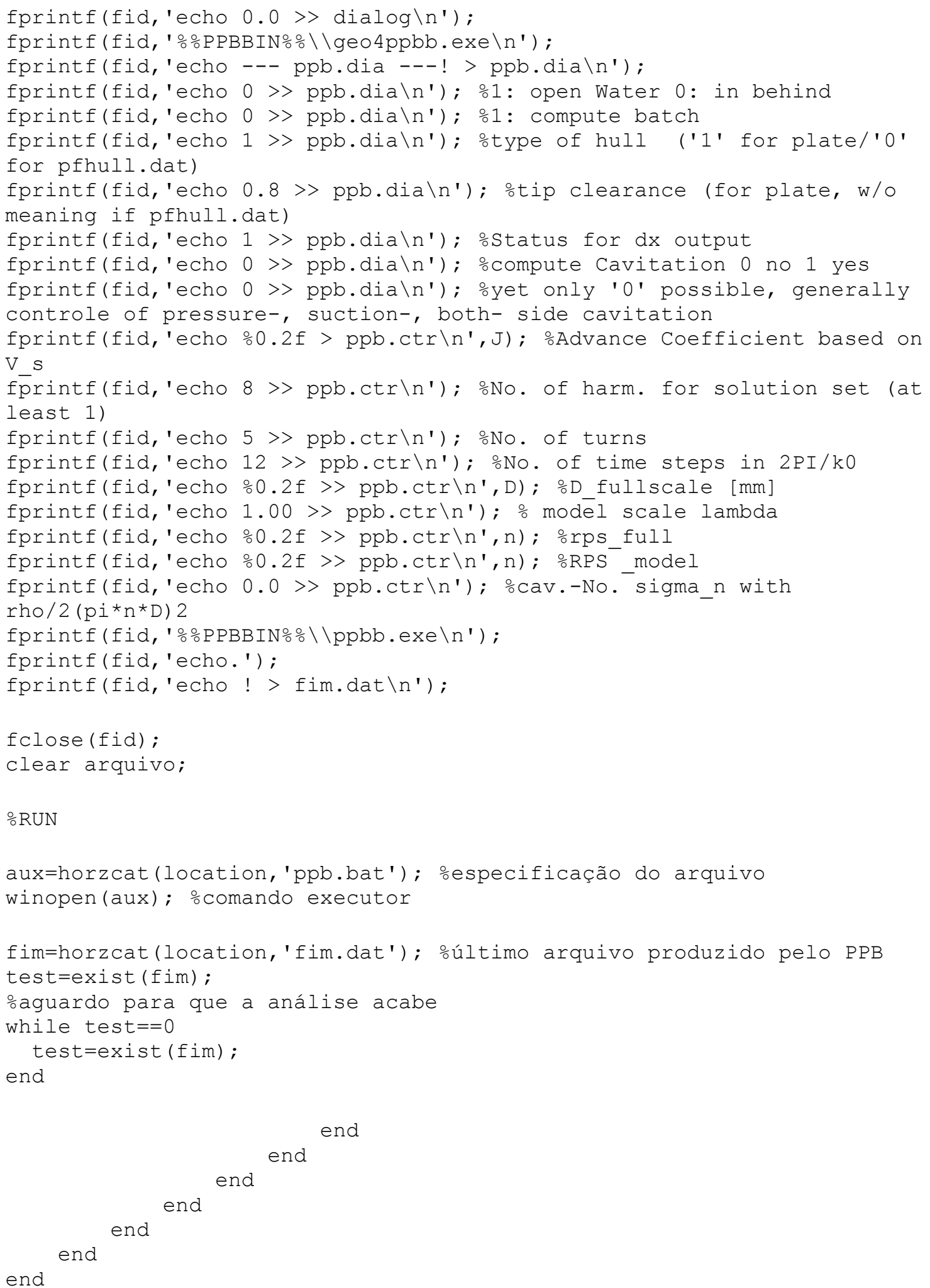




\section{ANEXO C - FORMULAÇÂO DE BURRIL}

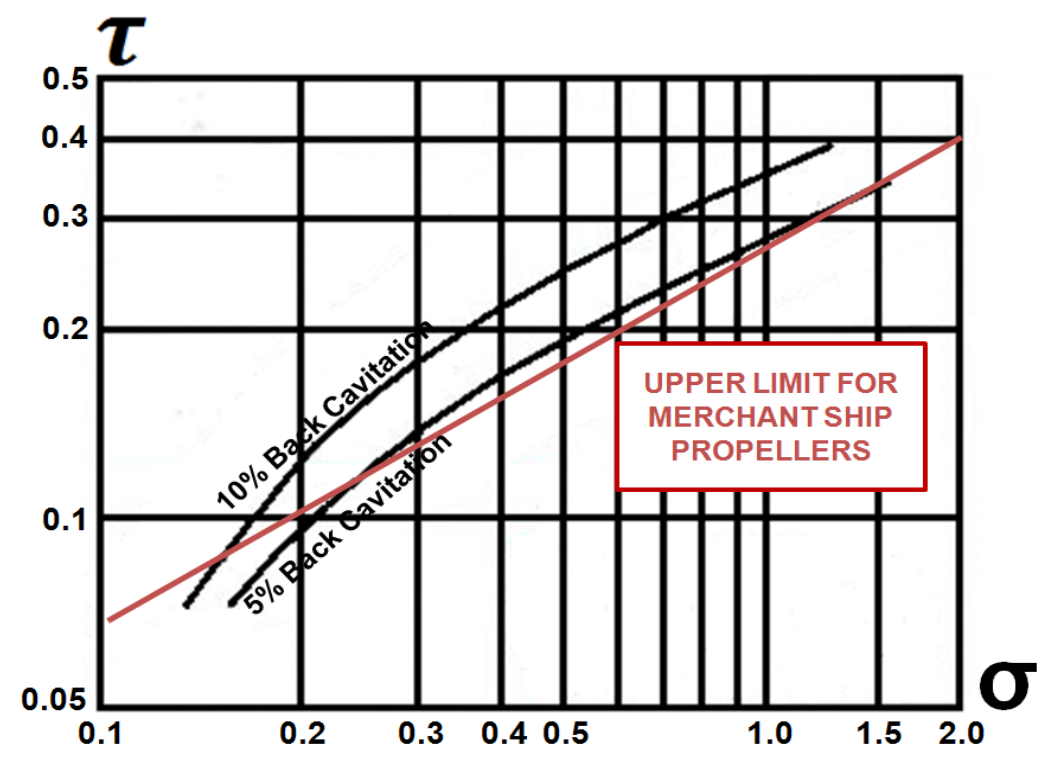

Figura 66 - Diagrama de Burril (adaptado de Harvald, 1980)

$$
\begin{gathered}
\tau=\frac{T / A_{p}}{q_{0.7 R}} \\
\sigma=\frac{p_{o}-p_{v}}{q_{0.7 R}}
\end{gathered}
$$

$T$ é o empuxo fornecido pelo propulsor

$A_{p}$ é a área projetada da pá $\left(A_{p} \sim A_{E}[1.067-0.229 P / D]\right)$

$q_{0.7 R}$ é a pressão dinâmica em $0.7 R\left(q_{0.7 R}=\frac{1}{2} \rho V_{0.7 R}{ }^{2}\right)$

$V_{0.7 R}$ é a velocidade em relação à água a $0.7 R$ composta pela axial e tangencial (rotativa) combinadas

$p_{v}$ é a pressão de vapor da água

$p_{o}$ é a pressão absoluta $\left(p_{o}=a t m+\rho g H\right)$

$H$ é a distância entra a linha d'água e o centro do propulsor 